\title{
I. Die Entstehungsgeschichte der Stalin-Note
}

„... in unserem Interesse die Bewegung für eine Neutralisierung Deutschlands ausnutzen"

Anfang 1951 konzipierte die Dritte Europäische Abteilung des sowjetischen Außenministeriums einen Vorschlag eines Friedensvertrages mit Deutschland, der nach Meinung ihres Leiters, Michail Gribanov, auf der kommenden Konferenz der Außenminister „vorgelegt und verhandelt werden sollte". ${ }^{1}$ Am 7.Februar setzte er seinen Außenminister, Andrej Vyšinskij, hiervon in Kenntnis. ${ }^{2}$ Am 14. Februar 1951 berichteten Stalins Repräsentanten in der DDR, General Čujkov, der Vorsitzende der Sowjetischen Kontrollkommission und dessen politischer Berater, Vladimir Semenov, nach Moskau, Walter Ulbricht gehe von der „planvollen Erfüllung der Remilitarisierung Westdeutschlands" durch die Amerikaner aus. $^{3}$

Wohl auch basierend auf den Papieren der Dritten Europäischen Abteilung und der Berichte der Sowjetischen Kontrollkommission in Deutschland, der sowjetischen Botschafter im Ausland u.a. verfasste Vyšinskij am 18. Februar 1951 ein ausführliches Memorandum über die „Bewegung für eine Neutralisierung Deutschlands“ und übermittelte es Vjačeslav Molotov. ${ }^{4}$

In diesem Memorandum informierte Vyšinskij Molotov zunächst über die Hauptrichtlinien der Gruppe Noacks (Nauheimer Kreis) für eine Neutralisierung Deutschlands. Noack gelte als „der populärste Propagandist der Theorie einer Neutralisierung Deutschlands“ und fordere ein „vereintes, neutralisiertes und entmilitarisiertes Deutschland“. Die Bewegung für eine Neutralisierung Deutschlands werde, so Vyšinskij, ,in Westdeutschland immer populärer“. Neben einem bedeutenden Teil der Intelligenz und der Studentenschaft, der Liga der Frauen für den Frieden und verschiedener Vereine werde die Bewegung von ehemaligen Landesministern, von Bischof Niemöller usw. unterstützt. Darüber hinaus werde die Bewegung „Ohne uns“ immer populärer und umfasse „die Masse der Arbeiter und werktätigen Jugend“. Sie genieße zudem die Unterstützung „einiger bourgeoiser Kreise, der evangelischen Kirche und [...] der Studentenschaft und Intelligenz“. Diese „objektiv antiamerikanische“ Bewegung trete „für den Verzicht auf Militärdienst und auf Remilitarisierung ein". 5

Über die Einstellung der Regierungen der drei Westmächte berichtete Vyšinskij, „dass die unter der westdeutschen Bevölkerung wachsende Popularität der Idee einer Neutrali-

${ }^{1}$ Loth, Die Entstehung der „Stalin-Note“, S. 20f. Nach Jochen Laufer war der Entwurf der „Grundlagen des Friedensvertrages mit Deutschland“ nicht neu, sondern entstand „in Vorbereitung der Moskauer Außenministerkonferenz 1947“. Laufer, Der Friedensvertrag mit Deutschland als Problem der sowjetischen Außenpolitik, S. 100.

2 Ebd., S. 21.

${ }^{3}$ Ersichtlich aus RGASPI, f. 82, op. 2, d. 1333, S. 161-168, Bericht Gromykos über die Einstellung verschiedener Kreise Wcstdeutschlands, cbcnso der Westmächte zur Frage über die Einführung der Wehrpflicht in Westdeutschland, 20.2.1951.

${ }^{4}$ RGASPI, f. 82, op. 2, d. 1182, S. 40-48, Vyšinskij an Molotov, 18.2.1951 (Dokument 3).

" Ebd. Zum „Nauheimer Kreis“ siehe auch RGASPI, f. 82, op. 2, d. 1334, S. 1f., Grigor'jan an Molotov, 15.3.1951 (Dokument 8). 
sierung die Remilitarisierung Westdeutschlands stört" und die USA, Großbritannien und Frankreich daher ablehnend dieser Bewegung gegenüber eingestellt seien. Nach Zeitungsberichten, so Vyšinskij, sei auf einer dreitägigen Sitzung der amerikanischen Botschafter in Europa und von Vertretern des State Departments beschlossen worden, dass es „in der jetzigen internationalen politischen Lage praktisch unmöglich sei, eine Neutralisierung Deutschlands zu verwirklichen“, und dass „die Westmächte auf einer vierseitigen Konferenz keinem sowjetischen Plan über eine Vereinigung Deutschlands zustimmen“ würden. Die US-Deutschlandpolitik werde sich, so Vyšinskij, nach Worten des amerikanischen Außenministers, Dean Acheson, nicht ändern. Ferner berichtete Vyšinskij, dass der Hohe Kommissar der USA in Deutschland, John McCloy, der britische Hohe Kommissar, Sir Ivone Kirkpatrick, und der französische Hohe Kommissar, André François-Poncet, gegen eine Neutralisierung Deutschlands seien. Jedes europäische Land könne nur „zwischen Ost und West wählen“, niemand könne „neutral bleiben“. Dass es sich hierbei nicht nur um die Meinungen der Hohen Kommissare handelte, untermauerte Vyšinskij mit Stellungnahmen des britischen Premierministers, Clement Attlee, und Anthony Edens, die im Februar 1951 im Unterhaus vehement den Einschluss Deutschlands in die Verteidigungsstrategie Westeuropas gefordert hatten, auch im Bewusstsein, ein neutralisiertes Deutschland würde ohnedies mehrheitlich antikommunistisch sein.

Über die Einstellung Adenauers berichtete Vyšinskij, dieser sei in den letzten Wochen am Parteitag der CDU in Nordrhein-Westfalen und an der Bonner Universität gegen eine Neutralisierung Deutschlands eingetreten, die seiner Meinung nach unweigerlich einem stetigen Abdriften in den sowjetischen Orbit gleichkäme. Deshalb müsse „das deutsche Volk mit all seiner Kraft gegen die Absicht der Sowjetunion“ auftreten, die „auf der bevorstehenden Konferenz der Vier eine Neutralisierung und Entwaffnung Deutschlands“ erreichen wolle. Ebenso seien der stellvertretende Vorsitzende des Bonner Bundestages, Schäfer, und SPD-Chef Schumacher gegen eine Neutralisierung. Eine solche habe die SPD abgelehnt und werde sie „stets ablehnen“.

Die SED nehme, so Vyšinskij, „gegenwärtig eine wohlwollende Position [...] zu den Neutralisten ein. " Nach der Meinung der SED-Führer Wilhelm Pieck und Walter Ulbricht sollte „die SED nicht gegen die Befürworter einer Neutralisierung Deutschlands auftreten, [...] sondern versuchen, [...] mit ihnen einen gemeinsamen Kampf gegen die Remilitarisierung und gegen die Einbeziehung Westdeutschlands in das Nordatlantikbündnis zu organisieren“. Ulbricht, so Vyšinskij, halte es „für möglich, dass die Sowjetunion selbst in der einen oder anderen Form einen Vorschlag über die Neutralisierung Deutschlands mit dem Ziel der Entlarvung der amerikanischen Kriegshetzer" einbrächte.

Abschließend fasste Vyšinskij in dem Memorandum „unsere Einstellung zur Bewegung für eine Neutralisierung Deutschlands“ zusammen. Die sowjetische Kontrollkommission (General Vasilij C̆ujkov und Vladimir Semenov) hielt es demnach „für zielführend, die Bewegung für eine Neutralisierung Deutschlands auszunutzen, weil sie einige Hindernisse für die Verwirklichung der Remilitarisierung Westdeutschlands durch die Regierungen der USA, Englands und Frankreichs schafft“. Čujkov und Semenov befürworteten sowjetische Vorschläge „über eine Entmilitarisierung Deutschlands, über den Abschluss eines Friedensvertrages [...], über die Wiederherstellung der Einheit Deutschlands auf demokratischer und friedlicher Grundlage und über einen freien Zugang Deutschlands zu den Weltmärkten“ einzubringen, was „die Bewegung für eine Neutralisierung Deutschlands begünstigen“ würde. Čujkov und Semenov schlugen zudem vor, „Deutschland das Recht abzuerkennen, militär-politische Bündnisse abzuschließen oder in militär-politische Koalitionen einzutre- 
ten, was den Forderungen der Befürworter der Bewegung für eine Neutralisierung Deutschlands entspricht, und ferner mit dem Vorschlag der Gewährung von Garantien der Neutralität Deutschlands von Seiten der Großmächte aufzutreten".

Vyšinskij schloss sich der Meinung der SED-Führung und der SKK an und gab die Empfehlung $a b$, die Bewegungen für eine Neutralisierung Deutschlands mittels der „Freunde“ in Westdeutschland, aber auch unter Ausnutzung der deutschen Presse und „der Tätigkeit verschiedener deutscher gesellschaftlicher Organisationen, die gegen die Remilitarisierung Westdeutschlands eintreten“, zu unterstützen. Dies würde „auch wohlwollend von den Befürwortern der Bewegung für eine Neutralisierung Deutschlands aufgenommen" werden. Offizielle Unterstützungserklärungen seitens der Sowjetunion hielt Vyšinskij allerdings für verfrüht, weil die Neutralisierungsbewegung, die noch „keinen breiten Massencharakter" trage, in diesem Falle von den Westmächten als sowjetisches Produkt hingestellt werden würde. Vyšinskij empfahl jedoch, bereits auf der bevorstehenden Tagung des Rates der Außenminister „in der ein oder anderen Form die Bewegung für eine Neutralisierung Deutschlands in der Form einer zusätzlichen Begründung unserer Position gegen die Remilitarisierung Deutschlands zu nutzen“ und „von sowjetischer Seite einige konkrete Vorschläge, die mit den Forderungen der deutschen Bevölkerung über eine Neutralisierung Deutschlands zusammenhängen, einzubringen “. ${ }^{6}$

Molotov unterstrich im ihm vorgelegten Memorandum folgende Worte:

- Idee über Neutralisierung „stört die Remilitarisierung“

- „Kirkpatrick“, „Attlee“, „Eden“, offizielle Vertreter „Frankreichs“ „gegen eine Neutralisierung Deutschlands"

- „Adenauer“ „gegen Neutralisierung“

- SPD „lehnte und lehnt sie ab“, SED „wohlwollend“

- „gemeinsamen Kampf gegen die Remilitarisierung und gegen die Einbeziehung Westdeutschlands in das Nordatlantikbündnis" organisieren

- „Bewegung für eine Neutralisierung Deutschlands ausnutzen“

- "Garantien der Neutralität Deutschlands von Seiten der Großmächte“

Die letzten drei Stellen versah Molotov zudem mit Häkchen, seinem Zeichen für Zustimmung. Darüber hinaus unterstrich er „Unterstützung“ der Bewegung für eine Neutralisierung, offizielles Auftreten unserer Seite „frühzeitig“, auf der Tagung des Rates der Außenminister Bewegung als „zusätzliche Begründung unserer Position“ nutzen und „konkrete Vorschläge" einbringen. Letzteres hob er durch zweimalige Unterstreichung hervor. Molotov war klar, dass es im Westen in Regierungskreisen keine Anhänger der Neutralisierungsidee gab. Und es finden sich nicht einmal in Ansätzen Hinweise darauf, was man aus sowjetischer Sicht unternehmen könnte, um den Westen „umzustimmen“, um ihn für eine Neutralisierung Deutschlands gewinnen zu können. Die Neutralisierungsbewegung sollte für sowjetische Zwecke ausgenutzt werden.

Im Memorandum finden sich konkrete Vorstellungen dessen, was sich das sowjetische Außenamt bzw. die DDR-Führung mit der in den nächsten Monaten verfolgten deutschlandpolitischen Strategie erhoffte. Walter Ulbricht schlug demnach vor, die UdSSR solle ,in der ein oder anderen Form“ Vorschläge einer Neutralisierung Deutschlands einbringen.

${ }^{6}$ RGASPI, f. 82, op. 2, d. 1182, S. 40-48, Vyšinskij an Molotov, 18.2.1951 (Dokument 3). 
Diese sollte die „amerikanischen Kriegshetzer“ entlarven. C̆ujkov und Semenov unterstützten Ulbrichts Idee und erhofften sich, diese würde „einige Hindernisse“ bei der „Remilitarisierung“ Westdeutschlands schaffen. Es kann nicht mit letzter Sicherheit gesagt werden, ob nun Ulbricht oder Semenov, dem auch die "geistige Vaterschaft" der Stalin-Note zugeschrieben wird, ${ }^{7}$ zusammen mit Čujkov den Anstoß zu jenem Prozess gaben, der in der Stalin-Note vom 10. März 1952 mündete. ${ }^{8}$ Die letztendlich verwirklichte Strategie dürfte wohl das Ergebnis gemeinsamer Beratungen gewesen sein. Pieck hatte jedoch später im Juli 1951, als es um die Umsetzung der weiteren Strategie ging, in seinem Tagebuch festgehalten, dass die „Initiative früher bei uns“ gelegen habe. ${ }^{9}$ Es ist jedoch kaum anzunehmen, dass die Initiative von Abteilungsleiter Gribanov ausging. ${ }^{10}$ Diese Fragestellung ist ohnedies zweitrangig. Schließlich zeigten sich alle Beteiligten mit der vorgeschlagenen Strategie einverstanden, wobei eine führende Rolle in der Anfangsphase sicherlich Ulbricht zukam. Und dieser stellte keinesfalls die DDR zur Disposition, ja er zog nicht einmal einen Misserfolg seiner vorgeschlagenen Strategie ins Kalkül. Einziges Ziel war die Entlarvung der „amerikanischen Kriegshetzer" und eine Behinderung der Wiederbewaffnung Westdeutschlands. Damit wurde die Stalin-Note, die schließlich am 10. März 1952 als „verlockendes Angebot" an die Westmächte gerichtet wurde, einen einheitlichen deutschen Staat angeblich wiederherstellen zu wollen, aus der Taufe gehoben.

${ }^{7}$ Wettig, Die Stalin-Note vom 10. März 1952 als geschichtswissenschaftliches Problem, S. 166.

${ }^{8}$ Forderungen Moskaus an die KPD, entschiedener gegen die sich abzeichnende Wiederbewaffnung Westdeutschlands aufzutreten, gab es freilich bereits früher. So wies das Politbüro des ZK der VKP(b) bereits am 5.1.1950 Čujkov und Semenov an, dass „ein Akzent auf den Kampf gegen die Remilitarisierung und in diesem Zusammenhang auf den raschesten Abschluss eines Friedensvertrages und die Einberufung einer konstituierenden Versammlung Deutschlands als unabdingbarer Schritt zu seiner Wiedervereinigung gesetzt werden muss“. Egorova, Evropejskaja bezopasnost' $i$ „ugroza“ NATO v ocenkach stalinskogo rukovodstva, S.78. Dies markiert jedoch keinesfalls den Beginn jenes Prozesses, der im Februar 1951 einsetzte und in der Stalin-Note vom 10.3.1952 mündete.

"So Grotewohl in einer Besprechung am 30.7.1951. Siehe Badstübner/Loth (Hrsg.), Wilhelm Pieck - Aufzeichnungen zur Deutschlandpolitik 1945-1953, S. 373.

10) Wilfried Loth konnte bereits Dokumenten aus dem Archiv des russischen Außenministeriums entnehmen, dass die Initiative des sowjetischen „Angebotes“, sieben Jahre nach Kriegsende einen Friedensvertrag mit Deutschland abzuschließen zu wollen, (auch) auf die DDR-Führung zurückzuführen ist. Er verweist auf eine Besprechung der SED-Führung mit Ğujkov und Semenov am 21.2. 1951. Den Ursprung der Stalin-Note sieht Loth allerdings ausschließlich in den Vorbereitungsarbeiten des sowjetischen Außenministeriums auf die Konferenz des Rates der Außenminister. Der Leiter der Dritten (für die sowjetische Deutschland- und Österreichpolitik zuständigen) Europäischen Abteilung, Michail Gribanov, „drängte“ dcmnach bereits Anfang Februar „bei seinen Vorgesetzten auf die Erarbeitung eines verbindlichen Vorschlags für einen Friedensvertrag mit Deutschland“. Loth, Die Entstehung der „Stalin-Note", S. 20f.; und zulctzt ders., Dic Sowjetunion und die deutsche Frage, S.159-161. Loth hebt hierbei erneut die Bedeutung von Dokumenten aus Gribanovs Feder hervor, die es nach seiner Meinung sehr wohl erlauben, Rückschlüsse auf Stalins Haltung zu ziehen. Loth zieht allerdings nicht ins Kalkül, dass es vor allem die Aufgabe der Abteilungen des Außenministeriums war, Vorschläge auszuarbeiten, die keineswegs in Einklang mit den Intentionen des Kremlchefs stehen mussten. Er räumt zwar ein, dass dies nicht immer „hundertprozentig richtig gewesen sein “ muss, „abcr auch nicht grundsätzlich falsch gewesen sein “ kann. Gerhard Wettig hingegen sagt, dass das vorbereitete, durchdachte Kalkül der DDR-Führung als Indiz gelten muss, „dass es nicht darum ging, das kommunistische Regime in der DDR irgendwie in Frage zu stellen “. Wettig, Die Note vom 10. März 1952, S. 183. Zum politischen Gewicht Gribanovs siehe Graml, Eine wichtige Quelle - aber mißverstanden, S. $120 \mathrm{f}$. Zur Rekonstruktion der Entstehungsgeschichte siehe auch Laufer, Die UdSSR, die SED und die deutsche Frage, S. 1203. 
Molotov forderte nunmehr „konkrete Vorschläge“ ein. ${ }^{\text {" }}$ Noch am selben Tag erhielt er von Vyšinskij zwei weitere Berichte über die Einstellung der Regierungen in Großbritannien, Frankreich, Belgien, Österreich usw. zur Neutralisierungsdiskussion über Deutschland. ${ }^{12}$ Vyšinskij zog auf der Basis der Berichte der sowjetischen Diplomaten den Schluss, dass „die Regierungskreise der USA, Frankreichs, Belgiens und Hollands [...] ablehnend, mit Unruhe und Besorgnis zur Bewegung für eine Neutralisierung Deutschlands eingestellt sind“, da sie „denken, dass diese Bewegung Hindernisse bei der Remilitarisierung schafft“. Vyšinskij berichtete Molotov, dass einige Kongressmitglieder und Senatoren offen ihre Unsicherheit darüber bekundeten, ob es gelingen würde, „die Deutschen zu zwingen, auf der Seite der USA zu kämpfen“. Meinungsumfragen in Westdeutschland beunruhigten einige hohe Repräsentanten Washingtons zutiefst. Vyšinskij berichtete Molotov indes auch, dass Acheson davor warnte, dass ein Abzug aus Europa und ein Nichtengagement die Neutralisierungsstimmung in Europa beflügeln würde, was einem politischen Selbstmord gleichkäme. Das Anwachsen der Neutralistenbewegung sei es, das die Amerikaner zwinge, die Remilitarisierung Westdeutschlands, so Vyšinskij, „nicht in solch offener Form durchzuführen, wie es früher vorgesehen war“. Vyšinskij zog ferner den Schluss, dass sich in der westdeutschen und amerikanischen Presse Berichte häuften, die ein Überschwappen der Ideen der Neutralistenbewegung auf andere NATO-Länder prognostizierten.

Wie im vorangegangenen Memorandum empfahl Vyšinskij die Neutralistenbewegung zu fördern, „da die Bewegung für eine Neutralisierung Deutschlands die Verwirklichung der amerikanischen Pläne der Bewaffnung Westdeutschlands“ erschwert. Der sowjetische Botschafter in Paris sprach sich ebenfalls hierfür aus, empfahl dennoch, auch weiterhin den „Kampf für ein einheitliches, demokratisches, friedliebendes Deutschland“ zu proklamieren. Der Leiter der Diplomatischen Mission in der DDR, Georgij Puškin, befürwortete ebenso die Nutzung der Neutralistenbewegung, die zwar auch antisowjetisch sei und deshalb auch nicht maßlos unterstützt werden sollte, um sich „nicht mit einer breiten Unterstützung der Idee der Neutralisierung Deutschlands die Hände zu binden “. ${ }^{13}$

Nachdem dieser Bericht getippt und Molotov übermittelt worden war, traf im sowjetischen Außenministerium schließlich auch der Bericht des sowjetischen Botschafters in London, Zarubin, ein. Vyšinskij fasste das Telegramm umgehend zusammen und übermittelte Molotov seine Ausführungen als Ergänzung zum zweiten Bericht. Zarubin berichtete

${ }^{11}$ Molotov versah den entsprechenden Absatz in Vyšinskijs Memorandum mit einem eingekreisten Kreuz, seinem Zeichen für besondere Dringlichkeit und Wichtigkeit. Die Worte „konkrete Vorschläge“ sind von Molotov doppelt im Memorandum Vyšinskijs unterstrichen. RGASPI, f. 82, op. 2, d. 1182, S. 48, Vyšinskij an Molotov, 18.2.1951 (Dokument 3). Solche Vorschläge wurden in der Folge von Gromyko vorbereitet, v.a. empfahl er am 27.2.1951 in einem Politbüro-Beschlussentwurf, den sowjetischen Repräsentanten anzuweisen, die Frage eines Friedensvertrages mit Deutschland auf die Agenda der Konferenz der stellvertretenden Außenminister in Paris (ab 5.3.1951) setzen zu lassen. Siehe hierzu Bjørnstad, Soviet German Policy and the Stalin Note of 10 March 1952, S. 56f.

12 RGASPI, f. 82, op. 2, d. 1182, S. 49-53, Vyšinskij an Molotov, 18.2.1951 (Dokument 4); ebd., S. 54f., Vyšinskij an Molotov, 18.2.1951 (Dokument 5). Die sowjetischen Botschafter in diesen Ländern dürften bei der Erstellung ihrer Berichte große Eile an den Tag gelegt haben und erst kurz zuvor damit beauftragt worden scin. Hierfür zeugt das Eintreffen des Berichtes des sowjetischen Botschafters in London, Georgij Zarubin, der unmittelbar nach der Überbringung des zusammenfassenden Bcrichtes der erstgenannten sowjetischen diplomatischen Vertreter rasch von Vyšinskij resümiert wurde und erst nach Fertigstellung des ersten Berichtes an Molotov weitergeleitet werden konnte. Alle drei Berichte (Dokumente 3, 4 und 5) erhielt Molotov am 18. Februar 1951.

13 Ebd. 
ebenso von einer „ablehnenden Haltung der Führungskreise Englands zur Bewegung für eine Neutralisierung Deutschlands“. ${ }^{14}$ In London ging man davon aus, so Vyšinskij, dass ein neutrales Deutschland „der ständigen Bedrohung eines kommunistischen Putsches nach tschechoslowakischer Manier“ ausgesetzt wäre. Zudem würden die „Anglo-Amerikaner“ ein mit der UdSSR handeltreibendes (neutrales) Deutschland nicht zulassen, um nicht auf diese Weise durch Produktionslieferungen aus dem Ruhrgebiet „das Militärpotential der UdSSR“ zu stärken. Großbritannien messe der Neutralisierungsbewegung, so Vyšinskij, keine allzu große Bedeutung zu, da sie ohnedies „keine entscheidende Rolle bei der Verhinderung der Remilitarisierung Deutschlands spielen“ könne. Auch Zarubin befürwortete eine Ausnutzung der Neutralisierungsbewegung, da sie, so Vyšinskij einmal mehr, „die Verwirklichung der anglo-amerikanischen Pläne der Remilitarisierung Deutschlands erschwert".

Vyšinskij berichtete folglich Molotov, dass es vor allem in den USA zwar Stimmen gäbe, die sich von einem Erfolg der „Remilitarisierung“ und dem Einschluss Deutschlands in die westliche Hemisphäre nicht überzeugt zeigten, US-Außenminister Acheson jedoch einen klaren Kurs vorgab. Allerdings sah man in den USA im Anwachsen der Neutralistenbewegung ein nicht unbeschwerliches Hindernis, weniger in Großbritannien. In Westeuropa stand keine Regierung einer Neutralisierung Deutschlands positiv gegenüber. Vyšinskij hob stets hervor, dass eine Unterstützung der Neutralisierungsbewegung die „Remilitarisierung“ Westdeutschlands erschweren würde. Von einer Verhinderung der „Remilitarisierung“ oder gar dem sowjetischen Wunsch nach einer Neutralisierung Deutschlands ist in den Dokumenten keine Rede. Washington und London waren von ihrem Kurs nicht abzubringen. So sahen es die sowjetischen Botschafter und so berichteten sie ihre Einschätzungen an das sowjetische Außenministerium. Außenminister Vyšinskij rapportierte dies Molotov und dieser, sei es schriftlich oder mündlich, Stalin (es gingen keine Abschriften des Memorandums und der folgenden Berichte vom 18. Februar an dritte Personen). Keine einzige Stellungnahme zeugt von Hoffnungen, der Kampf gegen die Wiederbewaffnung Westdeutschlands würde den Weg zu einem neutralisierten und vereinten Deutschland ebnen.

Im Gegenteil: Der KPD wurde die Schuld gegeben, nicht die Losung gegen die „Remilitarisierung " aufgegriffen zu haben und damit der SPD die Möglichkeit leichtfertig überlassen zu haben, ihren Einfluss in den Massen zu stärken. ${ }^{15}$ Eine Woche bevor vom sowjetischen Außenministerium Berichte der Botschafter im Westen über die Haltung zur „Remilitarisierung“ eingefordert worden waren, berichtete Vagan Grigor'jan, der Vorsitzende der Außenpolitischen Kommission des ZK der VKP(b), Stalin ausführlich über die Lage in der KPD. ${ }^{16}$ Trotz der typischen Diktion solcher Berichte an Stalin - beginnend mit Kritik an der KPD selbst, um dann zur Selbstkritik überzugehen und schließlich aufzuzeigen, welche Maßnahmen bereits getroffen worden waren, um Missstände zu beseitigen - gibt der Bericht einen interessanten Einblick in das Verhältnis zwischen SED und KPD, aus dem der Schluss gezogen werden kann, dass es der Sowjetunion wohl in erster Linie in den späten vierziger Jahren und danach um die Festigung der Macht der SED in Ostdeutschland ging, nicht, weil Stalin unbedingt nur einen Teil Deutschlands in den sowjetischen Orbit integrieren wollte, sondern in der deutschen Frage Realpolitiker war. Die sowjetische Führung war

\footnotetext{
14 Ebd.

15 RGASPI, f. 82, op. 2, cl. 1337, S. 24-31, Grigor'jan an Stalin, 12.2.1951 (Dokument 2).

${ }^{16}$ RGASPI, f. 82, op. 2, cl. 1337, S. 19-23. Molotov hatte den Bericht abgesegnet. Am 11.2.1951 übermittelte Grigor'jan diesen Bericht „in Entsprechung mit Ihren Grundrissen“ Molotov.
} 
sich durchaus bewusst, dass die KPD auf verlorenem Posten stand. Einerseits führte Grigor'jan gegenüber Stalin den Misserfolg der KPD darauf zurück, dass die „westlichen Besatzungsmächte und die Bonner Regierung [...] im Zusammenhang mit der Kommunistischen Partei systematisch eine Politik der Verfolgung und Repression " durchführten, andererseits gaben Molotov und er der KPD Mitschuld an der Lage, weil sie die „Bewegung der nationalen Front " ${ }^{\text {"17 }}$ unterschätzt und nur unzureichend mit sozialdemokratischen Arbeitern zusammengearbeitet habe, um die „breiten Massen der Bevölkerung für den Kampf um den Frieden und die Einheit, gegen die anglo-amerikanischen Pläne der ,Remilitarisierung“ Westdeutschlands und seine Umwandlung in eine Hauptbasis der amerikanischen Aggression in Europa an sich zu ziehen ". ${ }^{18}$ Zwar wurde die SED dafür kritisiert, dass sie bis Ende 1950 die KPD nicht unterstützt habe, doch ist kaum vorstellbar, dass dies unterblieben wäre, hätte der Kreml die SED darum „gebeten“.

Die KPD konnte nach Kriegsende und angesichts des zunehmenden Engagements der USA für Westdeutschland keinen „Nährboden“ für den Kommunismus in Westdeutschland schaffen. Stalin und Molotov ließen sich auch Anfang 1951 wohl kaum von Berichten über eine angebliche breite Ablehnung der "Remilitarisierung“ Westdeutschlands durch die westdeutsche Bevölkerung oder über die ernsthaften Probleme der Ratifizierungen der Vereinbarungen und Abkommen mit Westdeutschland in Paris „blenden“. Manche inneramerikanisch divergierende Meinungen über einen möglicherweise gefährdeten Erfolg bei der (militärischen) Westintegration der Bundesrepublik riefen wohl kaum Enthusiasmus bei ihnen hervor. Die Chancen, die „Remilitarisierung“ zumindest zu behindern, standen allerdings nicht schlecht. Und diese Chance sollte genutzt werden.

Am 24. Februar 1951 übermittelte der stellvertretende Außenminister der UdSSR, Andrej Gromyko, Stalin den Vorschlag der DDR-Führung (Molotov, Malenkov, Berija, Mikojan, Kaganovič, Bulganin und Chruščev erhielten eine Abschrift), dass sich die Volkskammer der DDR mit einem Appell an den Bundestag in Bonn wenden sollte. Dem Vorschlag zufolge sollten Ostberlin und Bonn mit der „Frage des Abschlusses eines Friedensvertrages mit Deutschland“ an die vier Großmächte herantreten und einfordern, dass die Frage der Unterzeichnung eines Friedensvertrages mit Deutschland auf die Tagesordnung der Konferenz der stellvertretenden Außenminister in Paris gesetzt werde. ${ }^{19}$

Was erhofften sich die DDR-Führer davon, dem Bonner Bundestag den Vorschlag zu machen, sich gemeinsam an die Großmächte zu wenden und den Abschluss eines Friedens-

17 Zum Konzept der „Nationalen-Volksfront-Strategie“ des Kremls siehe grundlegend Mark, Revolution by Degrees.

${ }^{18}$ RGASPI, f. 82, op. 2, d. 1337, S. 24-31, Grigor'jan an Stalin, 12.2.1951 (Dokument 2). Vgl. dazu auch den phrasenweise übernommenen Bericht Grigor'jans an Stalin ein Jahr später. RGASPI, f. 82, op. 2, d. 1337, S. 45-51, 15.3.1952 (Dokument 78).

19 RGASPI, f. 82, op. 2, d. 1169, S.1, Gromyko an Stalin, 24.2.1951 (Dokument 7). Der Inhalt des Schreibens ist bereits aus einem Schreiben Kudrjavcevs an Zorin vom 6.3.1951 bekannt. Das vollståndige Dokument wird hier erstmals abgedruckt, siehe Wettig, Die Deutschland-Note vom 10. März 1952 auf der Basis diplomatischer Akten, S. 792; Loth, Die Entstehung der „Stalin-Note“, S. 22, Graml, Eine wichtige Quelle - aber mißverstanden, S. 121. Erwähnt wird das Schreiben auch von Egorova in Egorova, Evropejskaja bezopasnost' i „ugroza"NATO v ocenkach stalinskogo rukovodstva, S. 70. Am 24. 2. 1951 hatte auch Gribanov Vyšinskij empfohlen, sich in Zukunft nicht bloß auf die Wiederholung der bisherigen Vorschläge in der deutschen Frage zu beschränken. Dies zeigt deutlich auf, dass auf höherer Ebene (Gromyko an Stalin) der Entscheidungsprozess bereits im Gange war und Gribanov in dieser Frage keine Initiativrolle zuzuschreiben ist. Loth, Die Sowjetunion und die deutsche Frage, S. 159-161; Wettig, Die Deutschland-Note vom 10. März 1952 auf der Basis diplomatischer Akten, S. 791; ders., Bereitschaft zu Einheit in Freiheit?, S. 205. 
vertrages mit einem geeinten Deutschland auf die Tagesordnung der Konferenz des Rates der stellvertretenden Außenminister setzen zu lassen? Waren sie bereit, ihren zwei Jahre zuvor gegründeten Arbeiter- und Bauernstaat zu opfern und auf die Macht zu verzichten? Erhofften sie sich gar, mit ihren Vorhaben ganz Deutschland in den kommunistischen Orbit einzuschließen, womöglich unter ihrer Führung? Auch wenn es einzelne euphorische Stimmen gegeben haben mag, die DDR-Führung, zumindest Walter Ulbricht, der federführend die sowjetische Propagandaoffensive initiierte, war Realist und unter keinen Umständen bereit, die DDR in Frage zu stellen. Bevor Stalin der Vorschlag der DDR-Führung unterbreitet wurde, vermeldeten Čujkov und Semenov nach Moskau, „dass nach der Meinung Ulbrichts trotz der anscheinenden Änderung der Taktik der Amerikaner die Remilitarisierung Westdeutschlands durchgeführt wird und durchgeführt werden wird, präzise und nach Plan, aber ohne großen Lärm in der Presse und ohne breit kundgetane Befehle und Erklärungen. In Westdeutschland werden bereits militärische Formationen im Ausmaß von Bataillonen geschaffen. Bei der Schaffung einer westdeutschen Armee wird die Erfahrung der schwarzen Reichswehr genutzt. Entwürfe über die Einführung der Wehrpflicht sind ausgearbeitet, sie werden aber einstweilen noch nicht veröffentlicht. "20 Ulbricht war sich im Klaren, dass die Remilitarisierung Westdeutschlands von den Amerikanern nach Plan vollzogen werden würde. Gromyko zog in seinem Bericht an Molotov den Schluss, „dass die Bewegung gegen die Remilitarisierung in Westdeutschland [...] die Annahme von Maßnahmen zur Einführung der allgemeinen Wehrpflicht erschwert“. ${ }^{21}$

Diesen bisher im Wortlaut nicht bekannten Dokumenten, insbesondere dem Schreiben Gromykos an Stalin vom 24. Februar 1951, sind konkrete Zielvorstellungen bzw. Hoffnungen darauf zu entnehmen, was die ausgeklügelten diplomatischen Schachzüge in der sowjetischen Deutschlandpolitik in der Folge bewirken sollten. Gromyko berichtete Stalin: „Pieck, Grotewohl und Ulbricht denken, dass eine solche Initiative der Volkskammer die allerwichtigste Frage des Friedensvertrages ins Zentrum der Aufmerksamkeit der deutschen Gesellschaft rückt und die Versuche der Amerikaner, den Friedensvertrag durch eine Deklaration über die Beendigung des Kriegszustandes mit Deutschland zu ersetzen, erschweren wird. Der Vorschlag der Volkskammer zum Friedensvertrag wird nach Meinung Piecks, Grotewohls und Ulbrichts breite Unterstützung in Westdeutschland finden und hilfreich für die Durchführung einer Volksbefragung gegen die Remilitarisierung sein. "22 Gromyko zeigte sich namens des Außenministeriums mit der von den DDR-Führern vorgeschlagenen Vorgangsweise einverstanden. Demzufolge sollte eine außerordentliche Sitzung der Volkskammer einberufen und noch vor der Pariser Vorkonferenz ihrer stellvertretenden Außenminister ein Appell an die vier Großmächte gerichtet werden. Molotov und Stalin gaben hierfür ihr Einverständnis. Čujkov und Semenov wurden beauftragt, Pieck, Grotewohl und Ulbricht mitzuteilen, „dass man in Moskau ihre Vorschläge [...] begrüßt“. ${ }^{23}$

Die DDR-Führer verbanden mit ihrem Vorschlag folglich drei Hoffnungen bzw. Zielvorstellungen: erstens, die deutsche Öffentlichkeit gegen Adenauers auf Westintegration gerichtete Politik zu mobilisieren; zweitens, die einseitige Aufhebung des westlichen Besatzungsstatutes zu erschweren und drittens, die Hoffnung, dass der Vorschlag über einen Friedensvertrag in der westdeutschen Bevölkerung breite Unterstützung finden und zur

20 RGASPI, f. 82, op. 2, d. 1333, S. 161-168, Gromyko an Molotov, 20. 2. 1951 (Dokument 6).

21 Ebd.

22 RGASPI, f. 82, op. 2, d. 1169, S. 1-3, Gromyko an Stalin, 24. 2. 1951 (Dokument 7).

2:3 Ebd. 
Durchführung einer Volksbefragung führen werde. Die Wortwahl, „die Versuche der Amerikaner [...] zu erschweren" zeigt, dass es der DDR-Führung nicht darum ging bzw. zwecks Aussichtslosigkeit nicht darum gehen konnte, effektiv zu be- oder gar verhindern. Zumindest Ulbricht war ohnedies überzeugt, die Amerikaner würden die Wiederbewaffnung und damit die Westintegration der BRD planmäßig realisieren. Die zusehends fortschreitende Westintegration Westdeutschlands war ein Faktum, auch wenn Anfang 1951 noch nicht klar sein konnte, wie weit diese gehen würde. „Die internationale Aufwertung der Bundesrepublik", so Gerhard Wettig, war aus sowjetischer Sicht - und dem ist im Lichte der neuen Quellen beizupflichten - eine „Herausforderung, auf die reagiert werden“ musste. ${ }^{24}$ Festzuhalten ist zudem, welche - in der Historiographie über die sowjetische Deutschlandpolitik nach wie vor mancherorts kolportierte - Absicht nicht von den DDR-Führern zum Ausdruck gebracht wurde, nämlich jene einer möglichen „Neutralisierung“ eines geeinten Deutschlands inmitten Europas zwischen NATO und Ostblock und dadurch folgend auch die „Bereitschaft" des Kremls, die DDR zu opfern. Auf einen Sieg des Kommunismus in Westdeutschland hofften 1951/52 - ob in Ost- oder Westdeutschland - höchstens noch realitätsfremde Genossen. In allen bisher zugänglichen Dokumenten wird nicht einmal eine entsprechende „Wunschvorstellung“ zum Ausdruck gebracht. Die DDR-Führung betrachtete nüchtern die Ereignisse in Westdeutschland und nützte sie zur Intensivierung des Aufbaus des Sozialismus und zur Festigung ihrer eigenen Macht in der DDR.

\section{Sowjetische Geheimdienstberichte zur Westintegration Westdeutschlands}

Der Kreml lehnte bekanntermaßen die europäische Integration ab. ${ }^{25}$ Die Europäische Gemeinschaft für Kohle und Stahl, die auf den Trümmern des Zweiten Weltkrieges, beflügelt von der Idee eines vereinten Europas, den Beginn eines dauerhaften Friedens innerhalb Westeuropas markierte, war für die Sowjets nichts anderes als ein Versuch der USA, wirtschaftliche und politische Macht über Europa zu erlangen. So wurde es Stalin berichtet, ${ }^{26}$ und so verstand er es auch. Aus sowjetischer Sicht sollte alles unternommen werden, um die Ausbreitung der amerikanischen „Hegemonie“ über Europa zu behindern.

Darüber, wie es um die Westintegration Westdeutschlands stand und wie massiv diese von den USA betrieben wurde, war der Kreml bestens informiert. Der Minister für Staatssicherheit (MGB), Semen Ignat'ev, ${ }^{27}$ erstattete 1951/52 regelmäßig der sowjetischen Führung Bericht über den Stand der Verhandlungen über den - in sowjetischen Quellen so bezeichneten - „allgemeinen Vertrag“ („Generalvertrag“, „Deutschlandvertrag“, Aufhebung des Besatzungsstatutes), über die Bemühungen zur Schaffung einer Europa-Armee und die Gründung der „Europäischen Verteidigungsgemeinschaft“ (EVG). Dem sowjetischen Ministerium für Staatssicherheit (MGB) war es gelungen, den Telegrammverkehr zwischen dem Außenministerium in Paris und seiner Vertretungen im Ausland abzufangen. ${ }^{28}$ Aus

24 Wettig, Die Note vom 10. März 1952, S. 184.

25 Zubok, The Soviet Union and European Integration, S. 85.

${ }^{26}$ RGASPI, f. 82, op. 2, d. 1334, S. 3-12, Zorin an Stalin, 5.4.1951 (Dokument 11).

27 Ignat'ev wurde am 9.8.1951 zum Minister für Staatssicherheit (MGB) ernannt. RGASPI, f. 17, op. 3, d. 1090, S. 16, Politbüro-Beschluss P. 82 (77) vom 9. 8.1951. Kokurin/Petrov (Hrsg.), Lubjanka, S. 266. ${ }^{28}$ Vgl. dazu Mastnys Analyse über die sowjetische Haltung zu den EVG-Verhandlungen und zur Europa-Armee. Auf der Basis von Quellen v. a. von tschechischen Archiven stellt er fest, dass „sowjetische Agenten [...] einige der vertraulichsten Unterredungen zwischen westlichen Staatsmännern heimlich 
diesen, aber auch britischen Quellen kamen übereinstimmende Informationen, die „Remilitarisierung“ Westdeutschlands werde realisiert werden. ${ }^{29}$ Informationen über Rekrutierungspläne der Bundesregierung bekräftigten wohl im Kreml diese Sicht der Dinge. ${ }^{30}$ Ignat'ev berichtete der sowjetischen Führung, dass sich Ende 1951 in den Verhandlungen zwischen den Westmächten und der Regierung Adenauer „ernste Schwierigkeiten“ ergäben hätten. Adenauer habe sich mit dem Entwurf des „Deutschlandvertrages“ nicht einverstanden gezeigt, demzufolge die Westmächte „in einer Reihe von Punkten“ Rechte als Besatzungsmächte beibehalten würden; über die Frage einer künftigen Souveränität Westdeutschlands habe man sich nicht einigen können. ${ }^{31}$ Ende Januar 1952 berichtete Ignat'ev über Adenauers Drängen, den Abschluss der EVG-Verhandlungen „maximal zu beschleunigen“, in der Kabinettssitzung am 18. Dezember 1951. Adenauer „begründete dies damit, dass die Gefahr eines Auftretens der Sowjetunion mit einem neuen verlockenden Vorschlag“ bestünde, „der im letzten Moment Unruhe und Störung sowohl in Washington als auch in Paris" erzeugen könnte".32 Man kann sich die rhetorische Frage stellen, warum der Kreml einen „verlockenden Vorschlag“ machte, obwohl man wusste, dass er bei Adenauer und vor allem den USA auf kein positives Echo stoßen würde? Von der SPD-Führung erwartete der Kreml nicht, sie werde sich stärker gegen „Adenauers Remilitarisierungskurs" engagieren. Die „verräterischen Tätigkeiten der Schumacheristen“ sollten ebenso „entlarvt“"werden. ${ }^{33}$ Bereits im Mai 1951 berichtete die Außenpolitische Kommission Molotov, die SPD arbeite de facto mit der CDU-Regierung zusammen, auch wenn sie die Ablehnung der „Remilitarisierung“ propagiere. ${ }^{34}$

Der Kreml verstand freilich auch, dass die drei Westmächte intern nicht jenen geschlossenen Block bildeten, als der sie gegenüber Moskau stets auftraten. Davon zeugen nicht nur die zahlreichen Berichte des MGB und des sowjetischen Außenamtes an Stalin, Molotov und die übrigen Politbüromitglieder über die Meinungsverschiedenheiten zwischen den Westmächten, vor allem zwischen Washington und Bonn auf der einen und Paris auf der anderen Seite über interne Diskussionen zur Frage der „Remilitarisierung“ und der Art

belauschen und [...] viele Geheimdokumente der NATO lesen konnten“. Mastny, Die NATO im sowjetischen Denken und Handeln, S. 410. Die Berichte über die Abhörung des französischen Außenministeriums standen ihm allerdings nicht zur Verfügung. Vladislav Zubok wertete 1995 in erster Linie die Berichte des KI für das Jahr 1953 aus. Zubok, Soviet Intelligence and the Cold War, zur sowjetischen Deutschlandpolitik 1953 insbesondere S. 469-471.

${ }^{29}$ RGASPI, f. 82, op. 2, d. 1041, S. 151, Berichterstattung Zorins an Gromyko, 31.7.1951 (Dokument 14).

${ }^{30}$ RGASPI, f. 82, op. 2, d. 1041, S. 175, Zorin an alle Mitglieder des Achterkollegiums („Vos'mërka“) sowie an Suslov, Vyšinskij, Vasilevskij und Grigor'jan, 5.9.1951 (Dokument 23).

31 RGASPI, f. 82, op. 2, d. 1042, S. 1, Berichterstattung Ignat'evs an Stalin, Malenkov, Berija, Mikojan, Chruščev und Gromyko, 2.1.1952 (Dokument 24). Siehe dazu auch die Berichterstattung Zorins, ebd., d. 1041, S. 158, 8. 8.1951 (Dokument 16); ebd., d. 1042, S. 27, Berichterstattung Ignat'evs an alle Mitglieder des Achterkollegiums und Vyšinskij, 29.1.1952 (Dokument 27); und ebd., S.31, Zorin an alle Mitglieder des Achterkollegiums sowie an Vyšinskij und Gromyko, 31.1. 1952 (Dokument 29).

32 RGASPI, f. 82, op. 2, d. 1042, S. 25, Berichterstattung Ignat'evs an alle Mitglieder des Achterkollegiums, 27.1.1952 (Dokument 25).

${ }^{33}$ RGASPI, f. 82, op. 2, d. 1042, S. 48, Berichterstattung Zorins an Stalin und alle Mitglieder des Achterkollegiums sowie an Vyšinskij und Gromyko, 14.2.1952 (Dokument 37); RGASPI, f. 82, op. 2, d. 1043, S. 225, Berichterstattung Ignat'evs an Malenkov, Berija und Bulganin, 25.6.1952 (Dokument 111). Zu Schumachers Haltung zur Neutralisierungsbewegung siehe Leugers-Scherzberg, Von den Stalin-Noten zum Deutschlandplan.

${ }^{34}$ RGASPI, f. 82, op. 2, d. 1334, S. 13-20, Grigor'jan an Molotov, 11.5.1951 (Dokument 12). 
und Weise, wie weit die Westintegration Westdeutschlands betrieben werden soll $^{35}$ sondern auch Aussagen französischer Politiker gegenüber sowjetischen Politikern und Diplomaten. ${ }^{36}$ Die Sowjets wussten, dass die Amerikaner um Kompromissregelungen bemüht waren, notfalls auf Empfindlichkeiten der Franzosen jedoch keine Rücksicht nehmen und die Verhandlungen über den „Plevenplan“ (Europäische Verteidigungsgemeinschaft mit deutscher Beteiligung, Aufstellung einer übernationalen westeuropäischen Armee mit Bindung an die NATO) durchpeitschen würden. ${ }^{37}$ Die sowjetische Führung charakterisierte den Pleven- und Schuman-Plan bzw. den beginnenden europäischen Einigungsprozess in dieser Zeit generell stets als Mittel zur „Remilitarisierung“Westdeutschlands. ${ }^{38}$ Aus Hinweisen aus dem britischen Verteidigungsministerium entnahm man Ende Juli 1951, dass bis Jahresende "die offene Verwirklichung der Remilitarisierungspläne Westdeutschlands“ begonnen werden sollte. ${ }^{39}$ Diese konnte der Kreml mit seinem „verlockenden Angebot“ vom 10. März nicht be- oder gar verhindern, selbst im Falle eines Scheiterns der Schaffung einer EuropaArmee. Just in dieser Zeit, ab September 1951, fanden auch erstmals die Forderungen nach Aufstellung „nationaler Streitkräfte“ Eingang in die Entwürfe des sowjetischen Außenministeriums für die „Prinzipien eines Friedensvertrages mit Deutschland“. Für die Zukunft gewährleistete dies die Argumentation des Kremls zur Aufrüstung der DDR, um das „Rüstungsprogramm als notwendige Gegenmaßnahme [zu] tarnen ".00 Dem sowjetischen Geheimdienst war ebenso aus britischen Quellen bekannt, dass die USA notfalls zum „Plan des unmittelbaren Einschlusses westdeutscher Streitkräfte“ in die NATO „zurückkehren “ würden. ${ }^{41}$ Solche Informationen waren wohl auch von dem generell Geheimdienstberichten gegenüber kritisch eingestellten Stalin kaum von der Hand zu weisen. Selbst Unstimmigkeiten in der NATO sah man im Kreml wohl kaum als Möglichkeit, einen Keil zwischen die Mitgliedsländer zu treiben oder gar den militärischen Zusammenschluss aufzuhalten. Die Drohung der USA gegenüber den europäischen NATO-Partnern, von der militär-strate-

35 RGASPI, f. 82, op. 2, d. 1042, S.31, Berichterstattung Zorins an alle Mitglieder des Achterkollegiums sowie an Vyšinskij und Gromyko, 31.1.1952 (Dokument 29). Ebd., S.40, Berichterstattung Zorins an Stalin und alle Mitglieder des Achterkollegiums sowie an Vyšinskij und Gromyko, 9.2. 1952 (Dokument 33); ebd., d. 1042, S. 47, Berichterstattung Ignat'evs an Stalin und alle Mitglieder des Achterkollegiums sowie an Vyšinskij, 16.2.1952 (Dokument 39).

${ }^{36}$ RGASPI, f. 82, op. 2, d. 1042, S.46, Berichterstattung Ignat'evs an Stalin und alle Mitglieder des Achterkollegiums sowie an Vyšinskij, 14.2.1952 (Dokument 36).

37 RGASPI, f. 82, op. 2, d. 1041, S. 151, Berichterstattung Zorins an alle Mitglieder des Achterkollegiums, 31.7.1951 (Dokument 13); ebd., S.170, Berichterstattung Zorins an Suslov und Grigor'jan, 1.9. 1951 (Dokument 20).

38 So Molotovs Einschätzung, die er in einem Bericht des sowjetischen Außenministeriums festhielt. RGASPI, f. 82, op. 2, d. 1348, S. 13f., Zorin an Molotov, mit getippten Beschlüssen Molotovs, 1 . bzw. 3.4.1951 (Dokument 10); ebd., S. 15-21, Bericht Arutjunjans, 28.3.1951 (Dokument 9); ebd., d. 1334, S.3-12, Zorin an Stalin, 5.4.1951 (Dokument 11). So auch die einschätzenden Berichte im Archiv des Präsidenten der Russischen Föderation. Siehe hierzu Egorova, Evropejskaja bezopasnost' i "ugroza“ NATO; Čubar'jan, Rossijskij Evropeizm, S. 311f.; sehr weitgehende Interpretationen bezüglich Stalins Denken in dieser Frage liefert Mastny, Die NATO im sowjetischen Denken und Handeln, S. 410. Siehe auch RGASPI, f. 82, op. 2, d. 1348, S. 3-6, 5.2.1951 (Dokument 1).

39 RGASPI, f. 82, op. 2, d. 1041, S. 151, Berichterstattung Zorins an alle Mitglieder des Achterkollegiums, 31.7.1951 (Dokument 13). Zur Entscheidungsfindung auf britischer Seite in der Frage der Remilitarisierung Westdeutschlands siehe Dockrill, Britain's Policy for West German Rearmament 19501955, S. 59-79.

40 Wettig, Stalins Aufrüstungsbeschluss, S. 640.

41 RGASPI, f. 82, op. 2, d. 1042, S.31, Berichterstattung Ignat'evs an Stalin und alle Mitglieder des Achterkollegiums sowie an Vyšinskij, 31.1.1952 (Dokument 28). 
gischen Verteidigungslinie am Rhein in Europa Abstand zu nehmen und sich auf Basen in den Pyrenäen, auf den britischen Inseln und in Nordafrika zu konzentrieren, erklärte MGBChef Ignat'ev dem sowjetischen Führer als vermutliches Druckmittel, den Widerstand der Europäer gegen eine Anhebung der nationalen Militärbudgets im Interesse der eigenen nationalen Sicherheit zu brechen. ${ }^{42}$

Im Januar 1951 hatte Stalin, wie erst seit kurzem bekannt ist, den Ostblockstaaten in einer Geheimkonferenz in Moskau ein gigantisches Aufrüstungsprogramm auferlegt. Die DDRFührung war zu dieser Konferenz nicht geladen.$^{43}$ Es stellt sich die Frage, ob die SED-Genossen von diesem Treffen erfuhren und ob ihre deutschlandpolitischen Vorschläge, die sie einen Monat später unterbreiteten, hiervon inspiriert wurden. Wahrscheinlich suchte man einen Weg, wie man einerseits nicht offen in die „Geburtsphase“ des Warschauer Paktes einbezogen wurde und andererseits be-, wenn auch nicht verhindern konnte, dass Westdeutschland zu einem weiteren Pfeiler der NATO werden würde, wo ja bereits westliche Truppen stationiert waren. ${ }^{44}$ Alles sollte nach außen hin den Anschein erwecken, als sei die endgültige Einbeziehung der DDR in den Ostblock eine Antwort auf die westliche Verweigerung einer politischen Lösung für Deutschland.

\section{Eine ausgeklügelte Taktik}

Nachdem der Kreml die von der SED-Führung im Februar 1951 vorgeschlagene Strategie gutgeheißen hatte, wurden bis in den Spätsommer 1951 keine weiteren konkreten Schritte unternommen. Dies entsprach der (oben dargelegten) Vorgangsweise. Die Neutralisten wurden seit Sommer 1951 von Moskau intensiv unterstützt, die SED pflegte Kontakte zu Adenauer gegenüber kritisch eingestellten Kreisen. Persönlichkeiten wie der ehemalige Reichskanzler, Joseph Wirth, der 1922 in Rapallo durch Abschluss des deutsch-sowjetischen Vertrages die damalige Isolation der UdSSR gebrochen hatte, und Bischof Niemöller und seine Weggefährten ließen sich vom Kreml instrumentalisieren. ${ }^{45}$ Niemöllers Reise nach

42 RGASPI, f. 82, op. 2, d. 1042, S. 42, Berichterstattung Ignat'evs an alle Mitglieder des Achterkollegiums, 10.2.1952 (Dokument 34).

43 Auf der Konferenz wurde u. a. beschlossen, Piloten in der UdSSR auszubilden. Bereits im November 1951 wurden auch ostdeutsche Piloten in die Ausbildung einbezogen. Wettig, Stalins Aufrüstungsbeschluss, S. 640 und 646. Den entsprechenden Beschluss, 220 deutsche Piloten auszubilden, fällte das Politbüro am 15.11.1951. Mit der Ausbildung sollte in der zweiten Jahreshälfte 1952 begonnen werden. RGASPI, f. 17, op. 162, d. 47, S. 22 und 147f.; ebd., op. 163, d. 1605, S. 169, Politbüro-Beschluss P 84 (377op) vom 15.11.1951; ebd., S. 15 und 109, Politbüro-Beschluss P 84 (250-op) vom 3.11.1951. Dem letzten Beschluss zufolge wurde die Militärabteilung der SKK um 10 Mitarbeiter aufgestockt, „um die Vorbereitung der Land-, Luft- und Polizeiformationen in der Deutschen Demokratischen Republik zu gewährleisten“. Ende Dezember 1951 beschloss das Politbüro, nach Polen, in die Tschechoslowakei, nach Ungarn, Rumänien und Bulgarien Bevollmächtigte des Kriegsministeriums zu schicken, um „den Ländern der Volksdemokratie in der Organisation der Verteidigung der Staatsgrenzen zu Luft zu helfen“. Ebd., d. 48, S. 6, Politbüro-Beschluss P 86 (150-op) vom 29.12.1951. In den folgenden Monaten folgten dutzende Politbüro-Beschlüsse betreffend einer Entsendung von Militärberatern (etwa am 4.1. zu Rumänien und Bulgarien, am 8.2. zur Tschechoslowakei und zu Ungarn usw.). Ebd., d. 48, S.8, 11,12 und 17.

${ }^{44}$ Dies entspräche Stalins generell konservativ ausgeprägtem Sicherheitsdenken für die UdSSR, dem auch im Atomzeitalter v. a. mit Panzern geführte Kricgstaktik zugrunde lag. Siehe Haslam, Litvinov, Stalin and the Road Not Taken, S.60; O'Sullivan, Stalins „Cordon sanitaire“, S. 310-313.

4: Wilke, Die SED und Konrad Adenauer, S. 30f. Siehe hierzu auch RGASPI, f. 82, op. 2, d. 1042, S. 49, Berichterstattung Ignat'evs an Malenkov und Gromyko, 23.2.1952 (Dokument 41). 
Moskau markierte einen der Höhepunkte der sowjetischen Propaganda für ein neutrales Deutschland. Im Kreml riefen Adenauers Reaktionen wohl Zufriedenheit hervor. ${ }^{46}$ Die Zeit arbeitete für Moskau, alles verlief nach Plan.

Die Dritte Europäische Abteilung des sowjetischen Außenministeriums verfasste in der Folge zwar weitere Vorschläge zur Deutschland-Frage, ${ }^{47}$ doch dies war ihr tägliches Brot. Ihr Leiter, Michail Gribanov, verfasste nach dem Scheitern der Konferenz der stellvertretenden Außenminister der vier Großmächte in Paris am 9. Juli 1951 ein Memorandum, in dem er die mögliche weitere Vorgehensweise der Westmächte in der deutschen Frage analysierte. ${ }^{48}$ Im Einklang mit dem im Februar eingeschlagenen deutschlandpolitischen Kurs des Kremls empfahl Gribanov, „um die Initiative im Kampf für die Wiederherstellung der Einheit des demokratischen Deutschlands nicht unseren Händen entgleiten zu lassen“, einen Appell an die westdeutsche Regierung zu richten. Gribanov ging davon aus, dass Bonn jeden Vorschlag ablehnen würde. Er zog den Schluss, dass damit „die DDR politisch im Gewinn“ und „wie bisher in den Augen des deutschen Volkes Bannerträger des Kampfes um die Wiederherstellung des geeinten Deutschlands“ bleibe. Für den Fall, dass Westdeutschland doch zustimmen würde, empfahl Gribanov, Verhandlungen über die „Verfahrensweise der Durchführung gesamtdeutscher Wahlen [... zu] fordern, womit die Bonner Regierung nicht einverstanden sein wird“. Gribanov ging davon aus, dass die Westmächte „systematisch gegen einen schnellen Abschluss eines Friedensvertrages auftreten“, daher erscheine es „zweckmäßig, dass die Sowjetunion die Initiative zur Vorbereitung der Grundlagen eines Friedensvertrages mit Deutschland ergreift“. Dies, so Gribanov, wäre „ein schwerer Schlag gegen das Manöver der drei Mächte“, die bloß die „formelle Erklärung über die Beendigung des Kriegszustandes mit Deutschland“ beabsichtigten. „Der schnelle Abschluss des Friedensvertrages hingegen und der Abzug aller Besatzungstruppen aus Deutschland [...] entspricht den vitalen Interessen des ganzen deutschen Volkes“. ${ }^{49}$ Mit dem Eintreten für solche Forderungen konnte der Kreml Terrain in der Propagandaschlacht gewinnen. ${ }^{50}$

Am 30.Juli 1951 berieten sich in Berlin Pieck, Ulbricht und Grotewohl mit Čujkov und Semenov über die nächsten Schritte. Die DDR-Führer schlugen eine Ausweitung der Kampagnen gegen die „Remilitarisierung“ in Westdeutschland vor, ${ }^{51}$ die Sowjetunion sollte den Abschluss eines Friedensvertrages mit Deutschland vorschlagen und die Grundlagen dieses

${ }^{46}$ RGASPI, f. 82, op. 2, d. 1042, S. 49, Berichterstattung Ignat'evs an Malenkov und Gromyko, 23. 2. 1952 (Dokument 41).

47 Wettig, Die Deutschland-Note vom 10. März 1952 auf der Basis diplomatischer Akten, S. 792; ders., Bereitschaft zu Einheit in Freiheit?, S. 206f. Auch in den Unterlagen des Sekretariates von Molotov finden sich keine weiteren Vorschläge. RGASPI, f. 82, op. 2.

48 Memorandum abgedruckt bei Loth, Die Sowjetunion und die deutsche Frage, S. 241-247.

$49 \mathrm{Ebd}$. In Gribanovs Memorandum werden grundlegende Überlegungen angestellt, wie in der deutschen Frage seitens der UdSSR weiter verfahren werden könnte. Vgl. hierzu den Diskurs zwischen Graml und Loth in Loth, Die Sowjetunion und dic deutsche Frage, S. 166f.

${ }^{50}$ In dieser Frage ist, in Kenntnis des oben Dargelegten, Graml Recht zu geben. Siehe Graml, Eine wichtige Quelle - aber mißverstanden, S. 126; sowie die Gegendarstellung Loths, der seine These mit einem selektiv ausgewählten, einseitig aus dem Kontext gerissenen Absatz des Memorandums zu untermauern versucht. Siehe Loth, Die Sowjetunion und die deutsche Frage, S. 169.

${ }^{51}$ Ersichtlich aus RGASPI, f. 17, op. 162, d. 46, S. 73 und 131-133, hier S.131; ebd., op. 163, d. 1597, S. 97, Politbüro-Beschluss P 82 (452-op) vom 8.9.1951. Auszüge des Politbüro-Beschlusses ergingen an Berija, Molotov und Vyšinskij. Vgl. auch Piccks Tagebuchaufzeichnungen über die Besprechung am 30.7.1951 in Karlshorst „mit nicht benannten Gesprächspartner“. Badstübner/Loth (Hrsg.), Wilhelm Pieck - Aufzeichnungen zur Deutschlandpolitik 1945-1953, S.371-373. 
Vertrages veröffentlichen ${ }^{52}$ In den folgenden Wochen arbeitete das sowjetische Außenministerium unter der Kontrolle Molotovs entsprechende Vorschläge für die weitere Vorgehensweise aus. Am 27. August 1951 stand die deutsche Frage auf der Tagesordnung des Politbüros. Stalin muss die Strategie grundsätzlich begrüßt haben, denn das Politbüro beauftragte Vyšinskij, innerhalb von drei Tagen „auf der Basis des Meinungsaustausches den vorgelegten Entwurf zu überarbeiten, d.h. Vorschläge zu den Fragen, die von den Gen. Pieck, Grotewohl und Ulbricht im Gespräch mit den Gen. Čujkov und Il'ičev am 30.Juli d. J. gestellt wurden, auszuarbeiten“. Berija, Bulganin, Kaganovič, Malenkov, Molotov und Chruščev stimmten für den Entschluss. ${ }^{53}$ In seiner Sitzung vom 8. September 1951 beschloss das Politbüro schließlich den „Fahrplan“ in der deutschen Frage für die nächsten Monate. ${ }^{54}$ Bezüglich der Frage eines Friedensvertrages „begrüßte“ das Politbüro die Vorschläge der DDR-Führung und „empfahl“ zudem, Maßnahmen zu ergreifen, „die der weiteren Entlarvung der antidemokratischen Bonner Regierung Westdeutschlands dienlich sein würden ". ${ }^{55}$ Vom Ernst der Sache zeugt deutlich die ungewöhnliche Vorgehensweise der sowjetischen Führung während der Sitzung. Einerseits segnete das Politbüro den vom Außenministerium eingebrachten Anweisungsentwurf für Čujkov und Semenov über die weitere Vorgehensweise bereits ab, andererseits aber wurde Außenminister Vyšinskij zusätzlich beauftragt, noch vor der Übermittlung der Anweisungen für Čujkov und Semenov die Meinungen Piecks und Ulbrichts einzuholen. ${ }^{56}$ Dem Laufe der Ereignisse nach zu urteilen, muss sich die DDR-Spitze sofort mit den Vorschlägen einverstanden erklärt haben. Dem Politbüro-Beschluss zufolge, der noch mit der SED-Führung abzusprechen war, sollte der Volkskammer der DDR „empfohlen“ werden, sich an den Bonner Bundestag zu wenden und ihm vorzuschlagen, ein gemeinsames Gremium aus Vertretern der west- und ostdeutschen Regierung einzuberufen, um die Fragen allgemeiner Wahlen und der Beschleunigung des Abschlusses eines Friedensvertrages zu erörtern. Im Falle einer Ablehnung der Vorschläge durch die Bonner Regierung sollte sich die DDR allein mit der Bitte um Beschleunigung des Abschlusses eines Friedensvertrages für Deutschland und anschließendem Abzug aller Besatzungstruppen aus Deutschland an die vier Mächte wenden. Die sowjetische Regierung würde diesen Vorschlag begrüßen und nunmehr einen Entwurf von Grundlagen eines Friedensvertrages mit Deutschland vorbringen.

${ }^{52}$ Loth, Die Entstehung der „Stalin-Note“, S. 27.

53 RGASPI, f. 17, op. 3, d. 1090, S. 51, ebd., op. 163, d. 1595, S. 140, Politbüro-Beschluss P 82 (259) vom 27.8.1951. Siehe hierzu auch Loth, Die Entstehung der „Stalin-Note“, S. 28-30.

${ }^{54} \mathrm{Im}$ Wortlaut des Politbüro-Beschlusses selbst heißt es: „Wir schlagen folgenden Handlungsplan [plan dejstvij] vor“. RGASPI, f. 17, op. 162, d. 46, S. 46 und 131-133, Politbüro-Beschluss P 82 (452-op) vom 8.9. 1951. Filitov, Sovetskij Sojuz i germanskij vopros, S. 335. Die Beschlussfassung ist auch ersichtlich aus RGASPI, f. 82, op. 2, d. 11 70, S. 1 f., die Entwurffassung des Politbüro-Beschlusses vom 6.2. 1951 ist abgedruckt bei Loth, Die Entstehung der „Stalin-Note“, S. 113-115. Allerdings wurde im Politbüro am 6. 2. 1952 kein Beschluss zu Deutschland gefasst. RGASPI, f. 17, op. 3, d. 1092, S. 80 f.; ebd., op. 162, d. 48, S. 17. Siehe auch Adibekov/Anderson (Hrsg.), Politbjuro CK RKP(b)-VKP(b), S. 868. Dem Irrtum bei Loth liegt wohl ein Tippfehler im Original bei Gromyko zugrunde. RGASPI, f. 82, op. 2, d. 1170, S.51. Ein Entwurf des Schreibens Gromykos an Stalin findet sich auch in RGASPI, f. 82, op. 2, d. 1170, S. 23. Siehe dazu auch Adibekov/Anderson (Hrsg.), Politbjuro CK RKP(b)-VKP(b), S. 868.

$5 \check{5}$ Keinesfalls wurde in dieser Sitzung die Einsetzung einer Kommission zur Ausarbeitung von Grundlagen eines Friedensvertrages für Deutschland beschlossen, was freilich nicht bedeutet, dass sich Beamte des sowjetischen Außenministeriums nicht weiterhin mit den Friedensvertragsentwürfen für Deutschland zu befassen hatten. Siehe hierzu Loth, Die Entstehung der „Stalin-Note“, S. 32-40; zu den sowjetischen Friedensvertragsentwürfen bereits lange vor 1951/52 siehe Laufer, Der Friedensvertrag mit Deutschland als Problem der sowjetischen Außenpolitik.

${ }_{56}$ RGASPI, f. 17, op. 162, d. 46, S. 46, Politbüro-Beschluss P 82 (452-op) vom 8.9.1951. 
Für den Fall der Fälle, nämlich dass die Bonner Regierung unerwartet ${ }^{57}$ auf den Vorschlag der DDR-Volkskammer eingehen würde, hatte sich der Kreml ebenfalls vorbereitet. Demnach sollten die DDR-Vertreter im einzuberufenden Gremium Fragen wie jene „der Erlaubnis der freien Tätigkeit von demokratischen Parteien und Organisationen in Westdeutschland“ oder „die Nichtzulassung einer Remilitarisierung Deutschlands“ und des Verbots der Mitgliedschaft in militärpolitischen Blöcken als unabdingbare Bedingung „für die Schaffung eines einheitlichen und friedliebenden Deutschland“ einbringen. ${ }^{58}$ Eine Woche nach dem Politbüro-Beschluss präsentierte schließlich der Ministerpräsident der DDR, Grotewohl, am 15. September 1951 den „Vorschlag“. ${ }^{59}$ Bundeskanzler Adenauer erkannte richtig, dass es sich um einen reinen Propagandaschachzug handelte und griff ihn nicht auf.

Am 30. September 1951 legte Vyšinskij Molotov einen Entwurf von Grundlagen eines Friedensvertrages mit Deutschland vor. ${ }^{60}$ Molotov versah einige Absätze mit Wellenlinien und forderte klarere Formulierungen ein. Auf dem Dokument hielt er handschriftlich fünf Punkte fest, an denen sich anscheinend das Außenministerium bei der weiteren Ausformulierung der Grundlagen zu orientieren hatte. Der erste Punkt betraf die Forderung, dass der Entwurf den Bestimmungen der Potsdamer Übereinkunft näher kommen müsse, der zweite jene, dass ein Friedensvertrag für Deutschland wie für alle anderen Länder eingefordert werden müsse, und der dritte galt dem „Schutz der Werktätigen in der Stadt und auf dem Land“. Ferner reklamierte Molotov Bestimmungen zu Reparationen und zur „Demilitarisierung " und Verteidigung Deutschlands. ${ }^{61}$

Am 31. Oktober 1951 gab das Politbüro den DDR-Führern grünes Licht, die ablehnende Haltung des Bundestages gegenüber dem Grotewohl-,,Vorschlag“ zu kritisieren. Ein Appell der Volkskammer an das deutsche Volk wurde jedoch als zu früh erachtet. ${ }^{62}$ Ein solcher sollte zu einem späteren Zeitpunkt erfolgen. Zunächst sollte sich der Präsident der DDR mit dem Vorschlag an den Präsidenten Westdeutschlands wenden, eine gesamtdeutsche Konferenz einzuberufen, um die Wahlfrage und die Beschleunigung des Abschlusses eines Friedensvertrages zu erörtern. Um sicherzugehen, dass die westdeutsche Regierung den Vorschlag ablehnen würde, ließ das Politbüro die DDR-Führung wissen, dass sie eine „deutsche Kommission zur Vorbereitung eines Wahlgesetzentwurfes" selbst bilden könne. Diesen Entwurf sollte die Regierung der DDR schließlich „zur Erörterung auf der gesamtdeutschen Konferenz“ vorlegen. Aus der Weisung des Politbüros: „Die Veröffentlichung dieses Entwurfs zur Erörterung im ganzen Volk kann der Bonner Regierung den Anlass geben, unter dem Vorwand dieser oder jener ihr unannehmbarer Vorschläge des Entwurfes den

${ }^{57}$ Der Leiter der Dritten Europäischen Abteilung, Gribanov, hielt dies in einem Schreiben am 15.8.1951 an Vyšinskij fest. Siehe Loth, Die Entstehung der „Stalin-Note“, S. 72f. Hierbei handelte es sich wohl kaum nur um Gribanovs eigene Meinung. Das von Loth edierte Dokument ist in vielerlei Hinsicht von großem Interesse. Einerseits zeigt es, dass der oben zitierte Politbüro-Beschluss vom 8.9.1951 inhaltlich bereits Mitte August vorlag, andererseits zeigt sich nunmehr auch klar, dass Gribanov freilich nur Formulierungsarbeit zu leisten hatte.

${ }_{58}$ RGASPI, f. 17, op. 162, d. 46, S. 46 und 131-133, Politbüro-Beschluss P 82 (452-op) vom 8.9. 1951.

59. Wettig, Bereitschaft zu Einheit in Freiheit?, S. $201 f$.

${ }^{60}$ RGASPI, f. 82, op. 2, d. 1169, S.73, Vyšinskij an Molotov, 30.9.1951; ebd., S.74-79, Entwurf von Grundlagen eines Friedensvertrages mit Deutschland.

${ }^{61}$ Ebd.

${ }^{62}$ RGASPI, f. 17, op. 162, d. 47, S. 8 und 91; ebd., op. 163, d. 1604, S. 40, Politbüro-Beschluss P 84 (203op.) vom 31.10.1951, Auszüge des Beschlusses ergingen an Berija, Malenkov, Molotov, Gromyko und Grigor'jan. 
Vorschlag der DDR über die Einberufung einer gesamtdeutschen Konferenz abzulehnen. "63 Der Kreml war an der Erörterung gesamtdeutscher Wahlen nicht interessiert. Am 23. Januar 1952 untersagte das Politbüro C̆ujkov, mit den Hohen Kommissaren bezüglich der Einberufung einer Konferenz der Besatzungsmächte „zur Frage der Durchführung gesamtdeutscher Wahlen" in Kontakt zu treten. ${ }^{64}$

In der Zwischenzeit feilten das Außenministerium und Molotov am Text der Grundlagen für einen Friedensvertrag für Deutschland ${ }^{65}$ und am gesamten Maßnahmenpaket. ${ }^{66}$ Ein Entwurf eines Schreibens Gromykos an Stalin, das er am 25.Januar 1952 Molotov zur Prüfung vorlegte ${ }^{67}$ zeugt davon, dass sich das Außenministerium auf alle Eventualitäten vorbereitete, um bei möglichen Verhandlungen, so sich denn der Westen darauf einlassen würde, die Trumpfkarte in der Hand zu behalten. So lehnte Gromyko den neuen Vorschlag der DDR-Führung ab, ${ }^{68}$ demzufolge in erster Linie nicht die Frage eines Friedensvertrages, sondern jene des "Generalvertrages" in den Vordergrund gestellt werden sollte. Nicht die Regierung der UdSSR, sondern die Volkskammer solite einen Entwurf eines Friedensvertrages für Deutschland vorlegen. Gromyko wies diesen Vorschlag zurück und verwies darauf, dass eine solche Vorgehensweise nicht den am 8.9.1951 vom Politbüro beschlossenen Maßnahmen und dem früher mit der DDR-Führung abgestimmten Plan entspräche. „Ein solcher Vorschlag“, hielt Gromyko fest, „bedeutet, dass ein besiegter Staat für sich selbst einen Entwurf von Grundlagen eines Friedensvertrages ausarbeitet.“ Der entscheidende Punkt allerdings war folgender: „Kritik und Einwände am Generalvertrag“, so Gromyko, wären „für die Bonner Regierung vorteilhaft, die daran interessiert ist, die Frage des Friedensvertrages mit Deutschland durch propagandistischen Lärm rund um den bevorstehenden Abschluss des ,Generalvertrages“ zu ersetzen." Gromyko weiter: „AuBerdem würde das Auftreten der Sowjetunion mit dem ganzen Text eines Friedensvertrages auf der Basis des vorgeschlagenen Entwurfes von Grundlagen dieses Vertrages durch die Volkskammer uns in möglichen Verhandlungen mit den Westmächten im Hinblick auf

03 Ebd.

64 RGASPI, f. 17, op. 162, d. 48, S. 14 und 67, Politbüro-Beschluss P 85 (307-op) vom 23. 1. 1952.

65 RGASPI, f. 82, op. 2, d. 1169, S. 82, Gromyko an Molotov mit der Bitte um Prüfung des Entwurfes „in der nächsten Zeit“, 11.1.1952; ebd., S.83-87, Grundlagen eines Friedensvertrages für Deutschland; ebd., S.88, Gromyko an Molotov, 14.1.1952; ebd., S.89-93, Grundlagen eines Friedensvertrages für Deutschland.

66 RGASPI, f. 82, op. 2, d. 1169, S.94, Gromyko an Molotov mit der Bitte die Frage „zu erörtern“, 18. 1. 1952; ebd., S.95f., Entwurf eines Schreibens Gromykos an Stalin (zur Prüfung durch Molotov); ebd., S.97-106, Entwurf eines Politbüro-Beschlusses (Maßnahmenplan zum Absenden der „StalinNote") mit beiliegenden Entwürfen von Anweisungen an Čujkov und Semenov, von Grundlagen eines Friedensvertrages mit Deutschland.

67 RGASPI, f. 82, op. 2, d. 1169, S. 108-111, Entwurf eines Schreibens Gromykos an Stalin zur Prüfung durch Molotov, 25.1.1952. Der Entwurf erging gemeinsam mit dem ausgebesserten Entwurf der Grundlagen eines Friedensvertrages und jenem eines Politbüro-Beschlusses an Molotov. Ebd., S. 107123. Dic Formulierungen gehen auf Gribanov, Puškin und Koptelov zurück. Der Entwurf ist abgedruckt bei Loth, Die Entstehung der „Stalin-Note“, S. 107-109.

${ }^{68}$ Diescr muss zwischen dem 18, und 21.2. 1952 von der DDR-Führung eingebracht worden sein. Im Entwurf des Schreibens Gromykos an Stalin vom 18.1.1952, in dem Gromyko die Übermittlung der Grundlagen eines Friedensvertrages an die Westmächtc cmpfahl, finden sich keine Hinweise auf den neuen Vorschlag der SED-Führung. Siehe Loth, Die Entstehung der „Stalin-Note“, S. 45; RGASPI, f. 82, op. 2, d. 1169, S.95f., Entwurf cines Schreibens Gromykos an Stalin, übersandt an Molotov am 18. 1. 1952. Den Entwurf formulierten Gribanov, Puškin und Koptelov. Er ist abgedruckt bei I.oth, Die Entstehung der „Stalin-Note“, S. 105f. 
einzelne Artikel des Friedensvertrages die Hände binden und den Gegnern einer Friedenslösung mit Deutschland den Anlass bieten, einige für die Deutschen unvorteilhaften Artikel des Vertrages zu dem Zweck auszunutzen, die Bedeutung unseres Auftretens in dieser Frage zu schwächen. "69 Der Anlass für das Umdenken der DDR-Führung, vor allem nunmehr gegen den „Generalvertrag“ zu wettern (Čujkov und Semenov erklärten sich mit diesem neuen Vorschlag einverstanden), ${ }^{70}$ könnte die Kenntnis des Textes des „Generalvertrages" gewesen sein. Gromyko hegte jedoch große Zweifel an der Echtheit des Textes und schloss nicht aus, dass „dieses Dokument speziell zum Zwecke der Desinformation vorbereitet wurde“. ${ }^{71}$

Für die Sowjetunion, so die Meinung Gromykos, wäre allein die Ablehnung des „Generalvertrages" zu wenig wert gewesen und hätte nur der Regierung Adenauer Vorteile gebracht. Einen vollen propagandistischen Sieg konnte die UdSSR nur mit dem Vorschlag erzielen, einen Friedensvertrag für Deutschland auf die aktuelle Tagesordnung zu setzen.

\section{Am Vorabend der Stalin-Note}

Zwei Tage, nachdem das Politbüro die Einberufung einer Konferenz der Besatzungsmächte zur Erörterung gesamtdeutscher Wahlen abgelehnt hatte, empfahl Gromyko am 25.Januar 1952 Stalin, dass nunmehr die DDR-Regierung mit einem Appell an die vier Mächte herantrete und um „die Beschleunigung des Abschlusses eines Friedensvertrages“ sowie die westdeutsche Regierung um Unterstützung des Vorschlags bitte. ${ }^{72}$ Als Antwort darauf, so Gromyko, könnte die UdSSR den Regierungen der Westmächte eine Note überreichen, in der sie vorschlage, zur Ausarbeitung eines Entwurfs eines Friedensvertrages für Deutschland überzugehen. Der Note sollte ein Entwurf über die Grundlagen eines Friedensvertrages beigelegt werden. Gromyko unterstrich, dass eine solche Vorgehensweise "große politische Bedeutung im Kampf für den Frieden und gegen die Remilitarisierung Westdeutschlands“ hätte und „den Befürwortern der Einheit Deutschlands und des Friedens bei der Entlarvung der aggressiven Absichten der drei Westmächte im Zusammenhang mit dem, Generalvertrag“ helfen würde“. Gromyko legte gegenüber Stalin dar, dass die Note auch „bedeuten würde, dass wir indirekt die Einberufung eines Rates der Außenminister der vier Mächte vorschlagen, wenn auch ohne diesbezüglichen formellen Vorschlag“. Je nach Reaktion der drei Westmächte könnte man daher die Frage der Einberufung einer Konferenz des Rates der Außenminister formell erst später entscheiden. Den neuen Vorschlag der DDR-Füh-

${ }^{69}$ RGASPI, f. 82, op. 2, d. 1169, S. 108-111, Entwurf eines Schreibens Gromykos an Stalin zur Prüfung durch Molotov, 25.1.1952. Der Entwurf ist abgedruckt bei Loth, Die Entstehung der "Stalin-Note“, S. 107-109.

70 Siehe auch Loth, Die Entstehung der „Stalin-Note“, S. 47.

71 RGASPI, f. 82, op. 2, d. 1169, S. 108-111. Vgl. die Interpretation bei Loth, Die Entstehung der „Stalin-Note“, S. 45-47.

72 RGASPI, f. 82, op. 2, d. 1169, S. 124f., Gromyko an Stalin, 25.1. 1952. Das Dokument ist in seinem Wortlaut als Entwurf Gribanovs u. a. abgedruckt bei Loth, Die Entstehung der „Stalin-Note“, S. $105 f$. Der zitierte Entwurf des Schreibens Gromykos vom 25. Februar 1952 ging anscheinend nicht in dieser Form an Stalin. Molotov wies wohl Gromyko an, den Entwurf des Schreibens vom 18. Februar als Grundlage zu nehmen. Ergänzt wurde das endgültige Schreiben nur mit einem abschließenden Absatz, in dem Gromyko kurz und bündig festhielt, dass dieser Vorschlag dem Politbüro-Beschluss vom 8.9.1951 widerspräche. Vgl. Loth, Die Entstehung der „Stalin-Note“, S.45-49. 
rung lehnte Gromyko ab. ${ }^{73}$ Die UdSSR würde folglich in den Augen der Weltöffentlichkeit als Verfechterin der Einheit Deutschlands dastehen.

Wenige Tage später wurde die weitere Vorgehensweise in der deutschen Frage am 30.Januar 1952 im Politbüro debattiert. Stalin bemängelte den „Fahrplan“. Das Politbüro setzte dem Außenministerium eine Frist von drei Tagen, die vorgelegten Entwürfe zu überarbeiten. ${ }^{74}$ Am 2. Februar 1952 präsentierte schließlich der sowjetische Außenminister Vyšinskij Stalin die überdachte weitere Vorgehensweise in der deutschen Frage. Nunmehr sollte der DDR-Führung „empfohlen“ werden, sich an die Regierungen der vier Großmächte „mit der Bitte um Beschleunigung des Abschlusses des Friedensvertrages mit Deutschland“ zu wenden, zuvor freilich den Entwurf eines solchen Appells der Sowjetregierung zu schicken. Nach Veröffentlichung des Appells sollte die UdSSR diesen zunächst begrüßen, um sich anschließend mit dem Entwurf von Grundlagen eines Friedensvertrages mit Deutschland an die Westmächte zu wenden und zuvor die tschechoslowakische und polnische Regierung darüber zu informieren. ${ }^{75}$ Am 8. Februar 1952 wies nunmehr das Politbüro Čujkov und Semenov an, der Regierung der DDR zu empfehlen, sich in den nächsten Tagen mit einer Note an die Großmächte zu wenden. ${ }^{76}$ Die sowjetische Regierung würde diese unterstützen. ${ }^{77}$ In seiner Anweisung an Čujkov und Semenov hielt das Politbüro fest, dass „die Maßnahmen im Zusammenhang mit dem Appell der Regierung der DDR an die Bonner Regierung über die Beschleunigung des Abschlusses des Friedensvertrages mit Deutschland und der Schaffung eines einheitlichen, friedliebenden, demokratischen deutschen Staates, die im Laufe des letzten halben Jahres in Deutschland durchgeführt wurden, und auch über die Durchführung gesamtdeutscher Wahlen zu diesem Ziel zweifelsohne positive Ergebnisse gebracht haben. Sie halfen, die Politik der USA, Großbritanniens und Frankreichs,

${ }^{73}$ Ebd. Von Interesse ist, dass Gromyko und Molotov Stalin anscheinend schriftlich nicht über die interne Begründung des Ablehnens der neuen Vorschläge der DDR-Führung informierten. Vgl. die Interpretation bei Loth, Die Entstehung der "Stalin-Note“, S. 47.

74 RGASPI, f. 17, op. 3, d. 1092, S.73; ebd., op. 163, d. 1612, S.63, Politbüro-Beschluss P 85 (352) vom 30.1.1952. Vgl. Loth, Die Entstehung der „Stalin-Note“, S. 49.

${ }^{75}$ RGASPI, f. 82, op. 2, d. 1170, S. 1f., Vyšinskij an Stalin, 2.2.1952 (Dokument 30); Filitov, Sovetskij Sojuz i germanskij vopros, S.333f. Bei dem bei Loth zitierten Schreiben Vyšinskijs an Stalin mit demselben Datum muss es sich um ein anderes Dokument handeln. Im hier abgedruckten Dokument ist keine Rede davon, dass Vyšinskij Stalin „die Vorteile eines Friedensvertrages für das deutsche Volk in den höchsten Tönen pries". Siehe dazu Loth, Die Entstehung der "Stalin-Note“, S.51. Zur Redaktion der Fassungen der "Grundlagen eines Friedensvertrages mit Deutschland" bis zum 6.2.1952, die schlussendlich in der Stalin-Note vom 10.3.1952 den Westmächten übermittelt wurden, siehe Loth, Die Entstehung der „Stalin-Note“, S. 20-52 bzw. S.63-115. In der Folge wurde von der sowjetischen Führung allerdings nicht „zunächst nur die Antwort auf den DDR-Appell“ fertiggestellt (ebd., S. 53), auch an den „Grundlagen eines Friedensvertrages" wurde kontinuierlich weiter gefeilt, wie im Folgenden zu zeigen sein wird.

${ }^{76}$ RGASPI, f. 17, op. 162, d. 48, S. 18 und 70-72, op. 163, d. 1612, S. 153, Politbüro-Beschluss P 85 (425op) vom 8. 2.1952. Die Endversion findet sich auch in RGASPI, f. 82, op. 2, d. 1170, S.52. Entwurf mit Korrektur Molotovs (ohne beiliegende Anweisungen an Čujkov und Semenov) in RGASPI, f. 82, op. 2, d. 1170, S.20f., 8.2.1952 (Dokument 32). Der Entwurf vom 6.2. des Politbüro-Beschlusses vom 8.2.1952 ist abgedruckt bei Loth, Die Sowjetunion und die deutsche Frage, S. 298-300. Der Entwurf entspricht in seinem Wortlaut der Endredaktion des Politbüro-Beschlusses.

77 RGASPI, f. 17, op. 162, d. 48, S. 71, Politbüro-Beschluss P 85 (425-op) vom 8. 2. 1952. Die SED-Führung wurde keineswegs vom Kreml zurechtgewiesen und erst wenige Stunden vor Veröffentlichung der Note in Kenntnis gesetzt, wie der Kreml auf den Appell der DDR-Regierung an die vier Mächte reagieren würde. Vgl. Loth, Die Sowjetunion und die deutsche Frage, S. 163. Am 8.2. wurden Čujkov und Semenov beauftragt, die SED-Führung darüber in Kenntnis zu setzen, dass die sowjetische Regierung den Appell unterstützen werde. Der Appell erfolgte am 13.2. 
die auf die Remilitarisierung Westdeutschlands, auf die Vertiefung der herrschenden Teilung Deutschlands und auf seine Einbeziehung in die Kriegspläne des Atlantischen Blocks mit dem Ziel der Beschleunigung der Vorbereitung eines neuen Krieges in den Augen breiter Schichten des deutschen Volkes zu entlarven." Entsprechend des mit der DDR-Führung im September 1951 abgestimmten Plans über die weitere Vorgehensweise zum Zwecke der „Beschleunigung des Abschlusses eines Friedensvertrages mit Deutschland“ sah das Politbüro nunmehr die Zeit gekommen, den nächsten Schritt zu tun, insbesondere im Zusammenhang mit der Forcierung des „Generalvertrages“ durch die Westmächte. ${ }^{78}$ Der Unterzeichnung musste der Kreml mit seinem „Angebot“ zuvorkommen, um es in der Öffentlichkeit als ernsthaft gemeint untermauern zu können.

Čujkov und Semenov hatten gemäß Politbüro-Beschluss der SED-Führung mitzuteilen, dass nach Meinung der Sowjetregierung die nunmehr zu treffenden Maßnahmen die „Beschleunigung des Abschlusses eines Friedensvertrages“ unterstützt würden, ebenso der „Mobilisierung der demokratischen Kreise Deutschlands, darunter [auch] in Westdeutschland“. Diese „Anweisungen“ stellen in keiner Weise die Meinung der sowjetischen Führung dar, sondern zeigen lediglich, wie die SED-Führung die Haltung der UdSSR zu propagieren hatte. ${ }^{79}$ Die Maßnahmen würden zudem „die Möglichkeit geben, dieses positive Programm den aggressiven Plänen der USA, Englands, Frankreichs und der Bonner Regierung entgegenzustellen“. ${ }^{80}$ Der „Generalvertrag“ sollte als Mittel zur faktischen Beibehaltung der Besatzung gebrandmarkt werden, der die Teilung Deutschlands vertiefe und „das deutsche Volk der Möglichkeit der Wiederherstellung der Einheit Deutschlands beraube“. Dieser führe zur Einbeziehung Westdeutschlands in den ,anglo-amerikanischen Block“ und zu einem neuen Krieg, sogar zu einem „selbstmörderischen Krieg zwischen den Deutschen selbst“. 81

Nur wenige Tage später stand die Frage erneut auf der Tagesordnung des Politbüros. Am 12. Februar segnete das Politbüro des ZK den Appellentwurf Grotewohls mit geringen Änderungen $\mathrm{ab}^{82}$ und beschloss endgültig, die DDR-Führung möge sich in den nächsten Tagen mit ihrem Appell an die vier Großmächte wenden. ${ }^{83} \mathrm{Am}$ Tag danach, dem 13. Februar 1952, richtete die DDR-Führung nunmehr ihren Appell an die Großmächte und die westdeutsche Regierung.

Am folgenden Tage wandte sich Gromyko, der in Vyšinskijs dreiwöchiger Abwesenheit als sein Stellvertreter die Verantwortung im sowjetischen Außenministerium trug, ${ }^{84}$ erneut mit

78 RGASPI, f. 17, op. 162, d. 48, S. 18 und 70-72, Politbüro-Beschluss P 85 (425-op) vom 8. 2.1952.

79 Bemerkenswert ist dennoch, dass „Deutschland“ in dieser Direktive des Politbüros als Synonym für die DDR verwendet wird. Die Anweisungen an Čujkov und Semenov können allerdings in keiner Weise als Grundlage zur Rekonstruktion der Ziele der sowjetischen Deutschlandpolitik dienen. Sie stellen lediglich Formulierungen dar, wie Čujkov und Semenov bzw. die SED-Führung in der Folge öffentlich [!] aufzutreten und welcher Strategie sie sich zu bedienen hatten. Loth sieht anhand dieses und anderer Dokumente seine Kernthese, Stalin wollte eine Neutralisierung Deutschlands erreichen, bestätigt. Loth setzt sich in diesem Zusammenhang mit keiner Quellenkritik auseinander. Siehe hierzu insbesondere Loth, Die Sowjetunion und die deutsche Frage, S. 166f.

${ }^{80}$ Ebd.

81 Ebd.

82 Die Westmächte sollten nicht als „imperialistisch“, sondern als „aggressiv“ tituliert werden. Der Appell sollte nicht mit dem Ausdruck der Hoffnung, sondern in Erwartung auf ein "positives" Echo seitens der Großmächte geschlossen werden. RGASPI, f. 17, op. 162, d. 48, S.21 und 74, Politbüro-Beschluss P 85 (453-op) vom 12.2.1952.

83 RGASPI, f. 17, op. 162, d. 48, S. 21 und 70-72, Politbüro-Beschluss P 85 (453-op) vom 12.2. 1952.

${ }^{84}$ Am 5.2.1952 "genehmigte" das Politbüro Vyšinskij einen dreiwöchigen Genesungs- und Erholungsurlaub. RGASPI, f. 17, op. 3, d. 1092, S.78, Politbüro-Beschluss P 85 (379) vom 5.2.1952. In diesem 
einem „Entwurf zur deutschen Frage“ an Molotov, für den er um sein Einverständnis bat, um ihn „zur Prüfung an die Instanz“, also Stalin, schicken zu können. ${ }^{85}$ Die „Prüfung“ betraf den Entwurf der für den 18. Februar vorgesehenen Antwort der sowjetischen Regierung auf den Appell der DDR-Führung in der Form einer Verbalnote, den Entwurf der „Grundlagen eines Friedensvertrages“, den Entwurf der für den 23. Februar abzuschickenden Note, mit dem der „Friedensvertragsvorschlag“ an die Westmächte übermittelt werden soll, und den Entwurf des Schreibens an die polnische und tschechoslowakische Regierung. ${ }^{86}$ Am 18. Februar 1952 übersandte Gromyko Stalin einen weiteren Entwurf eines Politbüro-Beschlusses, demzufolge die Antwort der sowjetischen Regierung auf den Appell der DDR am 19. Februar übermittelt werden sollte. ${ }^{87}$ Diese verzögerte sich um einen weiteren Tag, am 21. Februar wurde sie schließlich veröffentlicht. ${ }^{88}$ Vor Absendung der Note an die Westmächte mit dem „Friedensvertragsentwurf" wartete man indes Reaktionen der Westmächte und der westdeutschen Regierung ab.

In der Folge berichteten Ignat'ev und Zorin der sowjetischen Führung weiterhin über die Unstimmigkeiten im westlichen Lager bei den Verhandlungen zum "Generalvertrag“. 89 Ignat'ev legte am 26. Februar dar, dass es den Hohen Kommissaren und Adenauer nicht gelungen war, „die grundlegenden Unstimmigkeiten [...] zu überwinden “.90 Einen Tag zuvor hatte Zorin gemeldet, dass „die Unzufriedenheit mit der Politik der französischen Regierung in der Frage der Remilitarisierung Westdeutschlands nicht nur die demokratischen Kreise Frankreichs erfasst hat, sondern auch einige Schichten der Bourgeoisie". ${ }^{91}$ Am 2. März berichtete Zorin über den amerikanischen Druck, dem die westeuropäischen Länder ausgesetzt seien; er sei infolge des Scheiterns der Tagung des NATO-Rates in Ottawa im September 1951 noch weiter erhöht worden. ${ }^{92}$ Die auf der Tagung in Lissabon im Februar 1952 gefällten Entscheidungen interpretierte Zorin als „ein neues gewaltiges Zugeständnis

Zusammenhang stellt sich die Frage, ob Stalin absichtlich ein ärztliches Attest erstellen ließ, um in dieser entscheidenden Phase ausschließlich auf Molotov und Gromyko zu setzen. Vyšinskij war allerdings schwer nierenkrank. Zur Rolle Gromykos siehe Filitov, Sovetskij Sojuz i germanskij vopros, S. 319.

85 RGASPI, f. 82, op. 2, d. 1170, S. 22-24, Gromyko an Molotov, 14.2.1952. Nachdem Molotov das Aktenkonvolut gesichtet und seine Korrekturen angebracht hatte, übermittelte Gromyko die Akte am folgenden Tag Stalin. RGASPI, f. 82, op. 2, d. 1170, S.34f., Gromyko an Stalin, 15. 2. 1952 (Dokument $38)$.

${ }^{86}$ Ebd. sowie Loth, Die Entstehung der „Stalin-Note“, S.52f.

${ }^{87}$ RGASPI, f. 82, op. 2, d. 1170, S. 36f., Gromyko an Stalin, 18.2.1952 (Dokument 40).

${ }^{88}$ Filitov, Sovetskij Sojuz i germanskij vopros, S. 336; Loth, Die Entstehung der „Stalin-Note“, S. 53. Das Politbüro beauftragte General Puškin, noch am selben Tag die Antwort der UdSSR Grotewohl zu übergeben und diese am Tag darauf in der Presse zu veröffentlichen. RGASPI, f. 17, op. 3, d. 1092, S. 103 und 249, Politbüro-Beschluss P 85 (494) vom 20.2.1952.

${ }^{89}$ RGASPI, f. 82, op. 2, d. 1042, S. 47, Berichterstattung Ignat'evs an Stalin und alle Mitglieder des Achterkollegiums sowie an Vyšinskij, 16. 2.1952 (Dokument 39), und die in der Folge zitierten Dokumente.

90 RGASPI, f. 82, op. 2, d. 1042, S.54, Berichterstattung Ignat'evs an Stalin und alle Mitglieder des Achterkollegiums sowie an Gromyko, 26.2.1952 (Dokument 45). $\mathrm{Zu}$ den Verhandlungen der Westmächte siehe Steininger, Deutsche Geschichte, Bd.2, S. 156.

91 RGASPI, f. 82, op. 2, d. 1042, S. 54, Berichterstattung Zorins an Vyšinskij, Gromyko, Bogomolov und Grigor'jan, 25.2.1952 (Dokument 44).

92 RGASPI, f. 82, op. 2, d. 1042, S. 58, Berichterstattung Zorins an Vyšinskij, Vasilevskij, Gromyko und Grigor'jan, 2.3.1952 (Dokument 47). Die Briten forderten in Ottawa, auch Westdeutschland müsse einen finanziellen Beitrag zu seiner Verteidigung leisten. Siehe dazu Dockrill, Britain's Policy for West German Rearmament 1950-1955, S. 78. Siehe auch RGASPI, f. 82, op. 2, d. 1042, S. 40, Berichterstattung Zorins an Stalin und alle Mitglieder des Achterkollegiums sowie an Vyšinskijj und Gromyko, 9.2.1952 (Dokument 33). 
der Westmächte gegenüber der Bonner Regierung“, infolge derer der Weg zur Gründung einer Europa-Armee frei war, inklusive des Einschlusses Westdeutschlands in die NATO. ${ }^{93}$ Zorin zog den Schluss, dass „die Lissabonner Beschlüsse, die auf die Intensivierung des Tempos der Vorbereitung eines neuen Krieges gerichtet sind, [... jedoch] nicht die tiefen Gegensätze zwischen den Mitgliedern des aggressiven Blocks“ beseitigten. ${ }^{94}$

\section{„„... die Lage der drei Mächte und der Bonner Regierung noch mehr verkomplizieren"}

Am folgenden Tag, dem 3. März, wandte sich Gromyko mit weiteren Entwürfen der Note an die drei Westmächte, der „Grundlagen eines Friedensvertrages“, des Schreibens an die polnische und tschechoslowakische Regierungen und eines Berichtes an das ZK an Molotov. ${ }^{95}$ Gromyko meinte, dass nunmehr der richtige Zeitpunkt gekommen war, um das „Angebot“ eines Friedensvertrages mit Deutschland den Westmächten zu übermitteln. Der Appell der DDR und die Antwort der sowjetischen Regierung hätten in Deutschland ein starkes Echo. Die Regierung Adenauer sei aufgrund der Vorschläge der DDR-Führung gezwungen, „zu manövrieren und ihre Position zu maskieren“. Da sie die Vorschläge der DDR öffentlich nicht ablehnte, so Gromyko, stellte sie Bedingungen, die „die Beschleunigung des Abschlusses eines Friedensvertrages mit Deutschland" behindere. Gromyko berichtete, dass die Westmächte offiziell auf die Initiative der DDR-Regierung nicht reagierten und auch öffentlich nach der NATO-Tagung in Lissabon nichts verlautbarten. Pressemeldungen und Insiderinformationen entnahm Gromyko, „dass die USA, England und Frankreich nach wie vor fortfahren, ihre Pläne zur Schaffung einer ,Europa-Armee' unter Teilnahme westdeutscher Streitkräfte und den Einschluss Westdeutschlands in den aggressiven Atlantikblock zu verwirklichen“. Er schloss nicht aus, „dass die drei Westmächte hierzu, um zu versuchen, den Einfluss unserer Maßnahmen im Zusammenhang mit dem Friedensvertrag mit Deutschland zu schwächen, die Veröffentlichung des „allgemeinen Vertrages“ beschleunigen, und empfahl, „der Möglichkeit der Bekanntgabe des Entwurfes des ,allgemeinen Vertrages‘ zuvorzukommen“. Gromyko schrieb: „Dieser neue Schritt der sowjetischen Regierung wird die Möglichkeit geben, unser positives Programm der Beschleunigung des Abschlusses eines Friedensvertrages mit Deutschland den aggressiven Maßnahmen der drei Mächte und der Remilitarisierung Westdeutschlands und seiner Einbeziehung in die militärischen Pläne des Atlantischen Blocks entgegenzusetzen. Ein Auftreten der sowjetischen Regierung mit einem Entwurf von Grundlagen eines Friedensvertrages mit Deutschland würde die

93 Den Lissabonner Beschlüssen zufolge sollte Westdeutschland 1953 mit sechs und ab 1954 mit zwölf Divisionen an der Europaarmee teilnehmen; ebd., S.121. Zur Berichterstattung Ignat'evs über die Lissabonner Beschlüsse siehe ebd., S.76, 17.3.1952 (Dokument 81); ebd., S. 81, 19.3.1952 (Dokument 83); Egorova, NATO i evropejskaja bezopasnost': Vosprijatie sovetskogo rukovodstva, S. 309.

94 RGASPI, f. 82, op. 2, d. 1042, S. 58, Berichterstattung Zorins an Vyšinskij, Vasilevskij, Gromyko und Grigor'jan, 2.3.1952 (Dokument 47). Vgl. dazu die Interpretation Vojtech Mastnys, der einem nicht näher bezeichneten Memorandum über die Ergebnisse der Lissabonner Tagung entnimmt, die Sowjetunion hätte die von der NATO in Lissabon gestellten Ziele nicht ernst genommen, da diese nicht realisierbar wären. Mastny, Die NATO im sowjetischen Denken und Handeln, S. 413.

95 RGASPI, f. 82, op. 2, d. 1170, S. 48-52, Gromyko an Molotov, 3.3. 1952 (Dokument 48). Einen ersten Entwurf eines Politbüro-Beschlusses über die Versendung einer Note an die Westmächte mit dem Entwurf von Grundlagen eines Friedensvertrages übermittelte Gromyko bereits am 23.2. 1952 Stalin. Filitov, Sovetskij Sojuz i germanskij vopros, S. 336f. 
Lage der drei Mächte und der Bonner Regierung noch mehr verkomplizieren. ${ }^{\text {}}{ }^{6}$ Gromyko bat um Prüfung seiner an Stalin gerichteten Entwürfe. Am Freitag, dem 7. März, trafen Gromykos auf den 6. März datierte Entwürfe des „gemäß Ihren Anweisungen“ überarbeiteten Textes der Note und jene des entsprechenden ZK-Beschlusses, der „Grundlagen eines Friedensvertrages" und der Verbalnote an die tschechoslowakische und polnische Regierung sowie der Entwurf des Schreibens Gromykos an Stalin im Sekretariat Molotov ein. ${ }^{97}$ Da beide Entwürfe wortidentisch sind und weder der erste noch der zweite jeweils ausschließlich an Molotov gerichtet waren und von diesem nicht ausgebessert wurden, ist davon auszugehen, dass es sich bei oben Dargelegtem nicht nur um die Haltung Gromykos handelte, sondern sich auch Molotov damit einverstanden zeigte. Das heißt, auch Molotov muss davon ausgegangen sein, dass die Westmächte auf keinen Fall auf die militärische Integration Westdeutschlands verzichten würden und im besten Fall das Auftreten mit einer neuen sowjetischen Initiative die öffentliche Meinung in Westdeutschland polarisieren, zumindest aber die „Lage der drei Mächte und Bonner Regierung noch mehr verkomplizieren“ würde. Die Note an die Westmächte selbst unterzog Molotov einer weiteren Redaktion. Er strich nunmehr den gesamten Absatz der laut Wilfried Loth von Stalin in den Notenentwurf eingebrachten „vollmundigen Erklärungen über die Vorteile eines Friedensvertrages“.98 Die Beteuerungen, dass es sich verstehe, „in Deutschland eine einheitliche gesamtdeutsche Regierung“ auf der „Grundlage freier Wahlen“ zu bilden, tilgte Molotov. Die Westmächte hätten sich wohl schwerer getan, auf so ein Angebot nicht einzugehen, denn letztlich war die Reklamation freier Wahlen in ganz Deutschland der ausschlaggebende Grund, das sowjetische „Angebot“ abzulehnen. ${ }^{99}$ Wäre das sowjetische Angebot ernst gemeint gewesen, hätte Molotov diese Beteuerungen nicht schon aus dem Entwurf der ersten Stalin-Note eliminieren müssen. ${ }^{100}$ So nahm man erst am 9. April in der Antwortnote auf die

${ }^{96}$ Ebd. Vgl. hierzu die etwas mildere Tonart in den Schreiben Gromykos an Stalin vom 25. und 28.1.1952. Gromyko teilte Stalin darin bereits mit, dass der Zeitpunkt „zur Unterstützung der deutschen demokratischen Kräfte in ihrem Kampf um die Einheit Deutschlands und die Beschleunigung des Abschlusses eines Friedensvertrages mit Deutschland" gekommen sei. Die sowjetische Initiative „hätte große politische Bedeutung für die Verstärkung des Kampfes für den Frieden und gegen die Remilitarisierung Westdeutschlands und würde den Befürwortern der Einheit Deutschlands und des Friedens helfen, die aggressiven Absichten der drei Westmächte zu entlarven, die sie mit dem ,Generalvertrag" verbinden “. Zitiert nach Wettig, Die Deutschland-Note vom 10. März 1952 auf der Basis diplomatischer Akten, S. 798.

${ }_{97}$ RGASPI, f. 82, op. 2, d. 1170, S. 69-83, Gromyko an Molotov, 6. 3. 1952; ebd., S. 84-95.

98 Loth, Die Entstehung der „Stalin-Note“, S. 54.

${ }^{99} \mathrm{Zu}$ den „Befürchtungen“ auf westlicher Seite, die Sowjets wären tatsächlich bereit, den Preis freier Wahlen zu zahlen, siehe Steininger, Eine Chance zur Wiedervereinigung?, S.52f.

100 Auf diesen Aspekt geht Loth nicht ein bzw. er interpretiert die „kurzfristig verfügten Korrekturen“ als ungewollten Verlust von „Glaubwürdigkeit“. Ebd., S. 54 und 61. Von Interesse in diesem Zusammenhang ist das von Stein Bjørnstad aufgefundene Memorandum Kudrjavcevs an Zorin vom 21.3. 1951, in dem er die Nachteile einer Übertragung der Besatzungserfahrungen in Österreich, vor allem in Bezug auf freie Wahlen, auf Deutschland darstellte. Wenn die Sowjetunion hier dieselbe Besatzungspolitik verfolgt hätte, „würden die Vertreter der DDR in einer deutlichen Minderheit sein und könnten in keiner Weise auf Entscheidungen einer gesamtdeutschen Regierung Einfluss nehmen". Siehe Bjørnstad, Soviet German Policy and the Stalin Note of 10 March 1952, S. 55. Das Memorandum erstellte Kudrjavcev vermutlich auf Anweisung Molotovs. Einen Tag zuvor ließ sich Molotov von Zorin amerikanische, britische und französische Presseberichte über die "Österreichisierung Deutschlands" vorlegen. Molotov hob u. a. folgenden Absatz hervor: „Wenn die sowjetische Regierung sich nicht mit einer solchen Lösung [auf dem Weg einer Neutralisierung] der deutschen Frage einverstanden erklären würde, $[\ldots]$ würde der Westen als Befürworter einer Vereinigung Deutschlands erscheinen und der Osten als Gegner [einer Vereinigung]." RGASPI, f. 1182, op. 2, d. 1182, S. 58-76. Aufgrund der Er- 
ablehnende Note des Westens vom 25. März Bezug auf die Wahlfrage. ${ }^{101}$ Einige westliche Politiker hatten sich grundlos gefürchtet, der Kreml könnte sich mit freien Wahlen in Deutschland einverstanden erklären. ${ }^{102}$ Molotov nahm an dem am 7. März eingetroffenen Entwurf über die „Grundlagen eines Friedensvertrages“ keine weiteren Ausbesserungen vor. Da es sich um den letzten im Sekretariat Molotov eingelangten Entwurf handelt, gehen die allerletzten Änderungen wohl auf Stalin allein - mit oder ohne mündliche Absprache mit Molotov - zurück. Diese betrafen Absatz 5 der politischen Leitsätze; die Formulierung „Beseitigung der demokratischen Rechte des Volkes“ wurde gestrichen, ebenso der Vorschlag der Festlegung des deutschen Territoriums gemäß der Grenzen vom 1. Januar 1938. ${ }^{103}$ Am 8. März segnete das Politbüro schließlich die Texte der Note und der Grundlagen des Friedensvertrages ab. ${ }^{104}$ Am Sonntag, dem 9. März, wurde die DDR-Führung vorab über den Inhalt der Note informiert, ebenso die tschechoslowakische und polnische Regierung. ${ }^{105}$ Entgegen den Vorschlägen des sowjetischen Außenministeriums sollte die DDRFührung allerdings nicht davon in Kenntnis gesetzt werden, dass auch die tschechoslowakische und polnische Regierung vorab informiert würden. ${ }^{106}$

Am Montag, dem 10. März 1952, wurde schließlich der als Stalin-Note in die Geschichte eingegangene sowjetische „Vorschlag“ zur deutschen Frage den diplomatischen Vertretern der Westmächte in Moskau übergeben. Gromyko notierte in sein Diensttagebuch (Stalin, Molotov, Malenkov, Berija, Mikojan, Kaganovič, Bulganin und Chruščev erhielten eine Abschrift inklusive der Stalin-Note), dass er die Botschafter Großbritanniens, der USA und Frankreichs in Moskau zu sich gerufen und ihnen die gleichlautenden Noten ausgehändigt habe. Gromyko hielt fest: „Gascoigne, O’Shaughnessy und Brionval versprachen, den Text der Note und [die] Entwürfe der Grundlagen eines Friedensvertrages mit Deutschland umgehend ihren Regierungen zu übergeben. "107

fahrungen in Österreich war zumindest Kudrjavcev davon ausgegangen, dass freie Wahlen in ganz Deutschland wohl zu ähnlichen Ergebnissen wie in Österreich führen würden, wo die KPÖ während der Besatzungszeit bis 1955 stets nur an die fünf Prozent der Stimmen erlangen konnte. Keinesfalls kann es sich aber im März 1951 bei der Übertragung eines "Österreich-Modells" auf Deutschland um „Demokratie nach innen und Neutralität nach außen" handeln. Wettig, Bereitschaft zu Einheit in Freiheit?, S. 206. Erste Vorläufer einer Neutralitätsregelung für Österreich lassen sich zwar bis ins Jahr 1950 nachweisen, diese wurden zu jener Zeit im sowjetischen Außenministerium allerdings als ungerecht gegenüber Österreich zurückgewiesen. Siehe dazu Kapitel 2. Wenn im Frühjahr 1951 im sowjetischen Außenministerium „Österreicherfahrungen“ diskutiert wurden, kann hierbei nur von der Zulassung wirklich freier Wahlen und der Bildung einer Regierung auf der Basis freier Wahlen die Rede sein.

101 Wettig, Die Note vom 10. März 1952, S. 183.

102 So etwa der britische Außenminister Eden. Siehe dazu Steininger, Deutsche Geschichte, Bd.2, S. 180.

103 RGASPI, f. 82, op. 2, d. 1170, S. 69-83, Gromyko an Molotov, 6.3. 1952.

104 RGASPI, f. 17, op. 3, d. 1093, S. 11, 53-56; ebd., op. 163, d. 1614, S. 102-110, Politbüro-Beschluss P 85 (47) vom 8.3. 1952 mit handschriftlichem Vermerk Gromykos: „Gen. Poskrebyšev zur Ausfertigung. 8.III. A. Gromyko“. Die allerletzte Korrektur im Notenentwurf wurde in der Politbürositzung am 8.3. vorgenommen. Der letzte Satz - „Die Regierung der UdSSR hofft, in kürzester Frist eine Antwort der Regierung der USA auf den oben erwähnten Vorschlag zu erhalten“ - wurde umformuliert: „hofft" wurde durch „rechnet damit“ ersetzt. Es stellt sich die Frage, ob der Ausdruck der Hoffnung für Stalin eine zu riskante Formulierung war?

${ }^{105}$ Loth, Die Entstehung der „Stalin-Note“, S. 56f.

106 Pieck vermerkte sich diesbezüglich nichts. Badstübner/Loth (Hrsg.), Wilhelm Pieck - Aufzeichnungen zur Deutschlandpolitik 1945-1953, S. 381.

107 RGASPI, f. 82, op. 2, d. 1170, S. 96f., Diensttagebuch Gromykos, 10.3.1952 (Dokument 49); RGASPI, f. 82, op. 2, d. 1170, S.98-100, Friedensvertragsentwurf zu Deutschland, 10.3.1952 (Dokument 50). Siehe auch RGASPI, f. 82, op. 2, d. 1170, S.101, Aktenvermerk Gromykos über die Notenübergabe, 10.3.1952. 


\section{Dokumente}

\section{Dokument 1}

RGASPI, f. 82, op. 2, d. 1348, S. 3-6, 5.2.1951

Geheim. Ex. Nr. 1

„5“. Februar 1951

Nr. $54 / A B^{108}$

An Gen. Molotov V. M.

Anbei übermittle ich einen kurzen Bericht zur Frage über die Gründung der sog. „Europaarmee".

Bogomolov /A. Bogomolov/109

Geheim. ${ }^{110}$

Ex. Nr.1

Zur Frage der Gründung einer „Europaarmee“"111

(Kurzbericht)

Im August 1950 nahm die beratende Versammlung des Europarates auf ihrer zweiten Konferenz nach einem Vorschlag Churchills folgende Resolution an: ${ }^{112}$ „Die Versammlung bringt ihre Treue für die Erhaltung des Friedens und ihre Entschiedenheit zum Ausdruck, die vom Sicherheitsrat der Vereinten Nationen beschlossenen Tätigkeiten, die dem Ziel dienen, friedliebende Völker gegen Aggression zu schützen, zu unterstützen, und fordert die unverzügliche Schaffung einer vereinten Europaarmee unter der Führung der europäischen Verteidigungsminister, die sich unter demokratischem europäischem Kommando befinden und in Zusammenarbeit mit den Vereinigten Staaten und Kanada agieren wird". ${ }^{13}$

Am 24. Oktober 1950 erklärte der Vorsitzende des Ministerrates Frankreichs, Pleven, in seiner Rede in der Nationalversammlung, dass die französische Regierung auf der Grundlage des erwähnten Beschlusses des Europarates den Vorschlag der Gründung einer „Europaarmee“ einbringen wird. Hierbei wies Pleven darauf hin, dass eine solche „Europaarmee“ in den Bestand der „vereinigten atlantischen Kräfte“ eingebunden werden wird und „entsprechend den Grundsätzen, die vom Atlantikpakt sowohl auf dem Gebiet der allgemeinen Strategie als auch auf dem Gebiet der Organisation und der Ausrüstung festgesetzt wurden“, agieren wird. Was einen „europäischen Verteidigungsminister" betrifft, wies Pleven darauf hin, dass „seine Bevollmächtigten in Bezug auf die Europaarmee analog Bevoll-

\footnotetext{
108 Links oben der Vermerk: „zu den Akten." [Unterschrift unleserlich].

109 Links unten Eingangsstempel: Sekretariat Molotov, 5.II.1951, Nr. 1971s.

110 Rechts oben handschriftlich: „Frankreich (M) “.

111 Von Molotov unterstrichen.

112 Churchill wörtlich: „The Assembly, in order to express its devotion to the maintenance of peace and its resolve to sustain the action of the Security Council of the United Nations in defence of peaceful peoples against aggression, calls for the immediate creation of a unified European Army subject to proper European democratic control and acting in full co-operation with the United States and Canada." 113 Absatz von Molotov am linken Rand handschriftlich hervorgehoben.
} 
mächtigte des Ministers der nationalen Verteidigung in Zusammenhang mit den nationalen [Streit]kräften seines Landes sein werden und dass er Direktiven vom Rat erhalten wird, der aus den Ministern der Mitgliedsländer der „Europaarmee“ bestehen wird.

Aus der Rede Plevens folgte, dass Westdeutschland, das Mitglied des Europarates ist, an der Gründung der „Europaarmee“ auf ebenbürtiger Grundlage mit den anderen Ratsmitgliedern teilhaben wird. ${ }^{114}$

Nachdem die französische Regierung ihren Plan der Gründung einer „Europaarmee“ im Rahmen „vereinigter [Streit]kräfte“ des Nordatlantikbündnisses vorgebracht hatte, versuchte sie zu demagogischen Zwecken zu bekräftigen, dass dieser Plan die Möglichkeit der Gründung eines deutschen Generalstabes und einer nationalen deutschen Armee ausschließt, da nach diesem Plan die westdeutschen Truppen in der Form einzelner Einheiten in die „Europaarmee“, die dem europäischen Verteidigungsminister unterstellt ist, einbezogen und so bereits in den Bestand der ,vereinigten [Streit] kräfte des Nordatlantikbündnisses integriert werden. Diese demagogischen Ziele fanden ebenso im Beschluss der französischen Nationalversammlung zu dem von Pleven vorgeschlagenen Plan der Gründung einer „Europaarmee“ ihren Ausdruck. Der Beschluss beschränkt sich auf Folgendes: „Die Nationalversammlung heißt die Regierungserklärung und den Wunsch der Regierung, keine Wiedergründung einer deutschen Armee und eines Generalstabes zuzulassen, für gut, lehnt alle Ergänzungen ab und geht zur Tagesordnung über."115

Auf der Konferenz der Stabschefs und der Stellvertreter der Außenminister des Nordatlantikbündnisses wurde im Dezember 1950 in London beschlossen, „Frankreich zu erlauben, den Plan der Formierung einer, der Größe nach kleineren Armee der Mitgliedsländer des Nordatlantikbündnisses als der vereinigten Europaarmee zu verwirklichen ". ${ }^{116}$ Dieser Beschluss wurde vom Rat des Nordatlantikbündnisses in Brüssel am 19. Dezember 1950 bestätigt. Auf diese Weise wurde der Plan der Gründung einer „Europaarmee“ offiziell in die militärischen Maßnahmen des Nordatlantikbündnisses einbezogen.

Am 25. Januar 1951 teilte die Agence France Presse mit, dass die französische Regierung in Paris im Februar d.J. eine Konferenz zur Frage der Gründung der „Europaarmee“ einberufen wird. Einladungen zu dieser Konferenz ergingen an die europäischen Mitgliedsländer des Nordatlantikbündnisses und auch an die Regierung Westdeutschlands. Den USA und Kanada wurden Einladungen geschickt, Beobachter zu schicken.

Nach Mitteilungen der TASS haben zum 5. Februar die Regierungen Westdeutschlands, Belgiens, Hollands und Italiens die genannte Einladung der französischen Regierung angenommen. Die englische Regierung teilte mit, dass sie ihren Vertreter als Beobachter entsenden wird. Die Regierung der USA gab ebenfalls ihr Einverständnis, ${ }^{117}$ ihren Beobachter zu entsenden. In der Presse gibt es noch keine Mitteilungen über die Antworten der anderen Mitglieder des Nordatlantikbündnisses /Dänemarks, Portugals, Norwegens, Islands, Luxemburgs und Kanadas/.

Nach Pressemitteilungen ist die Konferenz für den 15. Februar angesetzt.

${ }^{114}$ Absatz von Molotov am linken Rand handschriftlich hervorgehoben.

115 Absatz von Molotov am linken Rand handschriftlich hervorgehoben.

116 Absatz von Molotov am linken Rand handschriftlich hervorgehoben.

${ }_{117}$ Absatz von Molotov am linken Rand handschriftlich hervorgehoben.

118 Links unten handschriftlich: „5.II." und Unterschrift Bogomolovs. 


\section{Dokument 2}

RGASPI, f. 82, op. 2, d. 1337, S. 24-31, 12.2.1951

Kopie

An Genossen Stalin

Ich lege einen Informationsbericht über die Lage in der Kommunistischen Partei Westdeutschlands vor.

Der Vorsitzende der Außenpolitischen

Kommission des ZK der VKP/b/

V. Grigorjan

(V. Grigor'jan)

12. Februar 1951

Kopien ergingen an die Genossen Malenkov, Molotov, Berija, Mikojan, Kaganovič, Bulganin, Chruščev

Nr. 25-S-224 $4^{119}$

Str. geheim

\section{Informationsbericht}

Über die Lage in der Kommunistischen Partei Westdeutschlands

Die Tätigkeit der Kommunistischen Partei Westdeutschland findet unter äußerst schwierigen Bedingungen statt. Die westlichen Besatzungsmächte und die Bonner Regierung verfolgen im Zusammenhang mit der Kommunistischen Partei systematisch eine Politik der Verfolgung und Repression. Anordnungen über die Entlassung von Kommunisten aus Staatsämtern und -organisationen wurden erlassen. Der Kommunistischen Partei wird es nicht erlaubt, unter der Bevölkerung Demonstrationen und Versammlungen durchzuführen. Die Herausgabe des Großteils der Zeitungen der Kommunistischen Partei wurde 1950 auf lange Zeit verboten und Redakteure verhaftet und verurteilt. Fälle der Konfiszierung von Gebäuden der Kommunistischen Partei kamen vor. Den Fraktionen der Kommunistischen Partei in den Landtagen und im Bundestag wurden ihre Verfassungsrechte entzogen. Dem Vorsitzenden der Kommunistischen Partei, Max Reimann, wurde die parlamentarische Immunität entzogen, er war gezwungen, in dem Gebiet der Deutschen Demokratischen Republik zu wohnen und von dort aus die Partei zu führen.

Die Lage der Kommunistischen Partei vergrößert die ernsthaften Mängel und Fehler in ihrer Arbeit, die die Partei schwächen und ihre Verbindung mit den breiten werktätigen Massen erschweren.

${ }^{119}$ Links unten Eingangsstempel: Sekretariat Molotov, 13.II.195 1, Nr. 1905; daneben der Vermerk: Zu den Akten. 13.2.51. Poljakov. 
Die Hauptmängel und -schwächen der Kommunistischen Partei bestehen in der Zersetzung ihrer Kader durch feindliche Elemente, in der weiten Verbreitung opportunistischer und sektiererischer Stimmungen unter den Parteimitgliedern und in der Bestürztheit der Kommunisten vor Angriffen der Reaktion. Die Kommunistische Partei unterschätzte die Bewegung der nationalen Front des demokratischen Deutschland und vermochte es nicht, breite Massen der Bevölkerung für den Kampf um den Frieden und die Einheit, gegen die anglo-amerikanischen Pläne der Remilitarisierung Westdeutschlands und seine Umwandlung in eine Hauptbasis der amerikanischen Aggression in Europa an sich zu ziehen. Die Kommunistische Partei hat nur wenig für den Aufbau der Einheit der Arbeiter in ihrem Kampf für die nächstgelegenen Forderungen, für die demokratischen Rechte und Freiheiten und für die Verbesserung der Lebensbedingungen der Arbeiter gemacht. In der Kommunistischen Partei herrscht nach wie vor Mangel an Zusammenarbeit mit gewöhnlichen sozialdemokratischen Arbeitern und an Arbeit in Gewerkschaften, unter der Bauernschaft, den Umgesiedelten und der Intelligenz. Die Kommunistische Partei stellte nicht prinzipiell und mutig vor den Massen die Fragen der östlichen Grenzen, der Freundschaft mit der Sowjetunion und der kolonistischen Politik der Westmächte in Deutschland. Sie verspätete sich mit dem Eintreten für Losungen, so wie dies zum Beispiel bei der Losung des Kampfes gegen die Remilitarisierung der Fall war, die von den Schumacheristen erfasst und von ihnen zur Festigung ihres Einflusses in den Massen genutzt wurde.

\section{Organisatorischer Zustand der KPD}

1950 führte die Kommunistische Partei eine Reihe von Maßnahmen durch, die auf die Festigung ihrer Kader und die Mobilisierung der Massen Westdeutschlands für den Kampf um Frieden und gegen die Remilitarisierung abzielten. Die Parteiführung nahm wichtige Beschlüsse über die ideologische und organisatorische Festigung der Partei, über die Arbeit der Kommunisten in den Gewerkschaften und unter der Jugend und Frauen an. Die Kommunistische Partei führte eine bedeutsame Arbeit zur Überprüfung der Parteidokumente zur Säuberung von Trotzkisten und Titoisten durch; sie führte in einigen Ländern Vorwahlen der Führungsorgane der unteren Parteiorganisationen durch. Unter der Führung der Kommunistischen Parteien sammelten die Friedensfreunde für das Credo des Appells der Stockholmer Konferenz mehr als zwei Millionen Unterschriften. Der Kommunistischen Partei gelang es in einigen Städten, abgestimmte Aktionen der Arbeiter zu erreichen und den Kampf der Werktätigen für eine Verbesserung der materiellen Lage anzuführen.

Nach den Angaben für den Oktober 1950 zählte die Kommunistische Partei ungefähr 178 Tausend Mitglieder. Mitgliedschaftsbeitrag zahlen ungefähr $65 \%$ der Parteimitglieder. Die soziale Zusammensetzung der Partei: Arbeiter - 57\%, Bauern - 0,6\%, Handwerker $7 \%$, Angestellte $-8,2 \%$, Hausfrauen $-13,5 \%$, andere: $13,7 \%$. Frauen in der Partei 16,5\%, Jugendliche bis 26 Jahre $-6,4 \%$.

Die Kommunistische Partei unterteilt sich in 11 Landes-, 477 Kreis- und mehr als 8000 territorial-betriebliche Organisationen.

Das Sekretariat des ZK der KPD steht nur schwach in Verbindung mit den unteren Organisationen. Führende Exponenten der Länder- und Zentralorgane der kommunistischen Parteien sind selten vor Ort, kennen nur schlecht das Leben der Grundorganisationen, treten nicht vor den Kommunisten auf und studieren ihre Stimmungen und Umfragen nicht. Die Beschlüsse der höheren Organe werden in der Regel nicht an die Mehrheit der 
Grundorganisationen weitergegeben, werden auf den Versammlungen der Kommunisten nicht erörtert und bleiben in der Regel unerfüllt.

Versammlungen in den Grundorganisationen werden selten durchgeführt und ihr Besuch überschritt im Jahr 1950 niemals 20-25\%. Ungefähr 30\% der Grundorganisationen führten im Jahre 1950 keine einzige Versammlung durch. Kritik und Selbstkritik in der Partei fehlen, die Aktivität der Parteimitglieder auf den Versammlungen ist schwach. Die Disziplin in der Partei steht auf niedrigem Niveau. Viele Kommunisten lehnen die Erfüllung von Parteiaufträgen aufgrund von Angst vor Repressionen ab und aus diesem Grund verlässt ein Teil von ihnen die Partei. Als nicht zufriedenstellend erweist sich auch die Arbeit zur Vergrößerung und Festigung der betrieblichen Organisationen, die ungefähr 1000 zählen. In betrieblichen Organisationen sind lediglich 16,8\% Kommunisten. Die Mehrheit dieser Organisationen ist nur fallweise aktiv. Es gibt viele Fälle, in denen Kommunisten aus Betriebsorganisationen austreten und sich in Kleingruppen von den Arbeitern isolieren.

Die Führungsorgane der Kommunistischen Partei wurden von feindlichen und zweifelhaften Elementen zersetzt. Im Jahr 1950 wurde im Sekretariat des ZK der KPD der alte Trotzkist Kurt Müller entlarvt. Wegen opportunistischer Tätigkeit wurden aus dem Sekretariat Nuding, Fisch und Ehrlich entfernt. Eine Reihe trotzkistischer und titoistischer Elemente wurde in Länder- und Bezirksorganen des Ruhrgebietes, Bayerns, Hamburgs, Hessens, Niedersachsens usw. entlarvt. Im Laufe des Jahres 1950 wurden mehr als 700 aktive Trotzkisten und Titoisten entlarvt und aus der Kommunistischen Partei ausgeschlossen. Diese Arbeit wurde aber nicht bis zum Ende durchgeführt und in den Führungsorganen der Partei verblieben noch viele zweifelhafte Elemente.

Die Mehrheit der Führungskader der KPD ließ sich in der Emigration in den USA, England, Frankreich, der Schweiz und anderen westlichen Ländern beeinflussen. Sie waren nie in der Sowjetunion und kennen das Leben [dort] nicht. Einige Mitglieder des Sekretariats des ZK der KPD hatten in der Vergangenheit Verbindung mit feindlichen Elementen und Gruppierungen, aber auch mit dem amerikanischen Agenten Field.

Das theoretische Niveau der führenden Exponenten der KPD ist äußerst niedrig. Unter den Führungskadern der KPD, besonders in den Länder- und Bezirksorganen bildete sich eine eigentümliche Kaste der „alten Arbeiter" heraus, die ihre Erfahrungen bis 1932 sammelten. Jugend wird in der Partei fast nicht zur Führungsarbeit gelassen. Es werden Vorkommnisse beobachtet, dass einzelne Exponenten eigenmächtig die Arbeit aufgeben, und in einer Reihe von Organisationen kommen Usurpatoren und ernennen sich zu Leitern. Die Führung der KPD übergeht diese Verletzungen der Parteidisziplin oft.

\section{Zustand der ideologischen Arbeit in der KPD}

Anfang des laufenden Jahres verbesserte die KPD-Führung das System der politischen Bildung der Kommunisten ein bisschen. Ein Einheitsjahr eines Parteilehrganges und Lehrprogramme und Lehrmittel zum Studium der Geschichte der VKP(b) wurden erstellt. Dennoch befindet sich die ideologische Arbeit in der KPD immer noch in vernachlässigtem Zustand. Der Besuch der Ringlehrveranstaltungen und Kurse durch Kommunisten überschreitet keine 15-20\%. Die alten Parteimitglieder schulen sich überhaupt nicht, sie halten sich für vollständig ausgebildet.

Im Netz der Parteiausbildung fehlt es an der nötigen Kontrolle, es mangelt an erfahrenen Propagandisten und an Unterrichtsliteratur. Die Kommunistische Partei gibt 10 Zeitungen heraus, mit einer Auflage von 100 Tausend Exemplaren. Lediglich ein kleiner Teil der Kom- 
munisten abonniert Parteizeitungen. Das politische Niveau der Zeitungen ist immer noch niedrig. Die Zeitungen widmen sich aktuellen Fragen Westdeutschlands, dem Leben in der Sowjetunion, der Deutschen Demokratischen Republik und den Ländern der Volksdemokratie in äußerst unzulänglicher Weise. Es gibt eine Reihe von Fällen, in denen das Zentralorgan der KPD, „Freies Volk“, die Aussagen M. Reimanns zu diesen Fragen verschwieg.

Als Resultat des niedrigen politischen Niveaus der Kommunisten in der KPD ist Unklarheit und Verwirrung in einer Reihe der wichtigsten politischen Fragen zu beobachten. Viele Kommunisten sprechen sich gegen die neue Grenze Deutschlands mit Polen aus, sie verstehen die sowjetische Deutschlandpolitik nicht. In den Führungsorganen der KPD wird weiterhin die Frage diskutiert, wer der Hauptfeind sei und wogegen der Hauptschlag geführt werden sollte. Die Losungen der Partei werden nicht immer mit den politischen Umständen abgestimmt.

Unter den Mitgliedern der Kommunistischen Partei herrscht die Meinung, dass die KPD nicht in der Lage ist, die ihr gestellten Aufgaben zu lösen, und dass die Frage Westdeutschlands nur mit Hilfe von außen entschieden werden kann. Einige führende Exponenten der KPD denken, dass die „Vereinigung Deutschlands auf demokratische Weise nur von der Sowjetischen Armee verwirklicht werden kann".

Bis vor kurzem wurde in der Kommunistischen Partei die Gefahr der Remilitarisierung Westdeutschlands unterschätzt. Ein bedeutsamer Teil der Mitglieder der KPD ist überzeugt, dass ein Krieg unausweichlich sei und es deshalb für die Kommunistische Partei keinen Sinn mache, die kräfteübersteigende Schwere des Kampfes mit der Remilitarisierung auf sich zu nehmen und die Tätigkeit für den Kampf um den Frieden zu organisieren. Sektiererische Stimmungen werden im Zusammenhang mit der Nationalen Front des demokratischen Deutschland beobachtet, wenn es viele Kommunisten ablehnen, gemeinsam mit ihnen gegen die bourgeoisen Elemente zu kämpfen. Ein Teil der Kommunisten zweifelt daran, dass die Deutsche Demokratische Republik eine Basis für die Schaffung eines einheitlichen demokratischen Deutschland ist.

\section{Die Arbeit der KPD in den Massenorganisationen}

Die Hauptschwäche der KPD liegt in ihren äußerst schwachen Verbindungen mit den Massen. Nicht in einer einzigen Massenorganisation der Werktätigen verfügt die KPD über den nötigen Einfluss. Die Kommunistische Partei vermochte es nicht, die wachsende Unzufriedenheit der Bevölkerung Westdeutschlands durch die Remilitarisierung und das Anwachsen wirtschaftlicher Schwierigkeiten für eine Verstärkung ihres Einflusses in den Massen zu nutzen. Neben diesen Fakten ist unter den Parteimitgliedern auch noch die Meinung verbreitet, dass die Massen nicht gegen die Remilitarisierung kämpfen wollen.

Von der schwachen Arbeit der KPD in der Bevölkerung und der Senkung ihres Einflusses in den Massen zeugen die Landtagswahlen 1950. Im Bundesland Nordrhein-Westfalen erhielt die Kommunistische Partei 5,5\% der Stimmen, in Schleswig-Holstein 5\%, in BadenWürttemberg 4,88\%, in Bayern 1,9\%. In diesen Bundesländern hatte die KPD in den Wahlen 1949 zwei- bis dreimal mehr Stimmen. Bei den im Oktober 1950 durchgeführten Fabrikskomitee-Wahlen im Ruhrgebiet erhielt die KPD nur 35\% im Vergleich zu 45-50\% bei den letzten Wahlen. Bei den Betriebsratswahlen der Hamburger Werft im Januar 1951 erhielten die Kommunisten nicht ein einziges Mandat.

Die Kommunistische Partei hat äußerst schwache Verbindungen mit den Gewerkschaften. Lediglich die Hälfte der KPD-Mitglieder ist in der Gewerkschaft. Viele Mitglieder der Kom- 
munistischen Partei setzen die Führung der Gewerkschaften mit Kadermitgliedern gleich und halten die Gewerkschaften für reaktionär und wollen nicht in ihnen arbeiten. Die Mehrheit der Gewerkschaftsfunktionäre und Kommunisten ist opportunistisch gestimmt, führt keine Parteipolitik in den Gewerkschaften durch und trottet den alten Gewerkschaftsbürokraten hinterher.

Erst in jüngster Zeit begann die KPD-Führung die Aktionen im Kampf gegen die Remilitarisierung mit einfachen Sozialdemokraten zu koordinieren. Zu diesem Zweck wurden gemeinsame Konferenzen in Hamburg und im Bundesland Nordrhein-Westfalen durchgeführt.

Die Bewegung der Friedensfreunde entfaltet sich nach der Sammlung der 2 Mio. Unterschriften unter den Stockholmer Appell schwach. Viele Komitees der Friedensfreunde sind tatenlos und erhalten nicht die nötige Hilfe von der KPD. Die im Januar d. J. abgehaltenen Konferenzen der Friedensfreunde in den Bundesländern Nordrhein-Westfalen, Niedersachsen und Bremen verliefen ohne aktive Teilnahme der Kommunisten.

Ein bisschen mehr Aufmerksamkeit begann die Kommunistische Partei auf die Frauen und die Jugend zu richten. Die unter Führung der KPD stehende Jugendorganisation begann aktiver zu arbeiten und erneuerte die Zusammensetzung ihrer Führung. Die Maßnahmen der Jugend im Kampf für den Frieden gegen die Remilitarisierung, gegen die sogenannten Überstunden der "Panzerschicht“ und ihre Losung „ohne uns“ werden von breiten Schichten der Werktätigen unterstützt.

\section{Hilfe der SED für die Kommunistische Partei Deutschlands}

Im Laufe des Jahres 1950 beschränkte die SED ihre Hilfe für die KPD auf [Bereitstellung] von Literatur und das Entsenden einzelner Instrukteure. Ernsthaft beschäftigte sich die SED nicht mit der Frage Westdeutschlands und der Festigung der KPD. Das Politbüro des ZK der SED unterschätzte die Arbeit in Westdeutschland. Die ganze Arbeit zur Hilfeleistung für die KPD wurde der von Gen. Dahlem geleiteten Westkommission beim Politbüro des ZK der SED aufgetragen. Diese Kommission erwies der KPD nicht nur keinerlei Hilfe, sondern verwandelte sich im Grunde in eine Bremse der Arbeit der KPD, entzog der KPD-Führung die Initiative und schnitt sie vom Politbüro des ZK der SED ab. Max Reimann konnte Fragen nur bei der Westkommission vorbringen. Franz Dahlem brachte als Vorsitzender der Kommission keine einzige wichtige Frage der Tätigkeit der KPD vor das Politbüro des ZK der SED. Die Westkommission und einzelne Politbüromitglieder des ZK der SED gaben der KPD-Führung gegenüber manchmal falsche Stellungnahmen ab, die der Partei nur Schaden zufügten.

Im Dezember 1950 löste das Politbüro des ZK der SED die Westkommission auf und nahm die ganze Führung der KPD auf sich, die über M. Reimann umgesetzt wird. Künftig wird Max Reimann alle Fragen der KPD dem Politbüro des ZK der SED vortragen. Die Hilfeleistung für die KPD wurde den Abteilungen des ZK der SED gemäß den entsprechenden Arbeitszweigen aufgetragen. Außerdem nahm das Politbüro den Vorschlag M. Reimanns an, dass das Sekretariat des ZK der KPD seine wichtigsten Sitzungen in Berlin durchführt, an denen M. Reimann teilnehmen und damit konkret die Partei führen kann. Zwischen M. Reimann und dem Sekretariat der KPD in Düsseldorf ist ein regelmäßiger Kurierdienst eingerichtet.

Neben der Verstärkung der massenpolitischen Arbeit in der Partei stellt sich die SEDFührung die Reinigung der KPD von feindlichen Elementen zur Aufgabe. Ungefähr 120 
Führungsexponenten der KPD, die Zweifel hervorrufen, werden in die DDR abberufen. Einige werden den Organen der Staatssicherheit zur Klärung ihrer Verbindungen mit dem amerikanischen Agenten Field übergeben. Die SED schickt 3 Bevollmächtigte des ZK der SED unter P. Verner zur Arbeit in das Sekretariat des ZK der KPD und zur unmittelbaren Führung der Kommunistischen Partei. Außerdem werden einige Instrukteure nach Westdeutschland geschickt, ebenso bis zu 50 Tausend führende Mitarbeiter aus Gewerkschaften, Frauen- und Jugendorganisationen der DDR. Die Zusammensetzung der führenden Mitarbeiter der Landes- und Bezirksorganisationen der KPD wird geprüft. In den Führungsorganen werden zunehmend junge Arbeiter aus Betriebsorganisationen ernannt, ebenso ehemalige Kriegsgefangene, die in der UdSSR antifaschistische Schulen durchliefen. Die SEDFührung deutet Maßnahmen zur Anhebung der Verbreitung von Zeitungen und Journalen der DDR in Westdeutschland und zur Verstärkung der Radiopropaganda an.

Vom 2.-4. März 1951 findet der KPD-Parteitag statt. Der Parteitag erörtert den Bericht des ZK der KPD und das Parteistatut. Zum Parteitag werden Thesen veröffentlicht, die gegenwärtig auf Versammlungen des Parteiaktivs erörtert werden. Gleichzeitig werden Bezirksund Landesdelegiertenkonferenzen abgehalten. An der Vorbereitung des KPD-Parteitages nimmt die SED-Führung unmittelbar teil.

\title{
Dokument 3
}

RGASPI, f. 82, op. 2, d. 1182, S. 40-48, 18.2.1951

\author{
Geheim. Ex. Nr. __ 120 \\ „18“. Februar 1951 \\ Dok. Nr. $\underline{247-V K}$
}

\section{Über die Bewegung für eine Neutralisierung Deutschlands}

Detailliert ausgearbeitete Entwürfe für eine „Neutralisierung Deutschlands“ gibt es keine. Ausnahme ist die Gruppe des Professors Ulrich Noack (Nauheimer Kreis). Diese Gruppe in Westdeutschland tritt als der populärste Propagandist der Theorie der Neutralisierung Deutschlands in Erscheinung.

\section{Die Hauptrichtlinien der Gruppe Noack für eine Neutralisierung Deutschlands}

a) Die politische und die militärische Neutralität Deutschlands muss von den vier Besatzungsmächten und von der UNO garantiert werden.

b) Deutschland muss mittels internationaler Verträge für immer das souveräne Recht zur Bildung und zur Erneuerung militärisch-politischer Verbände entzogen werden.

c) Die Wiedererrichtung der Einheit Deutschlands muss auf friedlichem Weg auf föderativer Grundlage erreicht werden, um die in der Ostzone durchgeführten Reformen und die in Westdeutschland bestehende Ordnung zu erhalten.

d) Abschluss eines Friedensvertrages mit Deutschland 
e) Breite und feste wirtschaftliche Verbindungen ganz Deutschlands mit osteuropäischen Ländern und der Sowjetunion als Grundlage zur Lösung der Probleme Umsiedler und Arbeitslosigkeit

f) Verbindungen Deutschlands mit Westeuropa durch Mitgliedschaft in kulturellen Organisationen und mittels einzelner Wirtschaftsabkommen

Nach Meinung Noacks sind die angespannten Beziehungen zwischen dem Osten und dem Westen damit zu erklären, dass sich in Deutschland die Gegensätze zwischen der UdSSR und den USA auf der Welt kreuzen: „Weder der Osten noch der Westen werden sich jemals damit einverstanden erklären, die absolute Herrschaft über Deutschland einem Einzigen zu überlassen." Noack meint, dass ein vereintes Deutschland neutralisiert und entmilitarisiert werden müsse und weder dem nordatlantischen Staatenblock noch an das osteuropäische Bündnis angeschlossen werden dürfe.

Nach der Meinung Noacks kann eine Neutralisierung eines der Besatzung entledigten Deutschlands „mit Hilfe eines internationalen Kontrollorganes, das auf internationalem Recht beruht und praktisch die Wiederherstellung des militärischen Potenzials Deutschlands verhindert", gewährleistet werden.

Am ausführlichsten sind die Programmrichtlinien Noacks in seiner Broschüre „Die Gewährleistung des Friedens mittels des Weges der Neutralisierung Deutschlands und seine stabilisierende weltwirtschaftliche Mission" dargelegt.

\section{Die Anhänger der Bewegung für eine Neutralisierung Deutschlands}

In letzter Zeit wird die Bewegung für eine Neutralisierung Deutschlands immer populärer in Westdeutschland. Als Anhänger einer Neutralisierung treten ein bedeutender Teil der Intelligenz und der Studentenschaft, die Liga der Frauen für den Frieden, verschiedene Vereine für den Kampf um Frieden, Angehörige der Intelligenz und ein Teil der Bourgeoisie auf. Im Januar 1951 wurde die „Wiesbadener Proklamation“" ${ }^{21}$ gegen die Remilitarisierung Deutschlands herausgegeben, die von 50 westdeutschen Politikern verschiedener Richtungen, darunter Vertreter der Gruppe Noacks, der ehemalige Minister für Landwirtschaft in der Regierung des Landes Niedersachsen (engl. Zone) - Gereke, der ehemalige Minister in der Regierung Schleswig-Holsteins [sic! ${ }^{122}$ (engl. Zone) - Erich Arp, Vertreter der deutschen nationalen Partei, der Leiter des deutschen Vereins für Frieden, Vertreter des Vereins der Gegner der Wehrpflicht und and. unterzeichnet wurde. Der Proklamation schloss sich auch Bischof Niemöller an. Die Wiesbadener Proklamation, die sich nicht direkt für die Neutralisierung Deutschlands ausspricht, fordert Abrüstung und einen Verzicht auf die Bildung militärischer Einheiten sowohl in Ost-als auch in Westdeutschland und ebenso eine friedliche Wiedervereinigung Deutschlands. In der Proklamation wird auch die Unterstützung der Massenbewegung unter der westdeutschen Bevölkerung unter der Losung „ohne uns“ zum Ausdruck gebracht, die gegen die Teilnahme des deutschen Volkes an den aggressiven Plänen der anglo-amerikanischen Kriegshetzer eintritt.

Die Bewegung „ohne uns“ (,ohne uns“) ${ }^{123}$ wird in letzter Zeit ebenfalls immer populärer. Sie erfasst die Masse der Arbeiter und werktätigen Jugend. Sie genießt ebenso Unterstüt-

121 Von Molotov unterstrichen.

122 Gereke war von Ende 1946 bis Februar 1947 Innenminister und stellvertretender Ministerpräsident von Niedersachsen, von 1948 bis 1950 Landwirtschaftsminister (CDU).

${ }^{123}$ Von Molotov unterstrichen. „Ohne uns“ im Original zweimal wiedergegeben (ins Russische transliteriert und ins Russische überset7.t). 
zung einiger bourgeoiser Kreise, der evangelischen Kirche und ist unter der Studentenschaft und Intelligenz populär. Konkret tritt diese Bewegung für die Absage an Militärdienst und Remilitarisierung ein und objektiv ist sie antiamerikanisch. Seit September 1951 wird in Hamburg die Zeitung „Ohne uns“ herausgegeben, die gegen die Remilitarisierung und Wiederbewaffnung, für die nationale Einheit, für gesamtdeutsche Abkommen und gegen Hetze des Westens gegen den Osten eintritt.

In den Thesen des im März d. J. anstehenden Parteitages der KPD wurde die Losung der Umwandlung der Bewegung "Ohne uns“ in eine aktive Widerstandsbewegung gegen die Remilitarisierung und gegen die Heranziehung von Deutschen zu einer gemeinsamen Armee in Westdeutschland proklamiert.

Die Bewegung für eine Neutralisierung Deutschlands und insbesondere die Bewegung „Ohne uns" sind in Westdeutschland verstärkten Angriffen ausgesetzt.

\section{Die Einstellung der Regierungen der USA, Englands und Frankreichs zur Bewegung für eine Neutralisierung Deutschlands}

Dem Umstand Rechnung tragend, dass die unter der westdeutschen Bevölkerung wachsende Popularität der Idee einer Neutralisierung die Remilitarisierung Westdeutschlands stört, sind die Besatzungsmächte der USA, Englands und Frankreichs ablehnend gegenüber dieser Bewegung eingestellt.

Vertreter der USA treten gegen eine Neutralisierung Deutschlands auf. Nach Mitteilung der Zeitung „Hamburger Echo“vom 8. Februar 1951 wurde auf der dreitägigen Sitzung der amerikanischen Botschafter in den europäischen Ländern und von Vertretern des Statedepartments der USA beschlossen, dass „es in der jetzigen internationalen politischen Lage praktisch unmöglich ist, eine Neutralisierung Deutschlands zu verwirklichen “ und dass „die Westmächte auf einer Viermächtekonferenz keinem sowjetischen Plan über eine Vereinigung Deutschlands zustimmen werden, der zu seiner Neutralisierung führt.

Am 14.Februar erklärte Acheson auf einer Pressekonferenz, dass die Meldungen über den Plan der Westmächte, Deutschland zu neutralisieren, jeglicher Grundlage entbehren, und teilte mit, dass die amerikanische Politik im Zusammenhang mit der Wiederbewaffnung Deutschlands unverändert bleibt seit dem Brüsseler Abkommen.

Der Hohe Kommissar der USA in Westdeutschland, McCloy, erklärte am 12.Januar: „Ich denke nicht, dass die westdeutsche Nation oder irgendein anderes westeuropäisches Land erwartet, dass ein anderes Land sie bzw. es verteidigen wird, wenn sie bzw. es nicht selbst an der Verteidigung teil nimmt.“

Eine analoge Position nimmt auch der englische Hohe Kommissar in Westdeutschland, Kirkpatrick, ${ }^{124}$ ein. Am 30. Januar trat Kirkpatrick im Frankfurter Presseklub auf und erklärte: „Ich habe die drei folgenden Schlussfolgerungen gezogen: 1. Niemand kann neutral bleiben. 2. Europa ist nicht stark genug, um die Rolle einer dritten Kraft zwischen den zwei Blöcken der Großmächte zu spielen. 3. Deshalb muss jedes europäische Land zwischen Ost und West wählen."

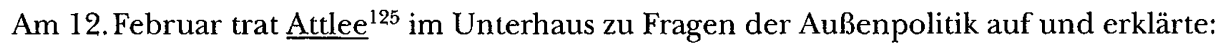
„...Wir sind gezwungen, uns um die Verteidigung Europas zu kümmern, und diese schließt die Verteidigung Westdeutschlands mit ein“. Und weiter: „...Ich erhalte eine große Zahl von

\footnotetext{
124 Von Molotov unterstrichen.
}

125 Von Molotov unterstrichen. 
Beschlüssen mit Protesten gegen die Bewaffnung Deutschlands. Wenn ich aber diese Leute fragen würde: ,Seid ihr bereit, Deutschland zu verteidigen, während die Deutschen nichts unternehmen“ - sie würden ihren Standpunkt ändern“.

Nach Mitteilung der Agentur Press Association, erklärte $\underline{\mathrm{Eden}}^{126}$ in einer Rede im Unterhaus am 12. Februar, dass Deutschland eine bestimmte Rolle in allen Bereichen der europäischen Zusammenarbeit spielen muss, darunter nicht nur im militärischen Bereich, und dass die Welt einen Vorteil hätte, wenn eine engere Zusammenarbeit mit Deutschland Ausdruck in der Teilnahme der Deutschen an einer Europa-Armee fände. Eden erklärte auch, dass ihn die Erklärung darüber, dass in einem neutralisierten und entmilitarisierten Deutschland die Mehrheit der Bevölkerung nicht kommunistisch wäre, nicht sehr beruhigt.

Offizielle Vertreter Frankreichs ${ }^{127}$ sprachen sich ebenso gegen eine Neutralisierung Deutschlands $^{128}$ aus. So erklärte der Hohe Kommissar Frankreichs in Westdeutschland, François-Poncet, am 12. Februar einem Korrespondenten der italienischen Zeitung „Tempo“ folgendes: „Ich denke nicht, dass eine Neutralisierung Deutschlands eine annehmbare und letztlich dauerhafte Lösung wäre. Ich denke nicht, dass es in der gegenwärtigen Zeit auf der Welt auch nur ein Land gibt, das unter der Regierungsform einer unbewaffneten Neutralität leben könnte. Kanzler Adenauer lenkte mehrmals die Aufmerksamkeit hierauf“.

\section{Die Einstellung der Bonner Regierung zur Bewegung für eine Neutralisierung Deutschlands $^{129}$}

Am 14. Januar d. J. trat Adenauer ${ }^{130}$ in Bielefeld auf dem Parteitag der CDU des Bundeslandes Nordrhein-Westfalen auf und sagte, dass ein neutralisiertes Westdeutschland innerhalb weniger Jahre in den Orbit der sowjetischen Macht hineingezogen werden würde. Außerdem birgt eine Neutralisierung die Gefahr in sich, dass die USA das Interesse an Europa verlieren. Der Kontinent wird nur dann existieren können, wenn sich die Bundesrepublik Deutschland im westlichen Lager befinden wird.

Am 11. Februar d. J. trat Adenauer vor Studenten der Bonner Universität auf und erklärte, dass sich das deutsche Volk mit all seiner Kraft gegen die Absicht der Sowjetunion auf der bevorstehenden Konferenz der Vier wenden muss, eine Neutralisierung und Entwaffnung Deutschlands vorzunehmen.

Der Vizepräsident des Bonner Bundestages, Schäfer, sprach sich in einer Rede am 9. Februar d. J. vor Studenten der Universität in Kiel gegen eine Neutralisierung ${ }^{131}$ Westdeutschlands aus. Das deutsche Volk, sagte Schäfer, ist sowieso gezwungen, zwischen dem Osten und Westen zu wählen.

SPD-Chef Schumacher trat in einer Rede am 14. Februar ebenso gegen die Neutralisierung auf und erklärte: „Eine Neutralisierung der deutschen Bundesrepublik war und ist kein Problem für die sozialdemokratische Partei. Sie hat und wird sie stets ablehnen." Führung der SPD Westdeutschlands erklärte eine Teilnahme am „Nauheimer Kreis“ Noacks als unvereinbar mit dem Verbleiben in der SPD.

\footnotetext{
126 Von Molotov unterstrichen.

127 Von Molotov unterstrichen.

128 Von Molotov unterstrichen.

129 Im Original unterstrichen.

130 Von Molotov unterstrichen.

131 Von Molotov unterstrichen.

132 Von Molotov unterstrichen.
} 


\section{Die Einstellung der SED zur Bewegung für eine Neutralisierung Deutschlands ${ }^{133}$}

Das ZK der SED nimmt gegenwärtig eine wohlwollende Position im Verhältnis zu den Neutralisten ein, hält sich mit Kritik an der Gruppe Noacks zurück und kritisiert Adenauer und Schumacher für ihr Auftreten gegen die Neutralisten.

In der Resolution des am 4.Oktober 1949 abgehaltenen 22. Plenums des ZK der SED, „Die nationale Front des demokratischen Deutschland und die SED“ steht:

„Einige bourgeoise Kreise meinen, dass es eine Möglichkeit gäbe, das deutsche Volk zu retten, wenn Deutschland die Position der Neutralität einnehme. Da solche Gruppen und Strömungen ebenso gegen das Besatzungsstatut und den Einschluss Deutschlands in den Nordatlantikpakt auftreten, sind sie eine positive Kraft, ungeachtet der Inkonsequenz und Unentschlossenheit ihrer Positionen in einer Reihe wichtiger Fragen, was dem bourgeoisen Charakter dieser Strömungen entspricht.“

Pieck und Ulbricht denken, dass die SED nicht gegen die Befürworter einer Neutralisierung Deutschlands auftreten soll, sondern versuchen sollte, mit ihnen einen gemeinsamen Kampf gegen die Remilitarisierung und gegen die Einbeziehung Westdeutschlands in das Nordatlantikbündnis ${ }^{134} \mathrm{zu}$ organisieren.

Ulbricht hält es für möglich, dass die Sowjetunion selbst in der einen oder anderen Form einen Vorschlag zur Neutralisierung Deutschlands mit dem Ziel der Entlarvung der amerikanischen Kriegshetzer einbringt.

\section{6. Über unsere Einstellung zur Bewegung für eine Neutralisierung Deutschlands ${ }^{135}$}

Die sowjetische Kontrollkommission (Gen. C̆ujkov und Semenov) hält es für zielführend, die Bewegung für eine Neutralisierung Deutschlands auszunutzen, ${ }^{136}$ weil sie einige Hindernisse bei der Verwirklichung der Remilitarisierung Westdeutschlands durch die Regierungen der USA, Englands und Frankreichs schafft. Hierbei gehen die Gen. Čujkov und Semenov davon aus, dass sowjetische Vorschläge über eine Entmilitarisierung Deutschlands, über den Abschluss eines Friedensvertrages mit [Deutschland] ${ }^{137}$, über die Wiederherstellung der Einheit Deutschlands auf demokratischen und friedlichen Grundlagen und über einen freien Zugang Deutschlands zu den Weltmärkten die Bewegung für eine Neutralisierung Deutschlands begünstigen werden.

Außerdem halten es die Gen. C̆ujkov und Semenov ebenso für möglich, von unserer Seite mit Vorschlägen aufzutreten, Deutschland Rechte abzuerkennen, militär-politische Bündnisse abzuschließen oder militär-politischen Koalitionen beizutreten, was den Forderungen der Befürworter der Bewegung für eine Neutralisierung Deutschlands entspricht, und ebenso mit dem Vorschlag über die Gewährung von Garantien der Neutralität Deutschlands von Seiten der Großmächte ${ }^{138}$ aufzutreten.

133 Im Original unterstrichen.

134 Von Molotov unterstrichen und mit einem großen, über vier Zeilen verlaufenden Haken (seinem Zeichen für Zustimmung) versehen.

135 Im Original unterstrichen.

136 Von Molotov unterstrichen. Das Wort „auszunutzen“von Molotov mit einem Häkchen versehen.

137 Im Original wird im Russischen das Personalpronomen „s nej“ verwendet.

138 Von Molotov unterstrichen. Das Wort „Garantien“ von Molotov mit einem Häkchen versehen. 


\section{Meinung des Außenministeriums der UdSSR ${ }^{139}$}

Von meiner Seite halte ich die Position der Führung der SED und der SKK, die sich für eine Unterstützung der Bewegung für eine Neutralisierung Deutschlands unter der deutschen Bevölkerung in Westdeutschland aussprechen, für richtig. Diese Unterstützung könnte man über unsere Freunde in Westdeutschland erweisen, aber auch unter Ausnutzung verschiedener deutscher gesellschaftlicher Organisationen, die gegen die Remilitarisierung Westdeutschlands eintreten, zu diesem Zweck und unter Ausnutzung der deutschen Presse.

Sowjetische Vorschläge zur Prüfung der Umsetzung des Potsdamer Abkommens über die Entmilitarisierung Deutschlands und auch unsere Vorschläge für einen unverzüglichen Abschluss des Friedensvertrages mit Deutschland und die Gründung eines gesamtdeutschen konstituierenden Rates werden wohlwollend auch von den Befürwortern der Bewegung für eine Neutralisierung Deutschlands aufgenommen.

Irgendwelche offiziellen, die These über eine Neutralisierung Deutschlands unterstützenden Auftritte unsererseits wären allerdings gegenwärtig verfrüht ${ }_{2}{ }^{140}$ weil die Bewegung für eine Neutralisierung einstweilen noch keinen breiten Massencharakter trägt. Unser Auftreten könnte von den Westmächten dazu benutzt werden, um diese Bewegung als eine von der sowjetischen Seite inspirierte darzustellen.

Auf der bevorstehenden Session des Rates der Außenminister kann man, in Abhängigkeit von der Lage, in der einen oder anderen Form die Bewegung für eine Neutralisierung Deutschlands in der Form einer zusätzlichen Begründung unserer Position ${ }^{141}$ gegen die Remilitarisierung Deutschlands nutzen. Es ist nicht ausgeschlossen, ${ }^{142}$ dass man sich im Zusammenhang damit als zielführend vorstellen kann, von sowjetischer Seite einige konkrete Vorschläge $^{143}$ einzubringen, die mit den Forderungen der deutschen Bevölkerung über eine Neutralisierung Deutschlands zusammenhängen. ${ }^{144}$

/A. Vyšinskij/

18. II.

\section{A. Vyšinskij}

\section{Dokument 4}

RGASPI, f. 82, op. 2, d. 1182, S. 49-53, 18.2.1951

Str. Geheim

An Genossen V. M. Molotov ${ }^{145}$

In Ergänzung zu dem von mir übersandten Bericht zur Frage über die Bewegung für eine Neutralisierung Deutschlands teile ich neue Angaben zu dieser Frage mit, die am 18. Januar

\footnotetext{
139 Im Original unterstrichen.

140 Von Molotov unterstrichen.

141 Von Molotov unterstrichen.

142 Von Molotov unterwellt.

143 Von Molotov doppelt unterstrichen.

141 Der letzte Absatz von Molotov am linken Rand mit ciner Wellenlinie und einem eingekreisten Kreuz versehen.

145 Rechts ein handschriftliches Kreuz Molotors. Auf der linken Seite der Vermerk: „zu den Akten“.
} 
auf unsere Anfrage hin von den Gen. Panjuškin, Pavlov (Paris), Puškin, Koptelov, Zajcev (Den Haag) und Požidaev (Brüssel) einlangten. Aus all diesen Mitteilungen kann man folgende Schlussfolgerungen ziehen.

1. Die Regierungskreise der USA, Frankreichs, Belgiens und Hollands sind ablehnend, beunruhigt und besorgt zur Bewegung für eine Neutralisierung Deutschlands eingestellt, und denken, dass diese Bewegung Hindernisse bei der Remilitarisierung schafft.

In diesem Zusammenhang verdienen folgende Mitteilungen Aufmerksamkeit.

In den Regierungskreisen der USA herrscht unverkennbare Unsicherheit darüber, ob es wirklich gelingen wird, die Deutschen zu zwingen, auf der Seite der USA zu kämpfen, wovon die Reden der Mitglieder des Repräsentantenhauses, Morris und St. George, und der Senatoren Langer und Butler zeugen. Morris trat am 12.Januar im Kongress mit einer Rede auf und bezog sich auf eine von der Redaktion der Zeitschrift „Der Spiegel“ durchgeführte Umfrage in der westdeutschen Bevölkerung über ihre Einstellung zur Frage der Bewaffnung Deutschlands. Er erklärte, dass von 33 Tausend befragten Deutschen $85 \%$ geantwortet hätten, dass sie keine Soldaten werden wollten und nicht wollten, dass ihre Angehörigen in eine Armee eingezogen werden. 68,4\% sprachen sich gegen eine Wiederbewaffnung Deutschlands sogar im Falle einer vollen Gleichstellung Westdeutschlands mit den übrigen Ländern aus und $82 \%$ gegen den Eintritt Westdeutschlands in den Nordatlantikblock. Bezug nehmend auf diese Angaben erklärte Morris in einer weiteren Rede im Kongress am 15. Januar: „Wenn wir versuchen, Deutschland in einer solchen Lage zu bewaffnen, wird das nicht eine gefährliche und unvernünftige Politik sein, können wir diese Politik verwirklichen oder ist es faktisch gar nicht mehr möglich, sie in die Tat umzusetzen“.

Senator Langer bezog sich in seiner Rede im Senat am 29. Januar auf eine Mitteilung der Zeitung "Wall Street Journal“, derzufolge eine von der Administration McCloys durchgeführte Umfrage in der Bevölkerung Westdeutschlands über den Wunsch, freiwillig dem „westlichen Verteidigungsbündnis“ beizutreten, derart negative Ergebnisse erbracht hat, dass McCloy ihre vollständige Publikation nicht erlaubt habe. Nach der Erklärung Langers werden nicht mehr als 5\% der deutschen Männer im wehrfähigen Alter freiwillig in einer „westlichen Verteidigungsarmee" dienen.

St. George, Mitglied des Repräsentantenhauses, erklärte in ihrer Rede vor dem Kongress am 14. Februar: „Wer weiß, dass Westdeutschland kämpfen wird? Ich denke, dass dies überaus zweifelhaft ist. Ich glaube nicht, dass sie den brennenden Wunsch haben, auf unsere Seite zu kommen."

Senator Butler erklärte am 12. Februar im Senat: „Wir befinden uns jetzt in einem Elend und wir bitten um die Hilfe der Deutschen. Sie sind nicht günstig gestimmt, unseren Armeen beizutreten. Kann man sich darüber wundern? Für uns ist eine Zusammenarbeit mit den Deutschen notwendig, wenn wir Westeuropa retten wollen."

Acheson erklärte am 16. Februar auf der gemeinsamen Konferenz der Kommission für auswärtige Angelegenheiten und der Kommission für Streitkräfte des Senats im Zusammenhang mit der Erörterung der Frage über die Entsendung amerikanischer Truppen nach Europa, dass, wenn sich die USA nicht aktiv an der „Verteidigung“ Europas beteiligten, inklusive der Entsendung von Truppen, dann „eine solche Strategie unsere Freunde in Europa zu einer Stimmung des Nichtwiderstandes, zu einer „Neutralisierungs“-Stimmung, führt, die sowohl bei ihnen als auch bei uns einem Selbstmord gleichkommt".

Das Anwachsen der Bewegung gegen die Remilitarisierung in Westdeutschland berücksichtigend, versuchen die Regierungskreise der USA einerseits die Bewegung für eine Neu- 
tralisierung Deutschlands zu schwächen, andererseits sind sie jedoch bemüht, die Remilitarisierung nicht in solch offener Form durchzuführen, wie es früher vorgesehen war. Zu diesen Zielen setzen die USA verschiedene Versprechungen von "Zugeständnissen“ an die Bonner Regierung in der Frage über die Gewährung großer Selbständigkeit in Umlauf und versuchen auch, die Deutschen vor der „Gefahr" seitens der UdSSR zu erschrecken.

Nach einer Mitteilung des Gen. Puškin nahmen die Amerikaner Abstand von der Absicht, die Wehrpflicht in Westdeutschland einzuführen und traten zur Formierung militärischer Einheiten mit freiwilligen Deutschen über, in der Hoffnung, auf diese Weise bis zu 150-200 Tausend Personen erfassen zu können.

Gen. Pavlov teilt aus Paris mit, dass die Regierungskreise Frankreichs gegenüber der Bewegung für eine Neutralisierung Westdeutschlands scharf ablehnend eingestellt sind und diese Bewegung als Schwächung des Lagers der Aggression und als Veränderung der Idee des atlantischen Bündnisses und der europäischen militärischen Bündnisse gegen die UdSSR und den Ländern der Volksdemokratie auslegen.

Über die feindliche Einstellung der belgischen Regierungskreise zur Bewegung für eine Neutralisierung Deutschlands berichtet Gen. Požidaev aus Brüssel.

2. Im Zusammenhang mit der in letzter Zeit wachsenden Popularität für die Bewegung für eine Neutralisierung Deutschlands bei der deutschen Bevölkerung erscheinen in der westdeutschen Presse Mitteilungen, in welchen Besorgnis darüber zum Ausdruck gebracht wird, dass sich diese Bewegung auch auf andere Mitgliedsländer des Nordatlantikblocks ausdehnt.

Am 15. Februar erklärte der amerikanische Radiokommentator Godwin, dass die Neutralisierungstendenzen ansteckend seien und sich ausdehnen könnten. Es besteht die Gefahr, dass im Falle eines neutralen Deutschlands Frankreich und Italien eine ähnliche Position vorteilhaft und populär fänden. Zu guter Letzt erklärte Godwin, dies führe zu einem neutralen Westeuropa und die USA seien gezwungen, allein der Sowjetmacht gegenüber zu stehen.

Die Pariser Zeitung „[Le] Monde“ kommentiert in ihrem Leitartikel „Die Neutralisierung Deutschlands"vom 17. Februar insgesamt wohlwollend einen deutschen Neutralismus und die Idee des Abzugs der Truppen des Westens und des Ostens auf gleiche Entfernung von den Grenzen Deutschlands.

Dem Umstand Rechnung tragend, dass die Bewegung für eine Neutralisierung unter den Arbeitern, der Intelligenz und sogar in Unternehmerkreisen auf breite Unterstützung trifft, gab die holländische Regierung den Presseverantwortlichen strenge Anweisungen, sich der Publikation von Materialien über die Bewegung für eine Neutralisierung Deutschlands zu enthalten.

Die österreichische Presse verschweigt die Bewegung für eine Neutralisierung Deutschlands gleichfalls. Die demokratische Presse steht in positivem Verhältnis zur Losung von "Ohne uns“. Die in der amerikanischen Zone erscheinenden „Salzburger Nachrichten“ sprechen sich gegen eine Neutralisierung aus und erklären, dass „die Meinung, Westdeutschland nicht aufzurüsten, gänzlich falsch sei“.

3. Die sowjetischen Noten bezüglich der Einberufung einer Konferenz des Rates der Außenminister zur Erörterung der Frage der Erfüllung der Beschlüsse der Potsdamer Konferenz über die Entmilitarisierung Deutschlands und das Eintreten der Regierung der DDR für Verhandlungen mit der Bonner Regierung über die Bildung eines gesamtdeutschen 
konstituierenden Rates erlauben in bedeutsamem Maße die Verbreitung der Idee einer Neutralisierung Deutschlands unter der westdeutschen Bevölkerung.

Nach Mitteilung von Gen. Panjuškin teilte die Agentur United Press am 6. Februar mit, dass die Teilnehmer der Versammlung der amerikanischen Botschafter in Europa, die in Frankfurt am Main stattfand, die Gefahr erörterten, dass im Falle der Einbringung eines Vorschlages über ein vereintes neutrales Deutschland durch die Sowjetunion auf der Konferenz des Rates der [Außen]minister auf einen solchen Vorschlag schwer zu antworten sein würde.

Die einflussreiche Bostoner Zeitung „Christian Science Monitor" bemerkte in einer Mitteilung aus Bonn vom 14. Februar, dass ,in der gegenwärtigen Zeit die Idee einer Neutralisierung unter der Bevölkerung Westdeutschlands stärker sei, als dies einige Monate zuvor der Fall war".

Unser Gesandter in Holland, Gen. Zajcev, teilt mit, dass die sowjetischen Noten bezüglich der von den Regierungen der USA, Englands und Frankreichs durchgeführten Maßnahmen zur Wiederbewaffnung Westdeutschlands eine Entfaltung der Idee der Neutralisierung begünstigen.

4. Die allgemeine Schlussfolgerung, zu der unsere Botschafter und Gesandten in den USA, Frankreich, Belgien, der DDR, Österreich und Holland kommen, läuft darauf hinaus, dass es für uns notwendig ist, weil die Bewegung für eine Neutralisierung Deutschlands die Verwirklichung der amerikanischen Pläne der Bewaffnung Westdeutschlands erschwert, diese Bewegung zu fördern. ${ }^{146}$ Hierbei unterstreicht Gen. Pavlov, dass dennoch der Kampf für ein einheitliches, demokratisches, friedliebendes Deutschland unsere Hauptaufgabe bleiben muss. Gen. Požidaev denkt ebenfalls, dass es nötig ist, die Bewegung der Neutralisten zu benutzen, sich aber von einer offenen Unterstützung dieser Bewegung zurückzuhalten. ${ }^{147}$ Gen. Puškin spricht sich für die Ausnutzung ${ }^{148}$ der Bewegung der Neutralisten durch uns aus, obwohl nach seiner Meinung diese Bewegung in ihrer weiteren Konsequenz auch antisowjetischen Inhalt haben kann und dass es deshalb nicht nötig sei, sich mit einer breiten Unterstützung ${ }^{149}$ der Idee der Neutralisierung Deutschlands die Hände zu binden. ${ }^{150}$

\section{A. Vyšinskij}

\section{Dokument 5}

RGASPI, f. 82, op. 2, d. 1182, S.54-55, 18.2.1951

\section{Ergänzung}

Erst nach Druck dieses Berichtes langte ein Telegramm von Gen. Zarubin aus London ein, in welchem er Beispiele anführt, die von der ablehnenden Haltung der Führungskreise Englands zur Bewegung für eine Neutralisierung Deutschlands zeugen. So erklärte der par-

\footnotetext{
146 Von Molotov unterstrichen.

147 Von Molotov unterstrichen.

148 Von Molotor unterstrichen.

149 Von Molotov unterstrichen.

150) Von Molotov unterstrichen.
} 
lamentarische stellvertretende Minister für auswärtige Angelegenheiten Englands, Younger, dass eine Neutralisierung Deutschlands mit einer vierseitigen Kontrolle in allen ihren Zonen die westlichen Länder nicht befriedigen kann. Er wies darauf hin, dass sich ein neutrales Deutschland unter der ständigen Bedrohung „eines kommunistischen Putsches nach tschechoslowakischer Manier" befinden würde. Nach seiner Meinung könnten die Westmächte vielleicht auf eine Neutralisierung Deutschlands eingehen, jedoch nur unter der Bedingung, dass in Bulgarien, Rumänien und Ungarn eine internationale Inspektion zur Überwachung der Umsetzung der Friedensverträge durch diese Länder eingerichtet werden würde. Younger ist aber überzeugt, dass sich die UdSSR mit dieser Bedingung nicht einverstanden erklären wird.

Dem Foreign Office und der Botschaft der USA in London nahestehende Personen erklärten, dass die Anglo-Amerikaner auch deswegen eine ablehnende Haltung im Zusammenhang mit einer Neutralisierung Deutschlands einnehmen, weil ein neutrales Deutschland mit der Sowjetunion Handel betreiben und auf diese Weise Produktion des Ruhr-Gebietes in den Osten verbringen und somit das Militärpotential der UdSSR stärken würde.

Viele einflussreiche britische Zeitungen und Journale sprechen sich gegen eine Neutralisierung Deutschlands aus und bemerken, dass eine Neutralität Deutschlands im Interesse der Sowjetunion wäre.

Gen. Zarubin teilt zudem mit, dass gegenwärtig in britischen politischen Kreisen der Bewegung für eine Neutralisierung Deutschlands weniger Bedeutung beigemessen wird als vor 2-3 Wochen, da sie denken, dass diese Bewegung, die über keine einheitliche politische Führung verfügt, keine entscheidende Rolle bei der Verhinderung der Remilitarisierung Deutschlands spielen kann. Außerdem denkt man in parlamentarischen Kreisen, dass die starken revanchistischen und militaristischen Strömungen unter den zahlreichen Gruppen der aus dem Osten umgesiedelten Deutschen Adenauer erlauben, ohne Annahme eines Gesetzes über die Wehrpflicht eine Millionenarmee aus Freiwilligen aufzustellen.

Wie auch unsere anderen Botschafter und Gesandten in den oben genannten Ländern hält es Gen. Zarubin für zielführend, die Bewegung für eine Neutralisierung Deutschlands in unserem Interesse zu nutzen, ${ }^{151}$ da sie die Verwirklichung der anglo-amerikanischen Pläne der Remilitarisierung Deutschlands erschwert.

\section{A. Vyšinskij}

„18.“ Februar 1951

151 Von Molotov unterstrichen. 


\title{
Dokument 6
}

RGASPI, f. 82, op. 2, d. 1333, S. 161-168, 20.2.1951

$\underline{\text { Geheim }}^{152}$

\author{
Bericht \\ über die Einstellung verschiedener Kreise Westdeutschlands, \\ ebenso der Westmächte zur Frage der Einführung \\ der Wehrpflicht in Westdeutschland ${ }^{153}$
}

\section{Westdeutschland}

Die Diskussion über die Einführung der Wehrpflicht in Westdeutschland wurde, beginnend mit ungefähr Juli 1950, unter dem Vorwand der Notwendigkeit des Erlasses eines Gesetzes, das die Frage der Wehrdienstverweigerung regelt, bis Januar 1951 geführt. Artikel 4 der Bonner Verfassung lautet bekanntlich:

„Niemand darf gegen sein Gewissen zum Kriegsdienst mit der Waffe gezwungen werden. Das Nähere regelt ein Bundesgesetz."

Dieser Art. 4 der Bonner Verfassung verhindert die Einführung der Wehrpflicht. Deshalb versuchen Adenauer und andere Vertreter der Bonner Regierung diesen Artikel zu umgehen oder ihn zu ändern.

Während des Besuches Eisenhowers in Westdeutschland verlautbarte Adenauer ihm Folgendes: „Gegenwärtig werden bereits Beratungen zur Frage über die Möglichkeit der Aufhebung des Paragraphen 4 des Grundgesetzes geführt, der die Möglichkeit bietet, den Militärdienst zu verweigern." 154

Der Innenminister der Bonner Regierung, Lehr, schrieb in einem Brief an den Staatssekretär der Kanzlei des Bonner Parlaments, Lex, der von der Hannover Zeitschrift „Der Spiegel" am 3.Januar 1951 veröffentlicht wurde, Folgendes:

„In meinem Ministerium ist inzwischen ein Referenten-Entwurf eines Kriegsdienstverweigerungsgesetzes erarbeitet worden. Ich habe den Entwurf noch nicht dem Kabinett zugeleitet, weil meines Erachtens die Bundesregierung ${ }^{155}$ zunächst darüber beschließen muss, ob die Vorlage eines Kriegsdienstverweigerungsgesetzes vor oder nach dem Entwurf eines etwaigen Wehrgesetzes eingebracht werden soll."156

Der für die CDU auftretende, bedeutende ${ }^{157}$ Kölner Kardinal Frings erklärte am 23.Juli 1950 in Bonn:

"Wenn sich die Notwendigkeit erhebt, wenn der Staat die militärische Pflicht hat, dann ist in diesem Fall das absolute Recht auf Verweigerung des Militärdienstes nicht vereinbar mit der christlichen Idee.“ (Zeitung „Badisches Tagblatt“vom 27.7.50)

\footnotetext{
152 Darüber ein handschriftliches Kreuz Molotovs. Links darüber der handschriftliche Vermerk Gromykos: „An Gen. V. M. Molotov. 20.II. A. Gromyko.“ Auf der linken Seite der Vermerk: „Zu den Akten“.

153 Von Molotov unterstrichen.

1:54 Absatz am linken Rand von Molotov durch einen Strich hervorgehoben.

155 Im russischen Text: „Dic Bonner Regierung“.

156 Absatz am linken Rand von Molotov durch einen Strich hervorgehoben.

157 Im Original: „Vidnyj dejatel' ChDS“.
} 
Nach Mitteilung der Agentur ADN aus Bonn erklärte Vizekanzler Blücher (Freie Demokratische Partei) im intimen Kreis, dass nur „mit 20-25 westdeutschen Divisionen wir nicht gemeinsam mit den Amerikanern und Engländern Ostdeutschland befreien können, sei es mittels Krieg oder mittels Kriegsandrohung. ["] Er sagte in diesem Zusammenhang, dass es noch schlimmer sei, 10 westdeutsche als gar keine Divisionen zu haben.

Die „Stuttgarter Nachrichten" schrieben am 27. Oktober 1950, indem sie sich auf die Schweizer „National-Zeitung“ bezogen:

„Die Bonner Regierung bereitete auf Initiative der Amerikaner hin einen Gesetzesentwurf über die Formierung von 10 Divisionen mit einer allgemeinen Stärke von 200 Tausend Personen vor. Im Gesetzesentwurf ist ebenso die Einführung einer allgemeinen Wehrpflicht vorgesehen."158

Die der CDU nahestehende Münchner „Süddeutsche Zeitung“ schrieb am 25. Oktober 1950:

„Hier wird bereits seit langem die Frage über ein deutsches Grundkontingent einer Europa-Armee diskutiert. Die Rede ist von einem Militärgesetz, das die allgemeine Wehrpflicht vorsieht".

Die Nürnberger Zeitung „Acht Uhr Blatt“ berichtete am 12. Januar 1951 über einen Auftritt des Ministers [recte: Ministerpräsidenten] des Bundeslandes Hessen, des Sozialdemokraten Zinn, gegen die Kriegspolitik Adenauers. Zinn beschuldigte Adenauer, dass Letzterer vorhabe, im Bundestag mit einfacher Mehrheit ein Gesetz über die allgemeine Wehrpflicht durchzuziehen."

Dieselbe Zeitung berichtete am 24.Januar d. J.: „Nach der Meinung deutscher Experten könnten die Forderungen der Alliierten lediglich im Falle der Einführung einer allgemeinen Wehrpflicht erfüllt werden. Wie sie aufzeigen, sind die Amerikaner an gut ${ }^{159}$ ausgebildeten, gesunden jungen Rekruten im Alter von 18 bis 24 Jahren und ebenso an Spezialisten im Alter bis 35 Jahren interessiert. In Bonn hegt man keine Hoffnung darauf, dass man eine ausreichende Anzahl an Freiwilligen solchen Alters finden wird. "160

Am 20. November 1950 erklärte Schumacher in München in einer Rede: „Wenn wir,[“] sagte Schumacher, [„] ein Gesetz über die Wehrpflicht im Geist der SPD erhalten werden, wird es keinen einzigen geben, der den Militärdienst ablehnen wird“. / Der Tagesspiegel“ am 21. November 1950/.

Angesichts der breiten Bewegung in Westdeutschland gegen die Remilitarisierung war Adenauer gezwungen, in der Frage über die Wehrpflicht vorsichtiger zu agieren.

Adenauer ist gezwungen, darauf Rücksicht zu nehmen, dass eine Reihe von Vertretern verschiedener Parteien und Gesellschaftskreise offen für eine Anwerbung von Freiwilligen und gegen die Wehrpflicht eintritt.

Der Abgeordnete des Bonner Parlaments, Mende, erklärte am 2. Februar 1951, dass von der Einführung einer allgemeinen Wehrpflicht in Westdeutschland aus praktischen und psychologischen Gründen keine Rede sein kann. ${ }^{161}$

Die Vorsitzende der Zentrumspartei in Deutschland (bourgeoise Partei), Helene Wessel, sprach sich in einer Rede in Oberhausen am 13. Januar d. J. für die Annahme eines Gesetzes aus, demzufolge niemand gegen seinen Willen zum Militärdienst eingezogen werden darf.

158 Absatz von Molotov am linken Rand durch einen Strich hervorgehoben.

159 Absatz von Molotov am linken Rand durch einen Strich hervorgehoben.

160 Absatz von Molotov am linken Rand durch einen Strich hervorgehoben.

161 Absatz von Molotov am linken Rand durch einen Strich hervorgehoben. 
Am 3. Februar d. J. verlautbarte der Minister für gesamtdeutsche Fragen der Bonner Regierung, Kaiser, die bevorstehende Gründung eines tätigen Selbstschutzes gegen jegliche „kommunistische Intrigen“ und rief die Jugend Westdeutschlands dazu auf, sich an diesen Einheiten des Selbstschutzes zu beteiligen.

Diese Erklärung Kaisers über die Gründung von freiwilligen Einheiten eines „Selbstschutzes“ stellte dem Wesen nach, nach der Meinung Gen. Puškins, die Auslegung des offiziellen Standpunktes der Bonner Regierung darüber dar, dass sich eine westdeutsche Armee zuerst auf freiwilliger Grundlage bilden wird. ${ }^{162}$

\section{Aussagen von Vertretern der USA, Englands und Frankreichs}

$\underline{\text { USA }}$

Der Washingtoner Korrespondent der Agentur Associated Press schrieb am 29. Januar d. J., Senator Johnson (Demokrat aus dem Staate Colorado) habe vorgeschlagen, in die amerikanische Armee 1 Mio. Menschen aus Ländern Westeuropas aufzunehmen, mit dem Ziel, die Einberufung 18-jähriger Amerikaner zum Militärdienst abzuwenden und das Problem des Mangels menschlicher Reserven innerhalb des Landes zu lösen. Johnson erklärte auch, dass es nötig sei, in diese „ausländische Legion“ Deutsche aus Westdeutschland aufzunehmen, ebenso Freiwillige aus Ländern Osteuropas; kommandieren sollen freilich amerikanische Offiziere.

Nach Mitteilung Gen. Puškins (Telegramm vom 8. Februar d. J. Nr. 82-84) haben die Amerikaner in letzter Zeit in der Frage der Remilitarisierung Westdeutschlands ihre Taktik geändert. Früher sei vorgesehen gewesen, mit der Verlautbarung der Wehrpflicht in Westdeutschland und der Abschaffung der entsprechenden Artikel der Bonner Verfassung zu beginnen. Die Antikriegsstimmung der Bevölkerung berücksichtigend, entschlossen sich die Amerikaner, nach der Meinung Gen. Puškins (auf der Grundlage von Pressemitteilungen), den Weg der $\underline{\text { Schaffung einer Freiwilligenarmee }}{ }^{163}$ einzuschla- $^{-}$ gen, in der Annahme, dass es ihnen gelingen würde, aus Befürwortern der Remilitarisierung Westdeutschlands zunächst eine Armee mit 150-200 Tausend Freiwilligen zu schaffen. ${ }^{164}$

Die Gen. Čujkov und Semenov teilten am 14. Februar mit, dass nach der Meinung Ulbrichts trotz der anscheinenden Taktikänderung der Amerikaner die Remilitarisierung Westdeutschlands durchgeführt wird und durchgeführt werden wird, präzise und nach Plan, aber ohne großen Lärm in der Presse und ohne breit kundgetane Befehle und Erklärungen. In Westdeutschland werden bereits militärische Formationen im Maßstab von Bataillonen geschaffen. Bei der Schaffung einer westdeutschen Armee wird die Erfahrung der schwarzen Reichswehr genutzt. Entwürfe über die Einführung der Wehrpflicht sind ausgearbeitet, sie werden aber einstweilen noch nicht veröffentlicht. ${ }^{165}$

\footnotetext{
162 Von Molotov unterstrichen. Der ganze Absatz von Molotov am linken Rand durch drei Striche hervorgehoben.

163 Von Molotov unterstrichen.

164 Absatz von Molotov am linken Rand durch einen Strich hervorgehoben.

165 Absatz von Molotov am linken Rand durch einen Strich hervorgehoben.
} 
England

Im Unterhaus fragte der Labour-Angehörige Emrys Hughes am 15. November 1950 Shinwell (Verteidigungsminister):

„Kann uns der Minister seine Zusicherung darüber geben, dass er gegen die Einführung der Wehrpflicht für Deutsche gegen deren Willen und die Wiedererrichtung der deutschen Armee unter der Führung der alten nazistischen Generäle Einspruch erheben wird; kann er auch sagen, wie seine Einstellung zu einer Schaffung einer taktischen Luftwaffe für Deutschland und einer Vergrößerung der deutschen Flotte ist?“.

Shinwell: „Wir werden kaum einen solchen Vorschlag prüfen, ohne vorher die deutsche Regierung zu konsultieren. Wir können ihnen natürlich nicht die Wehrpflicht, mit welcher Formulierung auch immer, oder die Schaffung von Streitkräften in Deutschland aufzwingen, ohne ein Abkommen geschlossen zu haben. ${ }^{166}$

Was die Schaffung von Streitkräften unter der Führung ehemaliger nazistischer Offiziere betrifft, so ist das eine Frage, über die man natürlich nachdenken muss.

Was die zweite Frage betrifft, so denke ich nicht, dass sich uns im gegenwärtigen Stadium dieses Problem stellen könnte."

\section{Frankreich}

Der Minister ohne Portefeuille, zuständig für Fragen der Information, [Deyvaux-] Gassier, erklärte am 6. Dezember 1950:

„Deutsche Kampfgruppen werden in die alliierten Divisionen eingebunden. Diese Kampfgruppen werden keine schweren Waffen haben. Sie werden sich von den gewöhnlichen Divisionen sowohl hinsichtlich ihrer Zahl, die nicht 4-5 Tausend Mann überschreiten wird, als auch in ihrer Zusammensetzung unterscheiden, denn sie werden infolge des Fehlens eines Dienstes im Hinterland keine Militäreinheiten in entsprechender Einheitsstärke darstellen. Die Gesamtzahl der deutschen Kampfgruppen wird 1/5 der Zahl der alliierten Streitkräfte nicht überschreiten. Die Anwerbung für die deutschen Kampfgruppen wird von zivilen Organen unter der Kontrolle der Alliierten durchgeführt werden."

/TASS, 7. Dezember 1950, S. 13-r/.

Der Korrespondent der österreichischen Tageszeitung „Neue Wiener Tageszeitung“ schrieb am 24.Januar 1951 aus Bonn:

„Die Vertreter der Alliierten Mächte debattierten lange Zeit über die Frage, ob die deutschen Truppen auf dem Weg der Einführung der Wehrpflicht oder mittels Freiwilligen aufgestellt werden sollen. Die Franzosen vertreten den Standpunkt, dass eine deutsche Armee aus 90000 Mann bestehen und aus Freiwilligen formiert werden soll. Der amerikanische Vertreter sprach sich dagegen aus. Er unterstrich, dass die deutschen Streitkräfte aller Voraussicht nach 150 Tausend Mann zählen werden. Wenn eine solche Armee nur unter Freiwilligen angeworben wird, sagte er, dann wird sie eine Armee von Wagehälsen sein. $^{167}$

Abschließend wurde der Beschluss gefasst, die Meinungen der einzelnen Regierungen einzuholen und in der nächsten Zeit die Erörterung über die Bewaffnung Westdeutschlands fortzusetzen".

Dic oben wiedergegebenen Aussagen von Vertretern der Bonner Regierung und anderer gesellschaftlicher und politischer Kreise Westdeutschlands sowie Pressemeldungen geben

166 Absatz links von Molotov durch einen Strich hervorgehoben.

${ }^{167}$ Absatz links von Molotov durch einen Strich hervorgehoben. 
einstweilen noch keine ausreichende Grundlage für Schlüsse darüber, welche Form der Aufstellung der westdeutschen Armee die Anglo-Amerikaner und die Regierung Adenauer wählen werden. Dennoch ist bereits klar, dass die Bewegung gegen die Remilitarisierung in Westdeutschland ihnen die Annahme von Maßnahmen zur Einführung der allgemeinen Wehrpflicht erschwert.

20. Februar 1951

A. Gromyko

Ausg. Nr. 59/AG

\section{Dokument 7}

RGASPI, f. 82, op. 2, d. 1169, S. 1-3, 24.2.1951

An Genossen Stalin I. V. ${ }^{169}$

Streng geheim, Ex. Nr. $\underline{3}^{168}$

Die Genossen Čujkov und Semenov haben aus Berlin (Telegramm Nr. 7/363) mitgeteilt, dass Pieck, Grotewohl und Ulbricht es für zielführend halten, dass die Volkskammer der Deutschen Demokratischen Republik dem Bonner Bundestag vorschlägt, ${ }^{170}$ sich gemeinsam an die vier Großmächte mit der Bitte, die Frage über den Abschluss eines Friedensvertrages mit Deutschland im Jahr 1951 in die Tagesordnung der Konferenz des Rates der Außenminister aufzunehmen, zu wenden. ${ }^{171}$

Falls der Bundestag diesen Vorschlag ablehnt oder bis zu einer bestimmten Frist nicht antwortet, wird sich die Volkskammer selbständig mit diesem Vorschlag an die vier [Groß] mächte wenden. Der Vorschlag der Volkskammer wird von dem Nationalrat der Nationalen Front des demokratischen Deutschland unterstützt.

Pieck, Grotewohl und Ulbricht denken, dass eine solche Initiative der Volkskammer die allerwichtigste Frage eines Friedensvertrages ins Zentrum der Aufmerksamkeit der deutschen Gesellschaft stellen und die Versuche der Amerikaner, den Friedensvertrag durch eine Deklaration über die Beendigung des Kriegszustandes mit Deutschland zu ersetzen, erschweren wird.

Der Vorschlag der Volkskammer zum Friedensvertrag wird nach den Meinungen Piecks, Grotewohls und Ulbrichts breite Unterstützung in Westdeutschland finden und der Durchführung einer Volksbefragung gegen die Remilitarisierung nützen.

Pieck, Grotewohl und Ulbricht bitten dringend um Anweisungen in dieser Frage, da sie beabsichtigen, in den nächsten Tagen eine außerordentliche Sitzung der Volkskammer einzuberufen, und es schaffen möchten, den Appell an die vier [Groß]mächte vor der Einberufung der vorläufigen Konferenz der Stellvertreter der Außenminister der UdSSR, der

168 Darüber ein handschriftlich eingekreistes Kreur, Molotovs Zeichen für besondere Wichtigkeit. Links daneben ein eingekreistes Häkchen und das Datum 27. II. Links oben: Zu den Akten: 28.II. Links unten Eingangsstempel: S[ekretaria]t V. M. Molotov: 25. II. 1951. Eingangsnummer [in russischer Abkürzung]: Nr. 2475.

169 Darüber: „Utv[ery̌deno]. $M[$ olotov]“; „Bestätigt Molotov“.

170 Von Molotov unterstrichen bzw. cher unterwellt.

17 Die Wörter „zu wenden“ sind dick unterstrichen, der Rest ist mit leichten Unterwellungen versehen. 
USA, Englands und Frankreichs zur Ausarbeitung der Tagesordnung der Konferenz des Rates der Außenminister zu schicken.

Die Genossen Čujkov und Semenov sind mit dem Vorschlag Piecks, Grotewohls und Ulbrichts einverstanden.

Das Außenministerium der UdSSR unterstützt diese Vorschläge ebenso.

Ein Beschlussentwurf liegt bei.

Ich bitte um Prüfung.

/A. Gromyko/

„24“. Februar 1951

Nr. 3.

Für die Richtigkeit: S. Nekrič

Kopien ergingen an die Genossen Molotov, Malenkov, Berija, Mikojan, Kaganovič, Bulganin, Chruščev.

[Beilage]:

Entwurf

Streng geheim

Beschluss des ZK der VKP/b/

Die Gen. Čujkov und Semenov sind zu beauftragen, Pieck, Grotewohl und Ulbricht auszurichten, dass man in Moskau ihre Vorschläge darüber, dass die Volkskammer der DDR dem Bonner Bundestag vorschlägt, sich gemeinsam an die vier Großmächte mit der Bitte zu wenden, die Frage des Abschlusses des Friedensvertrages mit Deutschland im Jahr 1951 auf die Tagesordnung der bevorstehenden Konferenz des Rates der Außenminister zu setzen, begrüßt. ${ }^{172}$

\section{Dokument 8}

RGASPI, f. 82, op. 2, d. 1334, S. 1f., 15.3.1951

\section{An Gen. V. M. Molotov}

\section{Informationsbericht}

Laut den der Außenpolitischen Kommission des ZK der VKP(b) zur Verfügung stehenden Informationen wird am 17.-18. März d. J. in Frankfurt am Main der „deutsche Kongress“ stattfinden, an dem Anhänger der Neutralisierung Deutschlands teilnehmen. Der Kongress wurde von dem Leiter des „Nauheimer Kreises“ Noack, dem Anführer der Deutschen Sozialen Partei, Gereke, und dem Anführer einer neofaschistischen Organisation „Dritte Front“ angeregt.

Am Kongress nehmen ca. 150 Personen teil. Zur Teilnahme werden nur diejenigen Personen zugelassen, die beweisen können, dass sie sowohl Gegner der Orientierung am Wes-

172 Im Original: „v Moskve otnoșatșja položitel'no“. 
ten als auch an der Sowjetunion sind. Das Ziel des Kongresses ist die Vereinigung aller politischen Gruppierungen, die gegen die Remilitarisierung und für die Neutralisierung Deutschlands auftreten.

Auf der Tagesordnung des Kongresses stehen folgende Fragen:

1. Die Zusammenarbeit zwischen verschiedenen Organisationen und Gruppierungen, die für die Neutralisierung Deutschlands, gegen ihre einseitige außenpolitische Orientierung sowie gegen die Remilitarisierung West- und Ostdeutschlands sind.

2. Aufgrund der Wiesbadener Ansprache (Noack und Gereke gegen die Remilitarisierung) soll eine Plattform für eine vierseitige Konferenz zur deutschen Frage erarbeitet werden.

3. Ein organisatorischer Rahmen für die Zusammenarbeit der Gegner der Remilitarisierung soll entwickelt werden. Geplant ist die Schaffung der „Deutschen Friedensfront“, eines Koordinationskomitees, bestehend aus den Vertretern einzelner Organisationen, dessen Mitglieder untereinander ein „Aktionskomitee“ wählen werden.

Im Zuge der Kongressvorbereitung kam es unter seinen Veranstaltern zu Unstimmigkeiten, der Einfluss der neofaschistischen Elemente verstärkte sich. Nach neusten Informationen finden die Vorbereitungsarbeiten derzeit unter Leitung der neofaschistischen Organisation „Dritte Front" statt. Noack und Gereke sind in den Hintergrund gedrängt worden.

Eine der Ursachen für diese Unstimmigkeiten besteht darin, dass die Anhänger von Noack und Gereke gleichzeitig gegen die Remilitarisierung und für die Neutralisierung Deutschlands auftreten, während sich die „Dritte Front“ (Schenke) bemüht, diese Bewegung auf den Kampf für die Neutralisierung zu beschränken. Zur Verstärkung seiner Positionen sucht Schenke nach der Unterstützung seitens anderer neofaschistischer Organisationen und hat zur Teilnahme am Kongress solche neofaschistischen Organisationen wie die „Nationale Reichspartei“ und die „Deutsche Reichspartei“ eingeladen. Am Kongress werden sich auch jene ehemaligen prominenten Sozialdemokraten beteiligen, die wegen des Widerstandes gegen Schumacher aus der Partei ausgeschlossen wurden.

Die Vorbereitung des „Deutschen Kongresses“ hat in den Bonner Kreisen ernsthafte Besorgnis hervorgerufen. Sie befürchten von dem Kongress die Vereinigung aller Gruppierungen, die gegen die Remilitarisierung auftreten. Das Bonner Ministerium für "gesamtdeutsche Fragen“ hat die Presse angewiesen, eine Kampagne gegen den „Deutschen Kongress" zu beginnen.

Die leitenden Organe der SED und KPD unterstützen die Tätigkeit der Anhänger der Neutralisierung Deutschlands und möchten sie zu aktiven Schritten gegen die Remilitarisierung bewegen.

Der Vorsitzende der Außenpolitischen

Kommission des ZK der VKP(b)

\author{
V. Grigorjan \\ /V. Grigor'jan/
}

15. März 1951

Nr. $25-\mathrm{S}-445^{173}$

${ }^{173}$ Links unten Eingangsstempel: S[ekretaria]t V. M. Molotov, „15“. III 1951. Eingangsn[ummc]r: M-3442ss. Daneben der handschriftliche Vermerk: „Zu den Akten. 17. 3.51.“ [Unterschrift unleserlich]. 


\section{Dokument 9}

RGASPI, f. 82, op. 2, d. 1348, S. 15-21, 28.3.1951

\section{Kurzer Bericht über den „Schuman-Plan“}

Der „Schuman-Plan“ ist ein Vertrag über die Gründung einer „Europäischen Stahl- und Kohlevereinigung“, der am 19. März d. J. in Paris von den Vertretern von sechs Ländern Frankreichs, Westdeutschlands, Italiens, Belgiens, Hollands und Luxemburgs - unterzeichnet wurde und stellt den Plan der Gründung einer übermonopolistischen Vereinigung der Kohle- und Metallindustrie dieser Länder unter der faktischen Kontrolle der amerikanischen Monopole dar. Die materielle Grundlage dieses Planes ist die Verbindung der französischen Erzindustrie mit der westdeutschen Kohle- und Metallindustrie.

In wirtschaftlicher Hinsicht wird diese Vereinigung durch folgende Kennzeichen charakterisiert:

Der Kohleabbau umfasst in den Mitgliedsländern dieser Vereinigung im Jahr 1950 nach vorläufigen Angaben 217 Mio. Tonnen. Davon aus Westdeutschland - 111 Mio. Tonnen, in Frankreich - 51 Mio., Belgien - 28 Mio., Holland - 12 Mio., Italien - 1 Mio. und im Saarland - 14 Mio. Tonnen.

Die Stahlproduktion erreichte in diesen Ländern 1950 31,8 Mio. Tonnen. Hiervon in Westdeutschland - 12,1 Mio. Tonnen, Frankreich - 8,7 Mio., Belgien - 3,9 Mio., Holland 0,5 Mio., Italien - 2,3 Mio., Luxemburg - 2,4 Mio. und Saarland 1,9 Mio.

Die amerikanischen Monopolisten beabsichtigen, die Industrien der westeuropäischen Länder zum Zwecke der Wiedererrichtung des militärisch-industriellen Potentials Westdeutschlands und Anpassung der Wirtschaft der Mitgliedsländer der Vereinigung an ihre aggressiven Pläne zur Vorbereitung eines dritten Weltkrieges auszunutzen und so in Westeuropa unter der Hegemonie der USA eine wirtschaftliche Basis des aggressiven Nordatlantikblocks zu schaffen. Unter dem Deckmantel einer solchen internationalen Vereinigung versuchen die amerikanischen Monopolisten ein breites Investitionsprogramm in der westdeutschen Industrie zu realisieren und ebenso eine nach außen für die französischen Regierungskreise annehmbarere Form der Einbeziehung Westdeutschlands und ihrer Wirtschaft in den aggressiven Nordatlantikblock zu schaffen. Gleichzeitig möchten die Regierungskreise der USA endgültig die Schwerindustrie des Ruhrgebiets von der Wirtschaft Deutschlands abtrennen und so mit den Potsdamer Beschlüssen in Bezug auf die wirtschaftlichen Prinzipien hinsichtlich Deutschlands brechen, ihre Kontrolle über Westdeutschland für den Fall festigen, dass das Besatzungsstatut aufgehoben werden muss und auch dem Bonner Staat den Anschein von Selbständigkeit und Ebenbürtigkeit zu gewährleisten und auf diese Weise seine Teilnahme am Nordatlantikblock erleichtern.

Die amerikanischen Monopolisten rechnen damit, ihre Vormachtstellung in der Europäischen Gemeinschaft für Kohle und Stahl zu sichern, indem sie dafür nicht nur die allgemeine politische und wirtschaftliche Abhängigkeit dieser Länder von den USA nutzen, sondern auch ihre unmittelbaren Beziehungen mit den europäischen Monopolisten.

Die amerikanischen Monopolisten haben umfangreiche Verbindungen mit deutschen und französischen (comité de forge) Monopolisten. Sie haben sogar spezielle Garantien für amerikanische Investitionen in der deutschen Industrie erreicht. In der geheimen Beilage zum Bonner Protokoll, das zwischen Adenauer und den Hohen Kommissaren im Novem- 
ber 1949 abgeschlossen wurde, sind spezielle Bedingungen für die Beteiligung amerikanischen Kapitals an Betrieben vereinbart, die aus den Listen der der Demontage unterliegenden Firmen ausgenommen wurden, vereinbart. Entsprechend diesen Bedingungen haben die Amerikaner das Recht zur Investition von 51\% des Grundkapitals in diesen Betrieben erhalten. In Zusammenhang damit schrieb das amerikanische Journal „Newsweek“ Ende 1949, dass die USA beabsichtigen, ein breites Investitionsprogramm in der westdeutschen Industrie zu verwirklichen und dass „dieses Kapital wahrscheinlich über Frankreich abgewickelt wird: auf diese Weise werden Bedingungen zur Vereinigung der französischen und deutschen Industrie geschaffen. Nach vorliegenden Hinweisen wird England zur Gänze von diesem Plan ausgeschlossen“. Auf solche Weise versuchen die amerikanischen Monopolisten über Beteiligung an deutschen und französischen Monopolen ihren Einfluss in der Vereinigung selbst zu gewährleisten.

Die amerikanischen Monopolisten nutzen dazu auch Kredite aus, die unmittelbar der neu geschaffenen Europäischen Gemeinschaft für Kohle und Stahl zur Verfügung gestellt werden. Diese Vereinigung wird selbstverständlich viel Kapital nötig haben, das ihr unter den gegenwärtigen Bedingungen nur die USA zur Verfügung stellen können. Der Vertrag über den „Schuman-Plan“ sieht die Möglichkeit vor, dass die Vereinigung internationale Anleihen und Kredite erhält.

Die USA nutzen zur Sicherung ihres Einflusses in der Vereinigung auch die Verwaltungsorgane dieser Vereinigung aus, die aus sogenannten unabhängigen Personen bestehen werden, die die amerikanischen Monopolisten an die Spitze der Vereinigung stellen werden, indem sie ihren Einfluss in der Industrie und in den Regierungskreisen der Mitgliedsländer des „Schuman-Planes“ nutzen.

\section{Die Position Englands}

Obwohl England aktives Mitglied des aggressiven Nordatlantikblocks ist, hat es sich dennoch nicht dem „Schuman-Plan“ angeschlossen. Das erklärt sich daraus, dass die englischen Führungskreise gegen die Vereinigung der deutschen Kohle mit dem französischen Metall eintreten, weil sie darin eine ernsthafte Bedrohung für die englische Metallurgie sehen.

Die englische Metallindustrie ist vom französischen Erz und von der Ruhrkohle unabhängig. Darüber hinaus ist England äußerst stark am Export der Produktion seiner Kohle- und Metallindustrie auf den Weltmarkt interessiert. Ein bedeutender Teil der Kohle und des Kokses, die für die französische Metallindustrie nötig sind, wird beispielsweise gegenwärtig aus England bezogen. England nimmt unter den westeuropäischen Ländern im Kohleabbau und in der Stahlerzeugung den ersten Platz ein. So erreichte im Jahr 1950 der Kohleabbau in England ungefähr 220 Mio. Tonnen, also mehr als der Kohleabbau aller sechs Länder, die sich dem "Schuman-Plan" angeschlossen haben, die Stahlerzeugung erreichte 15,5 Mio. Tonnen, also mehr als die Stahlerzeugung Westdeutschlands, von der Erzeugung der anderen Mitgliedsländer des „Schuman-Planes“ ganz zu schweigen.

Im Falle der Einbeziehung Englands in den „Schuman-Plan“ geht die Kontrolle über die englische Metall- und Kohleindustrie zum wirklichen Besitzer der Vereinigung des „SchumanPlanes“, den amerikanischen Monopolisten über, was die englischen Führungskreise wissen. Die englische Zeitung „Sunday Empire News“ schrieb am 11.Juni, dass mit dem „SchumanPlan“ ein „Generalangriff auf den Kohle- und Stahlmarkt Englands“ vorbereitet wird.

Ein Anschluss an den „Schuman-Plan“ würde für England den Verlust jener Vorteile bedeuten, die die englische Industrie [...] auf den Weltmärkten hat, und erleichtert eine wei- 
tere Einengung des englischen Kapitals und des englischen Einflusses insgesamt in den Ländern des britischen Imperiums durch die amerikanischen Monopolisten. Die Einschätzung des „Schuman-Planes“ betreffend schrieb Lord Beaverbrook am 26. Juni 1950 in der Zeitung „Daily Express“: [„]Das Ziel dieses Planes ist es, England zu zwingen, in der europäischen Wirtschaft unterzugehen. Die Folge dieses Planes würde der Verlust der Dominions und Kanadas sein und der Übergang ihrer Wirtschaften zum Wirtschaftssystem der Vereinigten Staaten."

\section{$\underline{\text { Widersprüche innerhalb der Mitgliedsländer des [Schuman-]Plans }}$}

Es gibt sogar ernsthafte Widersprüche unter den Mitgliedsländern des „Schuman-Plans“. Wirtschaftlich erklärt sich das damit, dass ganz starke Unterschiede in der technischen Ausrüstung der Industrie, in der Arbeitsproduktivität und in den Selbstkosten der Kohleproduktion und der Metallindustrie in diesen Ländern existieren. So beläuft sich der Preis einer Tonne Kohle in Belgien auf 13,7 Dol., in Frankreich auf 10,0 Dol. und in Westdeutschland auf 7,9 Dol. Der Preis einer Tonne Rohstahl beläuft sich in Frankreich auf 50,2 Dol., in Belgien auf 47,0 Dol. und in Westdeutschland auf 46,6 Dol.

Der „Schuman-Plan“ widerspricht den grundlegenden nationalen Interessen der Mitgliedsländer, da er die wirtschaftliche Grundlage der Unabhängigkeit und der Souveränität der westeuropäischen Länder untergräbt, indem ihnen die unmittelbare Verwaltung grundlegender Industriezweige wie die Kohle- und Metall[industrie] entzogen und sie in eine internationale Organisation überführt werden, die sich faktisch unter der Kontrolle des amerikanischen Kapitals befinden wird. Die amerikanischen Monopolisten werden hierbei ihre Bedingungen nicht nur in Bezug auf die Kohle- und Metallindustrie der westeuropäischen Länder diktieren, sondern auch in Bezug auf die Entwicklung anderer Industriezweige (Maschinenbau usw.) sowie den Transport und die Landwirtschaft, da diese Industriezweige von der Kohle- und Metallversorgung abhängig sind.

Die Widersprüche zwischen den westeuropäischen Ländern in Bezug auf den „SchumanPlan" sind derart gravierend, dass die Verhandlungen, die seit fast 10 Monaten andauern, unter Abbruchgefahr standen, und nur der Druck der USA diesen Abbruch gegenwärtig verhindert. Ein offener Bruch der Verhandlungen über den „Schuman-Plan“ wäre für die Regierungskreise der USA ungünstig, besonders angesichts des Umstands, dass die Verhandlungen der Vertreter der vier Mächte - der UdSSR, Englands, Frankreichs und der USA - über die Frage der Einberufung des Rates der Außenminister der vier Mächte zur Prüfung der Frage über die Remilitarisierung begonnen haben.

Die französischen Monopolisten rechnen damit, ebenso wie auch die deutschen Monopolisten, in der zu schaffenden Vereinigung eine Führungsrolle zu spielen, indem sie ihre Dienste dem amerikanischen Kapital zur Verfügung stellen. Die französischen und deutschen Monopolisten versuchten in den letzten Jahrzehnten kein einziges Mal im Kampf gegen die englische Metallindustrie eine Übereinkunft über eine Vereinigung der Kohleund Stahlindustrie Frankreichs und Deutschlands zu erreichen. Nunmehr wird dies von ihnen unter der Führung der amerikanischen Monopolisten verwirklicht.

Die Paraphierung des Vertrages über die Gründung der „Europäischen Gemeinschaft für Kohle und Stahl“ hebt die Widersprüche nicht auf, die zwischen den Mitgliedsländern des „Schuman-Planes“ bestehen. Die westdeutsche Kohle- und Metallindustrie, die über eine mächtige Produktionsbasis verfügt und die niedrigsten Selbstkosten hat, wird freilich die Abbaunormen und die Produktionspreise vorgeben. Dies wird zur Verschärfung der Wider- 
sprüche innerhalb der Vereinigung führen und ein Teil der französischen, belgischen und anderer Betriebe, wie unrentabler, wird mit Beschluss des „nationalen Organs“ geschlossen werden.

In den Kommentaren zum „Schuman-Plan“ in der amerikanischen Presse wurde darauf verwiesen, dass eine bedeutsame Erhöhung der Kohle- und Stahlproduktion in Westeuropa gegenwärtig in erster Linie durch den Beitrag Westdeutschlands erreicht werden könnte, da es über Ressourcen ungenutzter Produktionskapazitäten verfügt, die es nach der Meinung deutscher Experten erlaubten, im Laufe der nächsten Jahre eine jährliche Erhöhung der Stahlproduktion im Umfang von 3-4 Mio. Tonnen zu gewährleisten, was im Jahr 1952 einen Stahlschmelzertrag bis zu 18-20 Mio. Tonnen erlaubt. Im Jahr 1950 erreichte die Erhöhung der Stahlproduktion in Westdeutschland ungefähr 3 Mio. Tonnen. Eine solche Verstärkung der Metallindustrie in Westdeutschland wird zu einer Änderung der Kräftekonstellation innerhalb der Vereinigung zugunsten Westdeutschlands und zu einer weiteren Verschärfung der Widersprüche zwischen den Mitgliedsländern des „Schuman-Planes" führen.

\section{Der Wirkungsmechanismus des „Schuman-Planes“}

Der „Schuman-Plan“ sieht vor, dass an der Spitze der Vereinigung der Kohle- und Stahlindustrie der westeuropäischen Länder ein in seiner Tätigkeit von den Regierungen dieser Länder unabhängiges „nationales Organ“ stehen wird. Dieses Organ wird aus einer Anzahl „kompetenter Personen“ von einer allgemeinen Versammlung von Vertretern der Länder gewählt. Entsprechend dem „Schuman-Plan“verzichten die in der Vereinigung vertretenen Länder auf ihre souveränen Rechte in Bezug auf die Kontrolle über Produktion und Abbau von Kohle, Eisenerz, Gusseisen und Stahl, ebenso auf die Festsetzung der Preise für diese Waren und auf die Kontrolle der Kapitalinvestitionen in die Kohle- und Metallindustrie und übergeben diese Rechte dem genannten „nationalen Organ“. Die Beschlüsse dieses „nationalen Organs“ werden für die Regierungen der Mitgliedsländer verbindlichen Charakter haben. In einzelnen Fällen kann der Ministerrat der Mitgliedsländer des [Schuman-] Plans mit einstimmigem Beschluss die Beschlüsse des „nationalen Organs“ aufheben.

Der „Schuman-Plan“ sieht die Schaffung eines einheitlichen Marktes für Kohle und Metall in den westeuropäischen Mitgliedsländern dieses Plans vor. Beabsichtigt sind die Aufhebung von Zollbarrieren, diskriminierenden Maßnahmen auf dem Gebiet der Tarife für den Transport, die Aufhebung von Doppelpreisen und ebenso ein Verbot der Gewährung von Subventionen oder anderer Hilfe für konkurrierende Staaten. Auf diese Weise wird versucht, mehr oder weniger einheitliche Bedingungen für die Kohle- und Metallindustrie im Rahmen eines großen Marktes zu schaffen, der ein Gebiet mit einer Bevölkerung von 150 Millionen Menschen erfasst.

Der „Schuman-Plan“ sieht einen bestimmten Zeitraum vor, im Laufe dessen der stetige Übergang von den gegenwärtig bestehenden nationalen Märkten hin zu einem einheitlichen Markt der Mitgliedsländer dieses Planes verwirklicht wird. Im Einklang damit wurde am 19. März d. J. neben dem Vertrag über die Gründung der „Europäischen Gemeinschaft für Kohle und Stahl“ auch eine Übereinkunft paraphiert, die die sukzessive Inkraftsetzung des Mechanismus des „Schuman-Plans“ vorsieht. So ist die Schaffung eines einheitlichen Marktes für Kohle innerhalb von 6 Monaten nach Ratifizierung des Vertrages und für Stahl innerhalb von 8 Monaten vorgesehen. Hierbei wird Belgien in einem Zeitraum von fünf Jahren nicht am gemeinsamen Markt für Kohle und Italien nicht an dem für Stahl teilnehmen. 
Bei der Vereinigung wird eine „Ausgleichskasse“ geschaffen, mit Hilfe derer Maßnahmen verwirklicht werden sollen, die der Schaffung einheitlicher technischer Bedingungen der Produktion und Arbeitsproduktivität in den verschiedenen Ländern, die durch den „Schuman-Plan " vereinigt werden, helfen. Große Aufmerksamkeit wird der Modernisierung der Produktion geschenkt werden, also der kapitalistischen Rationalisierung auf Kosten einer Verschlechterung der Lage der Arbeiterklasse. Aus dieser Kasse werden Betriebsinhaber, die zu hohen Kosten bei der Herstellung einheitlicher Preise eine bestimmte Entschädigung erhalten, produzieren. Diese Maßnahmen können natürlich nicht die Widersprüche innerhalb der Vereinigung aufheben.

Die gegenwärtig herrschenden Widersprüche zwischen den Mitgliedsländer des „Schuman-Plans", der Opposition Englands und auch der Protestbewegung gegen diesen gegen das Volk [gerichteten] Plan in den westeuropäischen Ländern werden große Schwierigkeiten bei der endgültigen Unterzeichnung des Vertrages durch die Minister über die Gründung der „Europäischen Vereinigung für Kohle und Stahl“ und bei der Bestätigung dieses Vertrages durch die Parlamente der Mitgliedsländer der Vereinigung hervorrufen.

Für den 12. April d. J. ist in Paris eine Außenministerkonferenz für die endgültige Unterzeichnung des Vertrages und der Übereinkunft anberaumt.

\section{Dokument 10}

RGASPI, f. 82, op. 2, d. 1348, S. 13f., 1. bzw. 3.4.1951

1. Der Vorschlag Gen. Puškins bezüglich des Auftretens der UdSSR (+ der DDR) in der Angelegenheit des „Schuman-Planes“ ist zu überdenken, da dieser „Plan“ auf die Remilitarisierung Westdeutschlands ausgerichtet ist (widerspricht den Potsdamer Beschlüssen usw.).

2. Solch ein Auftreten soll nicht aufgeschoben werden (wenn man von seiner ZweckmäBigkeit ausgeht). ${ }^{174}$

(3. Der Bericht von Gen. Arutjunjan sollte unter dem Gesichtsfeld des 1. Punktes ergänzt werden und entsprechend präzisiert den Politbüromitgliedern zugeschickt werden.)

\section{IV.51 V. Molotov ${ }^{175}$}

\section{Geheim.}

\section{$\underline{\text { An Genossen V. M. Molotov }}$}

Ich lege einen Bericht zur Frage des Schuman-Plans vor.

In Zusammenhang mit der Paraphierung des Vertrages über die Gründung der „Europäischen Gemeinschaft für Kohle und Stahl“ wandte sich das Außenministerium der UdSSR

\footnotetext{
174 Im Original: „esli ischodit' iz priznanija ego celesoobraznosti“.

175 Links unten die Aktennummer: Nr. 4213s/1. IV.51. Auf der Rückseite: „Beschluss am 3.IV. 51 geschickt an V. Zorin. Kravec".
} 
an unsere Botschafter in den Ländern, die den Vertrag paraphiert haben, sowie an unseren Botschafter in England mit der Bitte, Vorschläge zu machen, ob, wie und in welcher Form die Sowjetunion auf den oben genannten Vertrag reagieren sollte.

Unser Botschafter in Rom, Gen. Kostylev, und der Geschäftsträger in Brüssel, Gen. Požidaev, denken, dass mit keiner offiziellen Erklärung zum Schuman-Plan aufzutreten sei. Der Botschafter der UdSSR in London, Gen. Zarubin, und der Botschafter der UdSSR in Den Haag, Gen. Zaijcev, halten es für nötig, den Besatzungsmächten - USA, England und Frankreich - eine Protestnote zu schicken. Der politische Vertreter der UdSSR in Berlin, Gen. Puškin, hält es für nötig, sich mit einer Protestnote an die französische Regierung zu wenden und der Regierung der DDR zu raten, mit einer eigenen Erklärung zur Angelegenheit der Paraphierung des Entwurfes des Vertrages zum Schuman-Plan durch die Bonner Regierung aufzutreten. Gen. Pavlov übermittelte keine Vorschläge.

Das Außenministerium der UdSSR denkt seinerseits, dass es nicht zweckmäßig ist, gegenwärtig im Namen der Sowjetunion mit irgendeiner offiziellen Erklärung im Zusammenhang mit dem Schuman-Plan aufzutreten, da der Vertragsentwurf über die Gründung der „Europäischen Gemeinschaft für Kohle und Stahl“ lediglich durch Experten paraphiert wurde und dieser Entwurf [erst] am 12. April d. J. in Paris auf der Konferenz der Außenminister der sechs Mitgliedsländer des Schuman-Planes geprüft wird.

Dem Umstand Rechnung tragend, dass sich in Westdeutschland gegenwärtig eine Bewegung gegen die Remilitarisierung entfaltet, erscheint es dennoch zweckmäßig, der Regierung der DDR zu empfehlen, mit einer Erklärung zur Frage der Paraphierung des Vertragsentwurfes über die Gründung der „Europäischen Gemeinschaft für Kohle und Stahl“ durch die Bonner Regierung aufuutreten, in der die wahre Absicht dieses Planes entlarvt würde und in diesem Zusammenhang auch die Politik der Bonner Regierung.

Ich bitte um Ihre Anweisungen.

V. Zorin

1.IV.51

Nr. 152/V3

Für die Richtigkeit: Kravec

\section{Dokument 11}

RGASPI, f. 82, op. 2, d. 1334, S. 3-12, 5.4.1951

Kopie.

Geheim.

An Gen. I. V. Stalin

Hiermit lege ich einen kurzen Bericht über den „Schuman“-Plan vor, der von der Wirtschaftsabteilung des Außenministeriums der UdSSR vorbereitet wurde. Aus dem besagten Bericht geht hervor, dass der „Schuman“-Plan mit der Remilitarisierung Westdeutschlands zusammenhängt und eine grobe Verletzung des Potsdamer Abkommens im Hinblick auf die Grundsätze der Wirtschaftspolitik gegenüber Deutschland darstellt. 
Vorschläge betreffend unsere Reaktion auf diese Maßnahme der westlichen Staaten werden vom Außenministerium zusätzlich vorgelegt.

\section{April 1951}

Nr. $\underline{48 / 3 \mathrm{~K}}$

Für die Richtigkeit: N. Voinov

Erging an die Gen. Molotov, Malenkov, Berija, Mikojan, Kaganovič, Bulganin, Chruščev

\section{Kurzer Bericht über den „Schuman-Plan“}

Der „Schuman-Plan“ ist ein Vertrag über die Gründung der „Europäischen Gemeinschaft für Kohle und Stahl“, der am 19. März dieses Jahres von den Vertretern der sechs Länder Frankreich, Westdeutschland, Italien, Belgien, Holland und Luxemburg in Paris paraphiert wurde. Es ist der Plan einer supermonopolistischen Gemeinschaft der Stahl- und Kohleindustrie dieser Länder unter der faktischen Kontrolle amerikanischer Monopolgesellschaften. Die materielle Grundlage dieses Plans stellt die Kombinierung der französischen Stahlindustrie mit der westdeutschen Stahl- und Kohleindustrie dar.

Unter dem wirtschaftlichen Aspekt besitzt diese Gemeinschaft folgende Merkmale.

Nach vorläufigen Angaben betrug die Kohleförderung in den Mitgliedsländern der Gemeinschaft 1950217 Mio. Tonnen. Darunter in Westdeutschland - 111 Mio. T., in Frankreich - 51 Mio., Belgien - 28 Mio., Holland - 12 Mio., Italien - 1 Mio., im Saargebiet - 14 Mio. T.

Die Stahlproduktion in diesen Ländern betrug 1950 31,8 Mio. T. Darunter in Westdeutschland - 12,1 Mio. T., in Frankreich - 8,7 Mio., Belgien - 3,8 Mio., Holland - 0,5 Mio., Italien - 2,3 Mio., Luxemburg - 2,4 Mio. und im Saargebiet - 1,9.

Mithilfe dieser Gemeinschaft der Kohle- und Stahlindustrie der westeuropäischen Länder bezwecken amerikanische Monopolgesellschaften den Wiederaufbau des Rüstungspotentials Westdeutschlands, die Anpassung der Volkswirtschaften der Mitgliedsländer an ihre aggressiven Pläne zur Vorbereitung eines dritten Weltkrieges sowie die Schaffung der wirtschaftlichen Basis für den unter der amerikanischen Hegemonie stehenden aggressiven Nordatlantischen Block in Westeuropa.

Die Anhänger des „Schuman-Planes“ selbst verheimlichen den militärischen Zweck der Gemeinschaft für Kohle und Stahl der westeuropäischen Länder nicht. Bekannt ist die Aussage von Schuman aus dem Jahr 1950 an Bord der „Ile de France“ vor der Abreise aus New York. Damals sagte Schuman, laut dem Bericht der Zeitung „[Le] Monde“, dass „der Plan der Gemeinschaft der Stahl- und Kohleressourcen europäischer Länder einen Weg für die militärische Zusammenarbeit für die daran interessierten Länder - Deutschland, Frankreich, Italien, Belgien, Holland und Luxemburg - öffnen kann“. 
In seiner Ansprache vor den Vertretern westeuropäischer Industrieunternehmen und Banken in Düsseldorf erklärte der amerikanische Oberkommissar McCloy, dass „der Schuman-Plan ein wichtiger Beitrag zur Gewährleistung der europäischen Sicherheit ist.

\section{Die Einstellung der USA}

Unter dem Deckmantel der EGKS versuchen die regierenden Kreise Amerikas eine für die französischen Regierungskreise akzeptable Form zu schaffen, die auf die Eingliederung Westdeutschlands mit seiner Industrie in den aggressiven Nordatlantischen Block hinausläuft. Dabei soll die Gemeinschaft dem Bonner Staat den Anschein der Selbstständigkeit und Gleichberechtigung verleihen und seine Beteiligung am Nordatlantischen Block erleichtern. Gleichzeitig beabsichtigen die Regierungskreise der USA eine endgültige Trennung der Schwerindustrie des Ruhrgebietes von der deutschen Wirtschaft, womit sie den Potsdamer Vertrag in punkto der Grundsätze der Wirtschaftspolitik gegenüber Deutschland endgültig beenden und ihre Kontrolle über Westdeutschland festigen werden, falls es zur Abschaffung des Besatzungsstatuts kommt.

Amerikanische Monopolgesellschaften beabsichtigen ferner, ihre hegemoniale Position in der EGKS zu sichern, indem sie zu diesem Zweck nicht nur die gesamtpolitische und wirtschaftliche Abhängigkeit dieser Länder von den USA, sondern auch ihre eigenen direkten Verbindungen mit den europäischen Monopolgesellschaften ausnutzen.

Die amerikanischen Monopolgesellschaften verfügen über weitgehende Verbindungen zu den deutschen und französischen Monopolgesellschaften (comité de forge). Sie haben sogar besondere Garantien für amerikanische Kapitalinvestitionen in der deutschen Wirtschaft erreicht. Die geheime Anlage zu dem zwischen Adenauer und dem Hohen Kommissar im November 1949 unterzeichneten Bonner Protokoll enthält Klauseln über besondere Konditionen der amerikanischen Kapitalbeteiligung an den aus der Demontageliste entfernten Betrieben. Nach diesen Konditionen haben die Amerikaner das Recht auf Investitionen von $51 \%$ des Grundkapitals dieser Betriebe erhalten. In diesem Zusammenhang berichtete die Zeitschrift „Newsweek“ Ende 1949, dass die USA die Realisierung eines breit angelegten Programms von Kapitalinvestitionen in die westdeutsche Wirtschaft planen, und dass „diese Kapitalmengen wahrscheinlich über Frankreich transferiert werden, womit Bedingungen für die Zusammenführung der französischen und der deutschen Wirtschaft geschaffen werden. Offenbar wird England von diesem Plan völlig ausgeschlossen sein." Auf diese Weise werden sich die amerikanischen Monopolgesellschaften bemühen, durch die Beteiligung an den deutschen und französischen Monopolgesellschaften ihren Einfluss innerhalb der Gemeinschaft selbst zu sichern.

Die amerikanischen Monopolgesellschaften benutzen zu diesem Zweck auch Kredite, die unmittelbar der neu gegründeten Europäischen Gemeinschaft für Kohle und Stahl zur Verfügung gestellt werden. Diese Gemeinschaft wird natürlich auf große Kapitalinvestitionen angewiesen sein, die nur durch die USA bereitgestellt werden können. Mit dem Vertrag über den „Schuman-Plan“ ist auch die Möglichkeit vorgesehen, internationale Anleihen und Kredite zu erhalten.

Zur Sicherung ihres Einflusses innerhalb der Gemeinschaft benutzen die USA auch die Führungsorgane der Gemeinschaft, die aus sog. „unabhängigen“ Personen bestehen sollen, d.h. im Grunde aus Personen, die von amerikanischen Monopolgesellschaften an die 
Spitze der Gemeinschaft gesetzt werden, indem diese ihren Einfluss in den Industrie- und Regierungskreisen der Mitgliedsländer des „Schuman-Planes“ geltend machen.

\section{Die Position Englands}

Trotz seiner aktiven Mitgliedschaft im aggressiven Transatlantischen Block ist England dem „Schuman-Plan“ nicht beigetreten. Dies erklärt sich daraus, dass die englischen Führungskreise gegen die Gemeinschaft der deutschen Kohle mit dem französischen Stahl auftreten, weil sie darin eine ernsthafte Gefahr für die englische Stahlindustrie sehen.

Die englische Stahlindustrie ist von dem französischen Erz und von der Kohle aus dem Ruhrgebiet unabhängig. England ist vielmehr selbst am Export eigener Stahl- und Kohleproduktion auf den Weltmarkt interessiert. Derzeit stammt z. B. ein erheblicher Anteil der für die französische Stahlindustrie notwendigen Kohle und des Kokses aus England. Gemessen an der Kohleförderung und Stahlproduktion liegt England unter den westeuropäischen Staaten an 1. Stelle. So betrug 1950 die geförderte Kohlemenge ca. 220 Mio. Tonnen, d.h. mehr als die Gesamtmenge der Kohleförderung aller sechs dem „Schuman-Plan“ beigetretenen Staaten. Die Menge der Stahlproduktion betrug 16,5 Mio. T., d.h. mehr als die Stahlproduktion Westdeutschlands, geschweige denn die Stahlproduktion anderer Staaten, die Mitglieder des „Schuman-Plans“ sind.

Im Falle des Beitritts Englands zum „Schuman-Plan“ geht die Kontrolle über die englische Stahl- und Kohleindustrie an die wahren Drahtzieher der Gemeinschaft nach dem „Schuman-Plan“ - an amerikanische Monopolgesellschaften über, was den Führungskreisen Englands wohlbekannt sein müsste. Die englische Zeitung "Sunday Empire News“ schrieb am 11.Juni, dass mit dem „Schuman-Plan“ ein Generalangriff auf den englischen Stahlexportmarkt vorbereitet wird.

Der Beitritt zum Schuman-Plan führt England zum Verlust jener Vorteile, die die englische Industrie dank des Systems der Präferenzen auf den imperialen Märkten genießt, und würde ferner die Verdrängung des englischen Kapitals und generell des englischen Einflusses aus den Ländern des Britischen Imperiums durch amerikanische Monopolgesellschaften begünstigen. In seiner Einschätzung des "Schuman-Plans" schrieb Lord Beaverbrook am 26. Juni 1950 in der Zeitung „Daily Express“: „Das Ziel dieses Plans ist es, England zu zwingen, in der europäischen Wirtschaft unterzugehen. Dies könnte zum Verlust der Dominions und Kanadas führen sowie zum Übergang zum Wirtschaftssystem der USA.“

\section{Widersprüche zwischen den Mitgliedsstaaten}

Zwischen den Mitgliedsländern des „Schuman-Plans“ bestehen ernsthafte Widersprüche. Wirtschaftlich kann man sie damit erklären, dass es ziemlich krasse Unterschiede im technischen Entwicklungsstand der Industrie, in der Produktivität und in dem Selbstwert der Stahl- und Kohleproduktion in diesen Ländern gibt. So liegt der Durchschnittspreis einer Tonne Kohle in Belgien bei 13,7, in Frankreich - bei 10,1 und in Westdeutschland bei 7,9 Dollar. Der Preis einer Tonne Rohstahls liegt bei 50,2 Dollar in Frankreich, bei 47,0 Dollar in Belgien und 46,6 Dollar in Westdeutschland.

Der „Schuman-Plan“ widerspricht den ureigenen nationalen Interessen der Mitgliedsstaaten, weil er die wirtschaftliche Grundlage der Unabhängigkeit und Souveränität der westeuropäischen Staaten untergräbt, indem er die Schlüsselzweige der Industrie - Stahlund Kohleindustrie - ihrer unmittelbaren Kontrolle entzieht und sie auf eine internationa- 
le Organisation überträgt, die de facto durch das amerikanische Kapital kontrolliert wird. Die amerikanischen Monopolgesellschaften werden dabei ihre Spielregeln nicht nur bezüglich der Stahl- und Kohleindustrie der westeuropäischen Staaten, sondern auch im Hinblick auf die Entwicklung anderer Industriezweige (Maschinenbau u.a.), des Verkehrswesens und der Landwirtschaft diktieren, da diese Wirtschaftsbereiche auf die Stahl- und Kohleversorgung angewiesen sind.

Die Widersprüche zwischen den westeuropäischen Staaten bezüglich des „SchumanPlans" sind so ernst, dass die bereits 10 Monate andauernden Verhandlungen kurz vor dem Abbruch standen. Nur durch Druck der USA gelang es, diesen Abbruch derzeit abzuwenden. Der offene Abbruch der Verhandlungen über den „Schuman-Plan“ wäre für die amerikanischen Regierungskreise ungünstig, besonders nach dem Beginn der Verhandlungen zwischen den Vertretern der vier Staaten - der UdSSR, Englands, Frankreichs und der USA - über die Einberufung eines Außenministerrates dieser Staaten, der die Frage der Demilitarisierung Deutschlands behandeln sollte.

Sowohl die französischen als auch die deutschen Monopolgesellschaften rechnen damit, in der neu gegründeten Gemeinschaft eine führende Rolle zu spielen, indem sie ihre Dienste dem amerikanischen Kapital anbieten. Im Kampf gegen die englische Metallindustrie versuchten die französischen und deutschen Monopolgesellschaften mehrmals eine Vereinbarung über die Gemeinschaft der Kohle- und Stahlindustrie Frankreichs und Deutschlands zu treffen. Nun wird sie unter der Aufsicht amerikanischer Monopolgesellschaften realisiert.

Die Paraphierung des Vertrages über die Gründung der „Europäischen Gemeinschaft für Kohle und Stahl“ beseitigt nicht die zwischen den Mitgliedsstaaten des "Schuman-Plans“ bestehenden Widersprüche. Die westdeutsche Kohle- und Stahlindustrie, die über die größte Produktionskapazität verfügt und den niedrigsten Produktionswert aufweist, wird die Normen der Kohleförderung und die Preise vorgeben. Dies wird zur Verschärfung der Widersprüche innerhalb der Gemeinschaft führen; ein Teil französischer, belgischer und anderer Betriebe werden als unrentable Betriebe aufgrund der Entscheidung eines „supranationalen Organs" geschlossen werden.

In den Kommentaren der amerikanischen Presse zum „Schuman-Plan“wurde darauf hingewiesen, dass eine wesentliche Steigerung der Stahl- und Kohleproduktion in Westeuropa derzeit nur dank Westdeutschland erreicht werden kann, da es über unverbrauchte Produktionsressourcen verfügt. Nach der Einschätzung deutscher Experten erlauben sie in den nächsten Jahren einen jährlichen Zuwachs in Höhe von 3-4 Mio. T. Stahlproduktion, was 1952 zu einer Gesamtstahlproduktion von 18-20 Mio. T. führen würde. 1950 lag der Zuwachs der Stahlproduktion in Deutschland bei 3 Mio. T. Eine solche Verstärkung der Stahlindustrie Westdeutschlands wird eine Verschiebung des Kraftverhältnisses innerhalb der Gemeinschaft zugunsten Deutschlands und eine weitere Verschärfung der Widersprüche zwischen den Mitgliedern des „Schuman-Plans“ zur Folge haben.

\section{Der Wirkungsmechanismus des „Schuman-Plans“}

Der Schuman-Plan sieht an der Spitze der Gemeinschaft der Kohle- und Stahlindustrie westeuropäischer Länder ein von den Regierungen dieser Länder unabhängig agierendes „supranationales Organ“ vor. Dieses Organ wird aus dem Kreise „kompetenter Personen“ auf der Generalversammlung der Länderrepräsentanten gewählt. Laut dem „SchumanPlan“verzichten die Mitgliedsländer der Gemeinschaft auf die souveränen Kontrollrechte 
über die Produktion und über den Absatz von Kohle, Eisenerz, Roheisen und Stahl, ferner über die Preisbestimmung für diese Warengruppe sowie auf die Kontrolle über die Kapitalinvestitionen in die Kohle- und Stahlindustrie, indem sie diese Rechte an das besagte „supranationale Organ“ übergeben. Die Entscheidungen dieses „supranationalen Organs“ haben für die Regierungen der Mitgliedsländer einen verbindlichen Charakter. In Einzelfällen kann der Ministerrat der Mitgliedsländer mit einem einstimmigen Beschluss die Entscheidung des „supranationalen Organs“ aufheben.

Mit dem „Schuman-Plan“ soll in den westeuropäischen Mitgliedsstaaten ein gemeinsamer Markt für Kohle und Stahl geschaffen werden. Damit sind die Aufhebung der Zollbarrieren, Diskriminierungsmaßnahmen im Bereich der Transporttarife, der Doppelpreise, und auch das Verbot der Subventionshilfe für die den Wettbewerb praktizierenden Staaten gemeint. Auf diese Weise sollen im Rahmen eines großen, ein Gebiet mit 150 Mio. Einwohnern umfassenden Marktes mehr oder weniger gleiche Bedingungen für die Kohle- und Stahlindustrie geschaffen werden.

Der „Schuman-Plan“ sieht eine Übergangsfrist für eine allmähliche Fusionierung von bestehenden nationalen Märkten zu einem gemeinsamen Markt der Mitgliedsstaaten vor. Angesichts dessen wurde am 19. März dieses Jahres neben dem Vertrag über die Gründung einer „Europäischen Gemeinschaft für Kohle und Stahl“ ein Abkommen paraphiert, das ein sukzessives Inkrafttreten des Mechanismus des "Schuman-Plans“ vorsieht. So ist die Schaffung eines gemeinsamen Marktes für Kohle nach 6 Monaten und für Stahl nach 8 Monaten ab der Vertragsratifizierung geplant. Dabei wird Belgien 6 Monate an dem gemeinsamen Markt für Kohle, und Italien 8 Monate an dem gemeinsamen Markt für Stahl nicht teilnehmen.

Innerhalb der Gemeinschaft wird eine „Ausgleichskasse“ entstehen, mit deren Hilfe Maßnahmen zur Schaffung von gleichen technischen Produktions- und Produktivitätsbedingungen in verschiedenen Mitgliedsländern des „Schuman-Plans“ realisiert werden. Ein besonderes Augenmerk gilt der Modernisierung, d.h. der kapitalistischen Rationalisierung der Produktion, die auf Kosten der Arbeiterklasse umgesetzt werden bzw. die Verschlechterung ihrer Lage zur Folge haben wird. Bei einheitlichen Preisen werden aus dieser Kasse die Besitzer derjenigen Betriebe entschädigt, die zu hohen Selbstkosten produzieren. Diese Maßnahmen können die innerhalb der Gemeinschaft bestehenden Widersprüche nicht beseitigen.

Die derzeit zwischen den Mitgliedsländern des „Schuman-Plans“ bestehenden Widersprüche, die Gegenposition Englands sowie die Protestbewegung in den westeuropäischen Ländern gegen diesen volksfeindlichen Plan werden zu großen Komplikationen bei der endgültigen Unterzeichnung des Vertrages über die Gründung der „Europäischen Gemeinschaft für Kohle und Stahl" durch die Minister und bei der Ratifizierung dieses Vertrages durch die Parlamente der Mitgliedsländer führen.

Für den 12. April ist in Paris eine Außenministerkonferenz zur endgültigen Unterzeichnung des Vertrages und Abkommens anberaumt. Es sollen noch ungelöste Fragen behandelt werden, unter anderem die der Anteile der einzelnen Länder im System des „Schuman-Plans“, der Abschaffung des internationalen Organs für das Ruhrgebiet und des Sitzes der Verwaltung, die im „Schuman-Plan“ vorgesehen sind.

\section{Der „Schuman-Plan“ widerspricht dem Potsdamer Abkommen}

Der „Schuman-Plan“ widerspricht scharf den wirtschaftlichen Richtlinien des Potsdamer Abkommens im Zusammenhang mit Deutschland. Das Potsdamer Abkommen sieht die 
Liquidierung des deutschen Rüstungspotentials vor und lenkt das Hauptaugenmerk auf die Entwicklung der zivilen Industrie Deutschlands. Dabei unterliegt die Stahlerzeugung strenger Kontrolle und Einschränkungen gemäß dem von den vier Staaten gebilligten Niveau des zivilen Bedarfes Deutschlands. Der „Schuman-Plan“ hat dagegen die Wiederherstellung des Rüstungspotentials Westdeutschlands zum Hauptziel.

Die Besatzungsmächte treffen schon jetzt praktische Maßnahmen zur Reorganisierung der Ruhrindustrie gemäß dem „Schuman-Plan“. Am 3. April haben die Besatzungsmächte der drei Westmächte die Bonner Regierung über eine neue Kontrollrichtlinie für die Industrie informiert, die die Einschränkungen für die westdeutsche Industrieproduktion aufhebt und die Rüstungsproduktion zulässt. Es wurde eine Menge der Stahlproduktion erlaubt, die die früher bestimmte Quote von 11,1 Mio. T. pro Jahr übersteigt, weil sie den "gemeinsamen Anstrengungen“ des Westens zur Kriegsvorbereitung entspricht.

Diese Maßnahmen zur Remilitarisierung der westdeutschen Wirtschaft zeigen, dass die französische und englische Regierung vor den Forderungen der USA in dieser Frage endgültig kapituliert haben. Die Regierungskreise der USA beschleunigen damit die Wiederherstellung des Rüstungspotentials Westdeutschlands und verletzen damit grob die internationalen Verpflichtungen im Sinne des Potsdamer Abkommens.

4. April 1951

Arutjunjan

\section{Dokument 12}

RGASPI, f. 82, op. 2, d. 1334, S. 13-20, 11.5. 1951

An Genossen V. M. Molotov

Ich lege Ihnen einen Informationsbericht über die Lage in der Sozialdemokratischen Partei Deutschlands vor, der im Auftrag der Außenpolitischen Kommission ZK VKP(b) erstellt wurde.

Der Vorsitzende der Außenpolitischen

Kommission des ZK der VKP(b)

/V. Grigor’jan/ V. Grigorj’an

„11“. Mai 1951

Nr. 25-S-835

$\underline{\text { Streng geheim }}$

$\underline{\text { Informationsbericht }}$

Über die Lage in der Sozialdemokratischen Partei Deutschlands

Die Sozialdemokratische Partei ist die größte Partei Westdeutschlands. Sie hat 736000 Mitglieder, von denen die Hälfte Arbeiter sind. Die Partei besteht aus 21 Bezirks- und 9000 lo- 
kalen Basisorganisationen. Der Zentralvorstand besteht aus 30 Mitgliedern, das Sekretariat aus 6 Personen. Der Vorsitzende der Partei ist Kurt Schumacher, sein Stellvertreter Erich Ollenhauer. Die SPD gibt 23 Zeitungen mit der Gesamtauflage von mehr als 2,5 Mio. Exemplaren heraus. Das Zentralorgan der Partei ist die Zeitung „Vorwärts“, ihre theoretische Zeitschrift „Das sozialistische Jahrhundert“.

Bei den Bundestagswahlen 1949 hat die SPD 29,2\% Stimmen bekommen und wurde somit zur zweitgrößten Partei des Bundestages. Bei den Landtagswahlen 1950 und 1951 haben die Sozialdemokraten 27 bzw. 36\% aller Stimmen erhalten, in Westberlin 44,7\%. Im Vergleich zu den Landtagswahlen 1949 hat die SPD zwischen 5 und 12\% Stimmen zugunsten neofaschistischer Parteien verloren. Unter dem Einfluss der SPD stehen: „Deutscher Gewerkschaftsbund“- 5 Mio. Mitglieder, „Sozialistische Arbeiterjugend“- 300 Tausend Mitglieder, „Sportjugend“- 400 Tausend Mitglieder und die Organisation „Falken“ - 150 Tausend Mitglieder.

Die SPD besitzt kein politisches Programm und orientiert sich in ihren Programmrichtlinien am „demokratischen Sozialismus“ der englischen Labour-Party. Als Satzung der SPD gelten die 1946 verabschiedeten „Organisationsprinzipien“, die lediglich das Verfahren der Einberufung der Konferenzen und der Parteikongresse definieren. Die ganze innerparteiliche Arbeit wird durch einzelne Beschlüsse des Sekretariats des Zentralvorstands geregelt, was zuletzt zur Verstärkung der Diktatur der Schumacher-Clique innerhalb der Partei geführt hat.

\section{Die Politik der rechten Sozialdemokraten}

Formell hat sich die SPD zur Opposition gegenüber den bürgerlichen Parteien im Bundestag erklärt, de facto arbeitet sie mit ihnen voll zusammen. Fast alle volksfeindlichen Gesetze im Bundestag wurden unter aktiver Mitwirkung der rechten Sozialdemokraten beschlossen. Zusammen mit den bürgerlichen Parteien sind die Sozialdemokraten an allen Kommissionen und Ausschüssen der Bonner „Regierung“ beteiligt, manche führen sie direkt an. Die Führung der SPD unterstützt alle Maßnahmen der westlichen Besatzungsmächte und tritt offen gegen die Schließung eines Friedensvertrages auf der Basis des Potsdamer Abkommens sowie gegen den Abzug der Besatzungsmächte aus dem westdeutschen Gebiet auf.

Eine besonders reaktionäre Politik vertreten die rechten Sozialdemokraten in Fragen der deutschen Einheit, des Friedenskampfes und der Remilitarisierung Westdeutschlands. Zur Herstellung der deutschen Einheit fordern sie eine bedingungslose Unterordnung von „Ostdeutschland“ unter das Regime der Bonner „Regierung“ und die Durchführung gesamtdeutscher Wahlen unter der Aufsicht der Besatzungsmächte. Den einzigen Weg zur Friedenserhaltung sehen sie in der „Verstärkung der Militärmacht des Westens gegenüber dem Osten“. Die Schumacher-Anhänger befürworten den „Beitrag Westdeutschlands“ zur „Verteidigung des Westens“, seine Remilitarisierung unter Voraussetzung der „Garantien“ seitens der westlichen Staaten, der Gleichheit im Rahmen der Atlantischen Allianz, der Verstärkung der militärischen Präsenz der Besatzungsmächte auf dem westdeutschen Gebiet, die aggressive militärische Aktionen ostwärts der Oder ermöglichen würden.

Die Einstellung der rechten Sozialdemokraten in Fragen der Remilitarisierung ist in einem geheimen Memorandum Schumachers an Adenauer vom Februar dieses Jahres formuliert worden. Aus dem Memorandum geht hervor, dass das Ziel der Remilitarisierung in „der Schaffung einer Lage bestehen sollte, die dem Westen die Führung eines Angriffskrieges gegen die Sowjetunion und gegen die Länder der Volksdemokratie“ ermöglicht. 
Zum Zwecke der Remilitarisierung hält Schumacher Folgendes für notwendig: auf die Politik der freien Marktwirtschaft zu verzichten und eine staatliche Regulierung der westdeutschen Wirtschaft einzuführen; eine Finanzhilfe für die Remilitarisierung Westdeutschlands seitens der westlichen Staaten bereitzustellen; mächtige Streitkräfte der westeuropäischen Staaten auf dem westdeutschen Gebiet zu konzentrieren; die volle politische Gleichstellung Westdeutschlands innerhalb der Nordatlantischen Allianz zu erreichen; die Gleichstellung der westdeutschen Streitkräfte mit denen anderer westlicher Mitgliedsstaaten der Nordatlantischen Allianz zu erwirken.

Ohne diese Bedingungen, heißt es im Memorandum, führt die „Remilitarisierung dazu, dass sich Deutschland zu einem Kriegsschauplatz und einem Verteidigungsvorfeld des Westens verwandelt. Unter diesen Umständen wird die Kampfmoral und Kampfbereitschaft der deutschen Streitkräfte mangelhaft sein“. Man solle, behauptet Schumacher, das Interesse der westlichen Staaten am Militärpotential Deutschlands nutzen, um von ihnen die Erfüllung der Forderungen nach den Voraussetzungen für die Remilitarisierung zu erreichen.

Ihr grundsätzliches Einverständnis mit der Remilitarisierung haben die Schumacheristen während des Besuches gezeigt, den Ollenhauer General Eisenhower in Homburg abstattete. Hier wurde eine endgültige Vereinbarung zwischen Adenauer und der rechten Führung der SPD über eine gemeinsame Durchführung der Remilitarisierungspläne getroffen. Über die Ergebnisse dieser Beratungsrunde berichtete Schumacher in Heidelberg: „Die Sozialdemokratische Partei ist grundsätzlich zu einer Zwei-Parteien-Verteidigungspolitik bereit“. In zahlreichen Sitzungen hat er sich mehrmals aggressiv gegen die Deutsche Demokratische Republik geäußert, indem er behauptete: „Die Sozialdemokraten sind wieder bereit, Waffen zu tragen." „Wir sollen für jeden Quadratmeter im Osten kämpfen“. In seiner Rede im Bundestag am 9. März dieses Jahres hat Schumacher Adenauer voll darin unterstützt, dass es zwecks „internationaler Sicherheitsgarantien“ notwendig sei, das amerikanische Besatzungsregime auf das Gebiet der Deutschen Demokratischen Republik und auf die westlichen Gebiete Polens auszuweiten.

In ihrem Versuch, die laufende Remilitarisierung zu verdecken, haben die Schumacheristen zuletzt eine breite Propagandakampagne gegen die Sowjetunion und die Deutsche Demokratische Republik begonnen. Die Sozialdemokratische Presse ist voller Angriffe gegen die Sowjetunion. Die Schumacheristen organisieren regelmäßig Propagandakampagnen zur Verteidigung der Kriegsgefangenen und für die Rückkehr der Umsiedler in die Heimat. Alle diese Kampagnen sind von revanchistischen Forderungen begleitet. Zusammen mit Adenauer haben die rechten Sozialdemokraten aktiven Anteil an der Unterdrückung der Bewegung gegen die Remilitarisierung und für die Verbesserung der wirtschaftlichen Lage der Arbeiter und verhindern auf allen möglichen Wegen einheitliche Vorgehensweisen der Arbeiter. Die Schumacher-Anhänger unterstützen aktiv das von der Bonner Regierung verhängte Verbot der Durchführung einer Volksabstimmung gegen die Remilitarisierung. Sie haben direkte Kontrolle über die Gewerkschafts- und Jugendorganisationen übernommen und unterdrücken dort jede Bewegung für die Durchführung der Volksabstimmung.

Die rechten Sozialdemokraten haben jetzt intensive Aktivitäten zur Korrumpierung und moralischen Zersetzung breiter Bevölkerungsschichten entfaltet. Sie schaffen es, die wachsende Unzufriedenheit der Metall- und Bergarbeiter des Ruhrgebiets mittels der Verteilung amerikanischer Lebensmittelpakete und anderen Vergünstigungen niederzuhalten. Es ist ihnen gelungen, eine Entschädigung aller Opfer des Faschismus, darunter auch der Kommunisten zu erwirken, die eine Zahlung von 1 bis 3 DM für jeden Tag der Gefängnis- bzw. 
KZ-Haft vorsieht. Manche Personen haben bis 15 Tausend DM Entschädigungsgeld bekommen. Eine weitere Maßnahme betraf die Kriegsgefangenen, die für jeden Tag der Gefangenschaft je 1 Mark erhalten haben, sowie die Ausbezahlung hoher Renten an die Offiziere. Im großen Stil betreiben die Amerikaner die Bestechung von Gewerkschaftsfunktionären über die Auszahlung von finanzieller Unterstützung. Laut den Aussagen der Führung der Kommunistischen Partei Deutschlands haben diese Maßnahmen der Schumacheristen und der westlichen Besatzungsmächte breite Bevölkerungsschichten demoralisiert und ihren Kampfgeist geschwächt.

\section{Die wachsende Unzufriedenheit in den Reihen der SPD}

Die Politik der SPD-Führung hat eine sichtbare Unzufriedenheit unter vielen Mitgliedern und Funktionären der SPD hervorgerufen. Diese Unzufriedenheit ist gestiegen, nachdem Schumacher den Vorschlag der Kommunistischen Partei, gemeinsam gegen die Remilitarisierung vorzugehen, abgelehnt hatte. Laut der deutschen Presse haben in den letzten Monaten mehr als 160 Tausend Mitglieder aus Protest gegen die Politik Schumachers die Partei verlassen. Ihren Austritt aus der Partei haben viele mit der ,vagen Haltung der SPD-Führung in der Frage der Remilitarisierung“ und mit dem „Fehlen eines wirtschaftlichen und sozialpolitischen Programms in der SPD“ begründet.

Ein Großteil der Sozialdemokraten tritt aktiv gegen die Remilitarisierung und für die Verbesserung der wirtschaftlichen Lage der Arbeiter auf. In Hamburg, München, Dortmund und Hannover haben gemeinsame Konferenzen von Sozialdemokraten und Kommunisten stattgefunden, bei denen ein gemeinsamer Kampf gegen die Remilitarisierung beschlossen wurde. In vielen Industriezentren nehmen die Sozialdemokraten zusammen mit Kommunisten an der Bewegung für die Erhöhung der Löhne im Zusammenhang mit dem Preisanstieg teil. In einer Reihe von Fabriken des Ruhrgebietes, in Hamburg und München haben sie zusammen mit Kommunisten gemeinsame Aktionskomitees gegen die Remilitarisierung geschaffen. Häufig organisieren die Sozialdemokraten zusammen mit Kommunisten Versammlungen und Demonstrationen und fordern dabei das Ende der Remilitarisierung und die Verbesserung der wirtschaftlichen Lage der Arbeiter. Zahlreiche Funktionäre der SPD aus Nürnberg und Niedersachsen unterzeichneten zusammen mit Kommunisten Erklärungen an die Landesregierungen, in denen sie eine Volksabstimmung gegen die Remilitarisierung fordern.

Am 22. März dieses Jahres fand in Frankfurt am Main, initiiert durch die Organisation "Sozialdemokratische Aktion“, eine Konferenz oppositioneller Sozialdemokraten statt. An der Konferenz nahmen ca. 1000 SPD-Funktionäre aus ganz Westdeutschland teil. Die Konferenz empfing mehr als 1000 Grußworte, viele davon kamen von Basisorganisationen. Unter den Konferenzteilnehmern befanden sich SPD-Abgeordnete, Bürgermeister, Stadträte, Vorsitzende von SPD-Kreisverbänden, Gewerkschaftsfunktionäre, Betriebsratsvorsitzende, Vertreter der Jugendorganisation „Falken“.

Auf der Konferenz wurde die Lage Westdeutschlands diskutiert und die politische Führung durch Schumacher scharf kritisiert. Außerdem wurde ein Appell an alle Mitglieder der SPD beschlossen, der die Forderung nach einem gemeinsamen Kampf gegen die Remilitarisierung und für den Abschluss eines Friedensvertrages noch 1951 enthält. Die Konferenzteilnehmer haben ein ständiges „Aktionskomitee“ zur Durchführung der Volksabstimmung gegen die Remilitarisierung gewählt. 
Die Bewegung innerhalb der SPD hat eine große Besorgnis in der Parteileitung hervorgerufen. Im März und April dieses Jahres haben alle prominenten SPD-Führer mit Schumacher an der Spitze in allen großen Städten die Versammlungen des Parteiaktivs durchgeführt. Dabei erteilten sie eine Anweisung, jede Selbstorganisierung unzufriedener Parteimitglieder zur Opposition zu verhindern. Alle, die "gegen die Linie des Zentralvorstandes“ sind, sollen aus der Partei ausgeschlossen und isoliert werden. Nach diesen Versammlungen wurden viele Parteimitglieder, Funktionäre und Bürgermeister, insbesondere aus Nürnberg, aus der Partei ausgeschlossen.

\section{Die Verstärkung des amerikanischen Einflusses in der SPD}

Innerhalb der Partei findet ein andauernder Kampf zwischen den Anhängern der amerikanischen und englischen Orientierung in der Parteipolitik statt. Dieser Kampf hat bereits dazu geführt, dass die Führung der SPD auf Erstellung eines politischen Parteiprogramms verzichtete. Die proamerikanische Gruppierung (Schmidt, Brauer, Reuter u.a.) fordert eine offene Orientierung an den USA und die Unterstützung der amerikanischen Pläne, die proenglische (Schumacher, Ollenhauer u.a.) versuchen die Partei von einem offenen Kurs abzuhalten und bestehen darauf, im Geiste „der sozialdemokratischen Traditionen“ zu handeln, um „die Loslösung von der Arbeiterklasse“ zu verhindern.

Nach dem Hamburger Kongress der SPD im Mai 1950 gelang es der proamerikanischen Gruppierung, verstärkt durch einen eingefleischten amerikanischen Agenten, den Renegaten Wehner, die Schumacher-Führung zu einer offeneren US-Orientierung und zu einer engeren Zusammenarbeit mit der Adenauer-Regierung zu bringen. Die Schlüsselrolle spielte dabei Wehner, den die Amerikaner zum Vorsitzenden des Bundestagsausschusses für gesamtdeutsche Fragen gemacht haben. Kurz darauf hat die Schumacher-Führung den Forderungen der Amerikaner folgend, den Atlantischen Pakt, die Trennung des Saarlandes von Deutschland sowie den Beitritt Deutschlands zum Europarat, in dem die SPD-Abordnung eine beratende Stimme genießt, anerkannt.

Angesichts der wachsenden Unzufriedenheit zögert die Schumacher-Führung noch, den Ratschlägen der Labouristen folgend, mit einer offenen und bedingungslosen Zustimmung zu der Remilitarisierung Westdeutschlands, worauf wiederum die Amerikaner „zwecks Kräftekonsolidierung" drängen. Ebenfalls zögert Schumacher, die Position der Labouristen vertretend, mit einer offenen Zustimmung zum „Schuman-Plan“. Indem er die negative Einstellung des Volkes gegenüber der Remilitarisierung und dem „Schuman“-Plan nutzt, verfolgt Schumacher das Ziel, die Mehrheit in den Landtagen und im Bundestag zu gewinnen und die SPD somit zu einer regierenden Partei zu machen. Danach streben auch die Labouristen.

Im Dezember 1950 hat das Exekutivkomitee der Labour Party einen Geheimbrief an Schumacher übergeben. In diesem Brief wird darauf hingewiesen, dass die SPD angesichts der Ablehnung der Remilitarisierung diese Stimmung des Volkes nutzen sollte, um ihre Partei von einer oppositionellen zu einer regierenden Partei zu machen. Während sie gegen die Remilitarisierung auftritt, sollte die SPD-Führung dennoch mit der Beteiligung Westdeutschlands an einer Europaarmee grundsätzlich einverstanden sein. Dabei solle man die Gleichberechtigung fordern und ihre Bedeutung betonen, und nicht mit der Rolle einverstanden sein, die Westdeutschland von den Amerikanern und von Adenauer aufgezwungen wird. Die SPD sollte sich künftig nicht in dieser Angelegenheit die Hände binden lassen. Die Labouristen empfehlen den Schumacheristen eine vorzeitige Durchführung 
der Bundestagswahlen, um die für die SPD günstige Lage auszunutzen. Aus diesem Brief gehen Widersprüche zwischen den USA und England in der deutschen Frage hervor. Die amerikanischen Labouristen bemühen sich, über die SPD ihren Einfluss in Deutschland zu bewahren.

Die Schumacher-SPD-Führung hält sich genau an die Forderungen der Labouristen in der Frage der Remilitarisierung. Diese zweideutige Position konnte die Amerikaner und ihre Agenten nicht zufrieden stellen. Daher brachte Eisenhower nach seiner Rückkehr aus den USA nach Europa eine Anweisung für amerikanische Agenten mit, den Widerstand gegen die amerikanischen Pläne in der SPD zu überwinden und die ganze SPD und die Gewerkschaften Westdeutschlands auf die Seite der USA zu ziehen. Mit Schumacher wurde bei McCloy ein Gespräch geführt. Ollenhauer, Reuter und Suhr wurden in die USA eingeladen, wo sie mit den führenden amerikanischen Regierungsmitgliedern gesprochen haben. Bei seiner Rückkehr aus den USA sagte Ollenhauer der „Stimme Amerikas“, dass die Ziele der SPD-Führung die gleichen wie Eisenhowers seien. Zuletzt hat sich die Tätigkeit der amerikanischen Agenten innerhalb der SPD wesentlich verstärkt. Die Schumacher-Führung hat die Entscheidung getroffen, alle, die die „kommunistische Friedenskampagne“ unterstützen und sich an der „von der SED organisierten Volksabstimmung gegen die Remilitarisierung beteiligen“, zur Rechenschaft zu ziehen. Die gleiche Politik verfolgen die Schumacher-Anhänger auch in den Gewerkschaften.

\section{Dokument 13}

RGASPI, f. 82, op. 2, d. 1041, S. 151, 31.7.1951

Zorin: Teilt mit, dass McCloy im Gespräch mit Adenauer am 6.Juli d. J. [ihn] darüber informierte, dass die amerikanische Regierung mit der Verzögerung der Verhandlungen über die Gründung der westdeutschen Streitkräfte unzufrieden ist. Er wies darauf hin, dass die Regierung der USA die rasche Formierung westdeutscher Militärverbände trotz möglichen Widerstandes der Franzosen für unabdingbar hält.

Nach der Rückkehr aus Washington gab McCloy der französischen Regierung in der Alliierten Hohen Kommission zu verstehen, dass die USA an der schnellstmöglichen Beendigung der Pariser Verhandlungen über den „Plevenplan“ interessiert sind und dass, wenn im Laufe der nächsten Zeit diese Verhandlungen keine „entscheidenden Resultate“ bringen, die USA entschieden für eine unmittelbare Gründung einer westdeutschen Armee im Rahmen des Nordatlantikblockes eintreten werden.

Erging an alle Mitglieder des Achterkollegiums und an Gen. Gromyko

\section{Dokument 14}

RGASPI, f. 82, op. 2, d. 1041, S. 151, 31.7.1951

Zorin: Teilt mit, dass nach aus dem Verteidigungsministerium Englands stammenden Hinweisen die offene Umsetzung der Remilitarisierungspläne Westdeutschlands Ende 1951 begonnen werden soll. Im Falle einer Verschärfung der internationalen Lage werden unverzüglich die engen Begrenzungen der Waffenproduktion aller Art in Westdeutschland aufgehoben.

Erging an die Gen. Molotov und Gromyko 


\section{Dokument 15}

RGASPI, f. 82, op. 2, d. 1041, S. 153, 2.8.1951

Ogol'cov: Informiert über die feindliche Tätigkeit der westlichen Besatzungsmächte und der Bonner „Regierung“, die auf eine Verhinderung des internationalen Jugend- und Studentenfestivals in Berlin abzielt. Die Westmächte haben die Kontrolle über den Schienenund Automobiltransport verstärkt. Die antidemokratische Jugendorganisation „Vereinigung der deutschen Jugend im Ausland“ und die sog. „Kampfgruppe gegen Unmenschlichkeit" bereiten die Durchführung verschiedener Provokationen an den Tagen des Festivals an der Demarkationslinie und in Berlin selbst vor. Zu bemerken ist eine bedeutende Aktivierung der feindlichen Propaganda, besonders die Verbreitung antisowjetischer Literatur und Flugblätter auf dem Gebiet der DDR und in Berlin. Über deutsche Sicherheitsorgane wurden vom 20. bis zum 30. Juli 58 Menschen festgenommen, die Untergrundarbeit zum Zwecke der Vereitelung des Festivals durchführten.

(Erging an die Gen. Malenkov, Berija).

\section{Dokument 16}

RGASPI, f. 82, op. 2, d. 1041, S. 158, 8.8.1951

Zorin: Berichtet über die Verhandlungen zwischen der Bonner Regierung und der Alliierten Hohen Kommission in der Frage über die Aufhebung des Besatzungsstatuts mittels zweiscitiger Verträge. Der Vertreter der Bonner Delegation in den Verhandlungen mit der Alliierten Hohen Kommission in dieser Frage, Grewe, erklärte auf der Sitzung des Komitees für ausländische Angelegenheiten des Bundestages, dass nach seiner Meinung vom Abschluss „echter international-rechtlicher Verträge“, die der Ratifizierung der Parlamente unterliegen, die Rede ist. Er wies darauf hin, dass im Zentrum der Verhandlungen zwei Fragen stünden: der künftige Status der Alliierten Vertreter in Westdeutschland, die nach Meinung der Alliierten Hohen Kommission nach wie vor die „bekannten politischen Funktionen" beibehalten müssen und ein Vertrag über den Status der Alliierten Streitkräfte auf dem Gebiet Westdeutschlands. Der auf der Sitzung anwesende Adenauer brachte seine Meinung zum Ausdruck, dass es nötig sei, das Besatzungsrecht teilweise zu erhalten, „indem seine Bedeutung für das Verhältnis mit dem Osten berücksichtigt wird“. Die Frage betreffend, welche Rechte die Westmächte für sich behalten möchten, teilte Grewe mit, dass sie die Lage beibehalten möchten, in der jegliche Änderung des Grundgesetzes nur mit Zustimmung der entsprechenden Vertreter der Westmächte durchgeführt werden kann.

Erging an Gen. Stalin und die anderen Gen. des Achterkollegiums, ebenso an die Gen. Vyšinskij, Gromyko.

\section{Dokument 17}

RGASPI, f. 82, op. 2, d. 1041, S. 164, 15.8.1951

Zorin: Teilt mit, dass in den ersten Augusttagen d. J. in Straßburg eine Sitzung des Ministerkomitees des Europarates stattfand, auf der die Frage über die Notwendigkeit einer Aufnahme der Tätigkeit des Rates diskutiert wurde. Auf der Sitzung wurde vermerkt, dass sich die führenden Organe des Nordatlantik-Bündnisses und das Washingtoner Zentralorgan der 
internationalen Konferenz zur Verteilung von Rohstoffen mit allen wichtigsten Fragen des politischen und wirtschaftlichen Lebens der westeuropäischen Länder beschäftigen. Das Ministerkomitee verwies auf die Notwendigkeit, die Führungskreise der USA davon zu überzeugen, dass der Europarat in der Form eines Organs zur Koordinierung der Politik der westeuropäischen Länder auf dem Gebiet der Bewaffnung und einer Tribüne zur Vorbereitung der öffentlichen Meinung in einem künftigen Krieg erhalten bleiben muss. Es wurde beschlossen, eine Konferenz des Komitees mit einer Gruppe bedeutender Mitglieder des US-Kongresses einzuberufen, auf der [folgende] Fragen geprüft werden; die Beibehaltung der amerikanischen Hilfe für die westeuropäischen Staaten in den sog. zivilen wirtschaftlichen Bedürfnissen; die koordinierte Durchführung einiger spezieller Reformen durch die Regierungen der westeuropäischen Staaten mit dem Ziel der Schwächung der Effektivität der kommunistischen Propaganda; die Unterstellung der Organisation für europäische wirtschaftliche Zusammenarbeit unter den Europarat.

Erging an die Gen. Vyšinskij, Gromyko.

\section{Dokument 18}

RGASPI, f. 82, op. 2, d. 1041, S. 164, 15.8.1951

Zorin: Trägt Zeugnisse zur Frage der Schaffung eines neuen Gegenspionageorgans der Mitglieder des Nordatlantik-Bündnisses vor. Im Juli d. J. schlug das Kolonialministerium Belgiens vor, den sog. konsultativen Rat mit Sitz in Brüssel einzurichten, in dem Vertreter aller Mitgliedsländer des Nordatlantik-Bündnisses Aufnahme finden würden. Die Aufgabe des konsultativen Rates soll die Organisation des Kampfes gegen den kommunistischen Einfluss in Westeuropa und gegen die Bewegung der Friedensfreunde sein. Seiner Organisationstätigkeit beabsichtigt der konsultative Rat einen gesetzlichen Anschein zu geben, indem seine Maßnahmen unter der Losung „der Verteidigung der Sicherheit der Nationen" durchgeführt werden.

Erging an die Gen. Bulganin, Vyšinskij, Ignat'ev, Grigor’jan, Zacharov ${ }^{176}$

\section{Dokument 19}

RGASPI, f. 82, op. 2, d. 1041, S. 169, 1.9.1951

Zorin: Legt eine Niederschrift von Aussagen des Agitationsführers des Hauptausschusses für die Durchführung einer Volksabstimmung gegen die Remilitarisierung Westdeutschlands, Dickel, des Abteilungsleiters des Berliner Radios, Gessner, und des Sektorenleiters des ZK der SED, Kling, über einige Mängel der Propaganda der SED in Richtung auf Westdeutschland und der Propaganda der KPD in Westdeutschland vor. Gessner, Kling und Dickel verlautbarten, dass die politischen Umstände in Westdeutschland gegenwärtig die Durchführung von Propaganda der SED in Westdeutschland begünstigen. Diese Propaganda ist aber nach wie vor unzureichend operativ und offensiv und beschränkt sich im Wesentlichen auf passive Verteidigung. Sie berücksichtigt nicht die verschiedenen Schichten der westdeutschen Bevölkerung. (Erging an die Gen. Suslov, Grigor'jan). 


\section{Dokument 20}

RGASPI, f. 82, op. 2, d. 1041, S. 170, 1.9.1951

Zorin: Informiert, dass Mitte Juli d. J. der amerikanische Hohe Kommissar in Westdeutschland, McCloy, Paris besucht hat, wo er gemeinsam mit dem Botschafter der USA in Paris, Bruce, einen Kompromissplan zur Regulierung der Uneinigkeit zwischen Frankreich und Westdeutschland in der Frage der Schaffung einer „Europa-Armee“ erörterte. Nach diesem Plan soll anstelle eines westdeutschen Generalstabes ein „ziviler Organisationsstab“ geschaffen werden, der sich mit der Formierung und der Organisation der westdeutschen Streitkräfte beschäftigt. Dieser Vorschlag wurde von allen Teilnehmern der Verhandlungen angenommen. Nach Ende der Pariser Verhandlungen schickte Adenauer den Mitgliedern der Bonner Regierung ein Schreiben, in dem er darauf verwies, dass im Falle eines Entscheides der Außenminister der drei Westmächte auf der Washingtoner Konferenz zur Schaffung eigener Truppen durch Westdeutschland, die Bonner Regierung rasch ihre Bereitschaft, darauf einzugehen, offiziell erklären wird. Ein wichtiges Ergebnis der Pariser Verhandlungen, zeigte Adenauer auf, war der Vorschlag der Amerikaner, Westdeutschland "Sicherheitsgarantien“ zu geben. Nach Meinung Adenauers bedeutet die Gewährung dieser Garantien praktisch, dass die Westmächte die ganze Garantie der Verteidigung Westdeutschlands vor der „Aggression aus dem Osten“ auf sich nehmen. (Erging an Gen. Stalin und die anderen Genossen des Achterkollegiums, ebenso an die Gen. Vyšinskij, Vasil'evskij).

\section{Dokument 21}

RGASPI, f. 82, op. 2, d. 1041, S. 173, 2.9.1951

Zorin: Teilt mit, dass die Londoner Abteilung der Agentur United Press Ende Juli d. J. den vom State Department der USA inspirierten Bericht des Washingtoner Korrespondenten dieser Agentur, Roper, erhalten hat, in dem es heißt, dass Truman die Führung der amerikanischen Außenpolitik in seine Hände genommen und die Unstimmigkeiten zwischen dem State Department und dem Pentagon liquidiert hat, nachdem er den Standpunkt der militärischen Kreise übernommen hat, der davon ausgeht, dass ein Krieg unausweichlich und nahe ist und dass in der Außenpolitik die USA anstelle eines „Positionskrieges“ einen „Manöverkrieg“ führen soll. Roper führt in seiner Mitteilung Beispiele für die Durchführung des neuen Kurses in der Politik der USA an: das Verhalten der USA in den Verhandlungen um einen Waffenstillstand in Korea, die Mission Sherman in Spanien, die Mission Harrimans im Iran, das Aufstellen von Fristen in der Wiederaufrüstung Deutschlands. Nicht eine englische Zeitung hat diese Meldung publiziert.

Geschickt an die Gen. Molotov und Vyšinskij.

\section{Dokument 22}

RGASPI, f. 82, op. 2, d. 1041, S. 173, 2.9.1951

Zorin: Teilt mit, dass der Vizekanzler Westdeutschlands, Blücher, in einem persönlichen Gespräch im Juli d. J. erklärte, dass der Druck der Amerikaner auf die Regierung Adenauer in der Frage der Remilitarisierung ,in Westdeutschland alle Militaristen in Bewegung ge- 
setzt hat, die an der Remilitarisierung teilhaben wollen“. Blücher erklärte auch, dass der Aufbau von Handelsbeziehungen mit der DDR eine Notwendigkeit darstellt.

Erging an die Gen. Molotov, Vyšinskij und Grigor’jan

\section{Dokument 23}

RGASPI, f. 82, op. 2, d. 1041, S. 175, 5.9.1951

Zorin: Teilt mit, dass in Westdeutschland zur gegenwärtigen Zeit die praktische Vorbereitung zur Schaffung von Streitkräften abgeschlossen ist. Der Mitarbeiter des Apparates des ZK der SED, Haid, erzählte, dass die Bonner Regierung schon einen Entwurf für die Rekrutierung von Soldaten in die Armee ausgearbeitet hat. Es ist vorgesehen, 200000 Menschen in Landstreitkräfte und 50000 in die Luftwehr einzubeziehen. Eine gewisse Verzögerung der Schaffung der westdeutschen Streitkräfte erklärt Haid nicht nur mit den Unstimmigkeiten zwischen den Westmächten, sondern auch damit, dass die Amerikaner nicht von günstigen Reaktionen auf die Remilitarisierung von Seiten der westdeutschen öffentlichen Meinung überzeugt sind, besonders von Seiten ehemaliger Soldaten und Offiziere. Der ehemalige Oberleutnant der SS-Panzertruppen, Siemens, teilte mit, dass es unter der ehemaligen deutschen Generalität und Offizierskreisen aktive Befürworter der Remilitarisierung ${ }^{177}$ (die ehemaligen Generäle: Speidel, Heusinger u. a.), die Gruppe der „Abwartenden“ (die ehemaligen Generäle: Guderian, Halder, Hansen u.a., die nicht an der Remilitarisierung teilhaben möchten, wenn die Schaffung einer „nationalen deutschen Armee“ nicht erlaubt wird und die deutschen Militärs nicht zur Gänze „rehabilitiert“ werden) und die Gegner der Remilitarisierung ${ }^{178}$ (die ehemaligen Generäle und Offiziere: Heim, Schrank, Wenk u.a., die glauben, dass die Sowjetunion unbesiegbar ist, die amerikanische Armee ein untauglicher Verbündeter und befürchten, dass die Remilitarisierung Westdeutschlands zu einem Bürgerkrieg führt).

Der Vorsitzende des westdeutschen Komitees der Kämpfer für den Frieden [Friedenskomitee der BRD], Eckert, und seine Stellvertreterin, [Hoereth-]Menge, teilten mit, dass Niemöller über Noack eine Einladung übergeben wurde, im Oktober d. J. nach Jugoslawien zu kommen, um an der sog. „Internationalen Friedenskonferenz“ teilzunehmen. Eckert und Menge brachten ihre Meinung zum Ausdruck, dass es wünschenswert wäre, „die Initiative Noacks abzufangen" und Niemöller nach Moskau einzuladen.

Erging an alle Mitglieder des Achterkollegiums, ebenso an die Gen. Suslov, Vyšinskij, Vasilevskij und Grigor'jan.

\section{Dokument 24}

RGASPI, f. 82, op. 2, d. 1042, S. 1, 2. 1.1952

Ignat'ev: Legt einen Bericht über die Verhandlungen zwischen den Westmächten und der Bonner Regierung vor, die im November 1951 zur Frage über die politische „Regelung“ für Westdeutschland stattfanden. In dem Bericht heißt es, dass sich mit Anfang November 1951 im Zuge der Verhandlungen zwischen den Hohen Kommissaren und Adenauer über die

177 Von Molotov unterstrichen.

178 Von Molotov unterstrichen. 
Vorbereitung zweiseitiger Verhandlungen zwischen Westdeutschland und den Westmächten „ernste Schwierigkeiten“ ergaben. Nach der Vereinbarung nebensächlicher Punkte traten die grundlegenden, prinzipiellen Fragen in den Vordergrund, zu denen keine Übereinkunft erzielt wurde. Zu den nicht geklärten Fragen gehörten „die Souveränität" Westdeutschlands. Im Entwurf des „Generalvertrages“ behalten sie in einer Reihe von Punkten ihre Rechte als Besatzungsmächte und damit die Entscheidungsgewalt bei. Adenauer bestand im Zuge der Erörterung dieses Entwurfes mit den Hohen Kommissaren darauf, dass "die Sonderrechte“ in einer Reihe von Punkten den Westmächten nicht als Rechte von Besatzungsmächten, sondern als Vereinbarung zwischen der Bonner Regierung und den Regierungen der Westmächte behandelt würden. In der Frage der Ostgrenzen Deutschlands bestand Adenauer darauf, dass die Westmächte bis zu einer friedlichen Regelung offiziell ihre Unterstützung der revisionistischen Forderungen der Bonner Regierung im Zusammenhang mit den Gebieten, die nach dem Krieg von Deutschland an die UdSSR und Polen übergingen, erklärten. Die Hohen Kommissare erklärten, dass diese Frage nur in einem Friedensvertrag geregelt werden kann. Betreffend die Frage über den „finanziellen Beitrag“ Westdeutschlands zur „Verteidigung des Westens“ traten die Westmächte mit der Forderung auf, dass Westdeutschland mehr als die Besatzungskosten von 13 Milliarden Mark für die Schaffung und Erhaltung seiner Streitkräfte aufbringt. Der Vertreter der Bonner Regierung erklärte, dass Westdeutschland diese Ausgaben nicht selbst wird zahlen können. Die Vertreter der Bonner Regierung forderten darüber hinaus die vollständige Aufhebung aller Begrenzungen und jeglicher Kontrolle auf dem Gebiet der industriellen Produktion.

Erging an die Gen. Stalin, Malenkov, Berija, Mikojan, Chruščev, Gromyko.

\section{Dokument 25}

RGASPI, f. 82, op. 2, d. 1042, S. 25, 27.1. 1952

Ignat'ev: Teilt mit, dass auf der Sitzung des Bonner Kabinetts am 18. Dezember 1951 Adenauer die Notwendigkeit hervorhob, den Abschluss des „Vertrages über die europäische Verteidigung" maximal zu beschleunigen. Er begründete dies damit, dass die Gefahr eines Auftretens der Sowjetunion mit „einem neuen verlockenden Vorschlag“ bestünde, der im letzten Moment Unruhe und Störung sowohl in Washington als auch in Paris erzeugen könnte. Nach der Meinung Adenauers und McCloys kann dieser Vorschlag der UdSSR die Frage der früheren „deutschen Ostgebiete“, aber auch andere Fragen betreffen.

Erging an alle Mitglieder des Achterkollegiums.

\section{Dokument 26}

RGASPI, f. 82, op. 2, d. 1042, S. 25, 27.1.1952

Ignat'ev: Berichtet, dass Eisenhower am 17. Januar d. J. in einem Gespräch mit dem zweiten Generaldirektor der Internationalen Arbeitsorganisation, dem Amerikaner Morse, mitteilte, dass gemäß einem Auftrag einer einflussreichen Gruppe von Parteiführern der Republikaner [Harold] Stassen zu ihm nach Paris gekommen war, der ihm Bedingungen vortrug, unter denen die Präsidentschaftskandidatur Eisenhowers von der Republikanischen Partei bei den bevorstehenden Wahlen in den USA vorgeschlagen werden kann. Unter diesen 
Bedingungen ist vorgesehen, dass im Falle der Wahl Eisenhowers zum Präsidenten, er Stassen oder Dewey zu Staatssekretären ernennen und andere republikanische Führer für wichtige Posten in der Regierung vorsehen muss. Außerdem muss Eisenhower den jetzigen Kurs der Außenpolitik der USA ändern, um Übereinkünfte mit der UdSSR in Streitfragen auf einer vernünftigen Grundlage zu erlangen. Eisenhower gab zu den ihm vorgetragenen Bedingungen sein Einverständnis. Eisenhower erzählte Morse, dass die Regierungen der Länder Westeuropas davon Abstand nehmen, ihre finanziellen Beiträge für das Aufrüstungsprogramm zu erhöhen, und dies damit erklären, dass die finanzielle und wirtschaftliche Anstrengung in ihren Ländern unausweichlich in nächster Zukunft zu sozialen Konflikten führt sowie zu einer Vergrößerung und Verstärkung der linken Bewegung und die kommunistischen Parteien befähigen wird, an die Macht zu kommen. Eisenhower brachte seine Meinung zum Ausdruck, dass die heutige finanzielle und wirtschaftliche Anstrengung in Westeuropa nicht lange fortgesetzt werden kann.

Erging an alle Mitglieder des Achterkollegiums.

\section{Dokument 27}

RGASPI, f. 82, op. 2, d. 1042, S. 27, 29.1.1952

Ignat'ev: Berichtet, dass am 8. Dezember Adenauer über seine Verhandlungen mit Churchill und Eden in London Anfang Dezember Bericht erstattete. Nachdem er eine allgemeine Bewertung der Ergebnisse seines Besuches in England gegeben hatte, erklärte Adenauer, dass seine Reise erfolgreich war, aber sich nicht alle seine „Hoffnungen“ verwirklicht hätten. Insbesondere wies Adenauer darauf hin, dass ihn Eden davor gewarnt hätte, dass „es unangebracht wäre, sich an Churchill mit einer offiziellen Bitte um Beteiligung Großbritanniens an einer Europa-Armee“ zu wenden. Adenauer erwähnte auch, dass er gezwungen war, in London von einer Erörterung der Fragen über Rohstofflieferungen zur Produktion strategischer Waren, über die Währungslage in Westdeutschland und über anderes Abstand zu nehmen. Adenauer erklärte Churchill, dass die Bonner Regierung die Wiedererrichtung einer „deutschen nationalen Armee“ nicht wünscht und die Idee der Gründung einer „Europa-Armee“ unterstützt. Adenauer wies aber auch daraufhin, dass „einige Merkmale“ Grund zur Vermutung liefern, dass „bestimmte Kreise“ in Frankreich die Gründung einer „Europa-Armee“ vereiteln möchten. Churchill erklärte angeblich Adenauer, dass „das britische Volk im Prinzip jegliche Remilitarisierung Deutschlands ablehnt", die englische Regierung aber den Vorschlag über die Aufnahme eines deutschen Kontingentes in eine Europa-Armee" unterstützt.

Im Gespräch mit Churchill schnitt Adenauer die Frage der Notwendigkeit an, die Gründung deutscher Betriebe zur Produktion besonders wichtiger Waffenarten in den Überseegebieten zu erlauben. Churchill antwortete darauf, dass nach seiner Meinung von der Überführung der deutschen Rüstungsbetriebe nach Kanada und in die Südafrikanische Union die Rede ist und brachte seine Bereitschaft zum Ausdruck, in der Form eines Vermittlers an die Regierungen dieser Länder heranzutreten. Adenauer teilte Churchill mit, dass im Zusammenhang mit der Boykottierung der Engländer im Iran die Bonner Regierung einen Beschluss gefasst hat, demzufolge jeder Deutsche, der zu einem Dienst im Ausland antreten möchte, vorzeitig eine Erlaubnis der „Bundesregierung“ erhalten muss. Churchill wies in diesem Zusammenhang darauf hin, dass nach der Abreise der Engländer aus Abadan im Iran ungefähr 1400 deutsche Spezialisten eintrafen. Churchill bemerkte, 
dass „mit der Zeit die Tätigkeit dieser Spezialisten den britischen Interessen Schaden zufügen wird".

Erging an Gen. Stalin und die and. Genossen des Achterkollegiums, ebenso an Gen. Vyšinskij.

\section{Dokument 28}

RGASPI, f. 82, op. 2, d. 1042, S. 31, 31.1.1952

Ignat'ev: Berichtet, dass die Regierung der USA, da sie mit der Möglichkeit des Zusammenbruchs des Planes der Gründung einer „Europa-Armee“ rechnet, beabsichtigt, zu dem früher von ihr vorgebrachten Plan des unmittelbaren Einschlusses westdeutscher Streitkräfte in die Streitkräfte des Nordatlantikbündnisses zurückzukehren. Adenauer sprach in einem Gespräch mit Churchill im Dezember 1951 auch über die Verwirklichung des amerikanischen Planes der Schaffung „selbständiger“ Streitkräfte Westdeutschlands, im Falle einer erfolglosen Gründung einer „Europa-Armee“. Die Bonner Regierung erwägt verschiedene Varianten politischer und militärischer Übereinkünfte mit den Westmächten. Als eine dieser Varianten einer solchen Übereinkunft schlägt Adenauer einen „neuen Verteidigungsplan für Europa“ vor, der auf dem Weg des Abschlusses eines „4er Paktes“ verwirklicht werden soll. Entsprechend diesem Plan Adenauers soll der 4er Pakt den „Kern der Zukunft" Europas darstellen. Entsprechend Zeugnissen der französischen Spionage begrüßt nur die italienische Regierung den Plan eines „4er Paktes“; Engländer, Franzosen und Amerikaner haben angeblich keinen großen Enthusiasmus in dieser Frage gezeigt.

Erging an Gen. Stalin und die and. Genossen des Achterkollegiums, ebenso an Gen. Vyšinskij

\section{Dokument 29}

RGASPI, f. 82, op. 2, d. 1042, S.31, 31.1.1952

Zorin: Legt den Bericht „Unstimmigkeiten im imperialistischen Lager zur Frage der Rolle Westdeutschlands im aggressiven Block“ vor. Im Bericht heißt es, dass die Regierung der USA konsequent den Kurs zur schnellen Wiedererrichtung und Entwicklung des westdeutschen militärisch-industriellen Potentials und zur beschleunigten Gründung schlagkräftiger Streitkräfte Westdeutschlands verfolgt. Die Amerikaner denken, dass Kredite und direkte Kapitalinvestitionen in der westdeutschen Wirtschaft diese dauerhaft an die Wirtschaft der USA bindet und dass unter diesen Bedingungen das wiederbewaffnete Westdeutschland keine andere Politik als die Politik des Nordatlantikblocks verfolgen kann. Die Regierungskreise Englands und Frankreichs, die bestrebt sind, Westdeutschland gegen die UdSSR zu verwenden, befürchten derzeit als Folge der Wiedererrichtung der militärischen und wirtschaftlichen Stärke des deutschen Imperialismus eine weitere Schwächung ihrer internationalen Positionen. Die Bonner Regierung und die hinter ihr stehende Großbourgeoisie streben nach den günstigsten Bedingungen der Einbeziehung Westdeutschlands in den antisowjetischen Block, um die Voraussetzung zur Umwandlung Westdeutschlands in den stärksten imperialistischen Staat Westeuropas zu schaffen. In diesem Zusammenhang genießen sie die Unterstützung seitens der USA. Die Unstimmigkeiten in der deutschen Frage im imperialistischen Lager führten zu einer Verzögerung der Verhandlungen bezüglich der 
Gangart der Einbeziehung Westdeutschlands in den antisowjetischen Block. Gelöst wurde inzwischen die Frage der Nutzung des westdeutschen militärisch-industriellen Potentials für aggressive Ziele. Das fand seinen Ausdruck im Vertrag über die Gründung der MontanUnion. Die Verhandlungen über die Schaffung von Streitkräften Westdeutschlands traten ins Endstadium ein. Unter dem Deckmantel deutscher Kontingente für eine „Europa-Armee" zeichnet sich die Gründung von 12 Panzer- und motorisierten Divisionen und einer mächtigen Luftwehr ab. Die Verhandlungen über eine „politische Regelung“ für Westdeutschland führten einstweilen zur Übereinkunft des Entwurfs des „Generalvertrages“, der die formale Aufhebung des Besatzungsstatutes vorsieht, aber [auch] die politisch nicht rechtlich gleich gestellte Lage Westdeutschlands im Block der Westmächte festigt.

Erging an Gen. Stalin und die and. Genossen des Achterkollegiums, ebenso an die Gen. Vyšinskij, Gromyko.

\title{
Dokument 30
}

RGASPI, f. 82, op. 2, d. 1170, S. 1f., 2.2.1952

\author{
Kopie $^{179}$ \\ Streng geheim
}

An Genossen Stalin I. V.

Im September 1951 wurde durch das ZK der VKP/b/ in Übereinstimmung mit der Führung der DDR der Beschluss gefasst, der den Plan der Entfachung einer Kampagne in Deutschland für die Beschleunigung des Abschlusses eines Friedensvertrages mit Deutschland und für die Vereinigung Deutschlands bestätigt hatte. In diesem Plan wurde vorgesehen, dass im Falle der Ablehnung der Vorschläge der Volkskammer der DDR über die Einberufung einer gesamtdeutschen Konferenz durch die Bonner Regierung sich die Regierung der DDR an die Regierungen der UdSSR, der USA, Großbritanniens und Frankreichs mit der Bitte um Beschleunigung des Abschlusses eines Friedensvertrages mit Deutschland wenden würde. Im Beschluss wurde auch vorgesehen, dass sich die sowjetische Regierung als Antwort auf diese Bitte der Regierung der DDR an die Regierungen der USA, Englands und Frankreichs mit dem Vorschlag wenden wird, einen Entwurf von Grundlagen eines Friedensvertrages mit Deutschland zu prüfen,.

Nachdem die Bonner Regierung den Vorschlag der Volkskammer über die Einberufung einer gesamtdeutschen Konferenz und ebenso den Vorschlag, zweiseitige Kommissionen zur Vorbereitung eines Wahlgesetzes zu organisieren, abgelehnt hatte, legte das Außenministerium der UdSSR dem ZK der VKP/b/ seine Vorschläge über den Plan weiterer Maßnahmen zur Frage über einen Friedensvertrag mit Deutschland vor. Bei der Prüfung dieser Vorschläge auf der Sitzung des Politbüros des ZK der VKP/b/ wurden am 30.Januar Mängel dieses Planes festgestellt und die Anweisung gegeben, Vorschläge in verbesserter Form unter Berücksichtigung des stattgefundenen Meinungsaustausches vorzulegen. Entsprechend dieser Anweisungen legen wir einen überarbeiteten Entwurf an Vorschlägen vor.

179) Links dancben ein handschriftliches Kreuz, Molotovs 7eichen für bcsondere Wichtigkeit. Auf der linken Seite der handschriftlichc Vermerk: „,u den Akten“. Links unten Eingangsstempel: S[ekretaria]t V. M. Molotov: 2. II. 1952. Eingangsnummer [in russischer Abkürzung]: Nr. 1452. 
In diesen Vorschlägen sind folgende Maßnahmen vorgesehen:

1. Über die Gen. [ossen] Čujkov und Semenov der Führung der DDR zu empfehlen, dass sich die Regierung der DDR, ausgehend vom Plan, der mit ihr im September 1951 abgestimmt wurde, nunmehr an die Regierungen der UdSSR, der USA, Großbritanniens und Frankreichs mit der Bitte um Beschleunigung des Abschlusses eines Friedensvertrages mit Deutschland wende.

Die Genossen Čujkov und Semenov müssen ebenso den Wunsch äußern, dass der Entwurf dieses Appells zur vorherigen Einsichtnahme der sowjetischen Regierung geschickt wird.

2. Der DDR-Führung ferner zu empfehlen, gleichzeitig der Bonner Regierung eine Kopie dieses Appells zu schicken mit dem Vorschlag, diesen zu unterstützen.

3. Als Antwort auf den Appell der Regierung der DDR an die vier Mächte soll die sowjetische Regierung die Regierung der DDR mittels Note über ihr Einverständnis in Kenntnis setzen und erklären, dass die sowjetische Regierung ihrerseits alle nötigen Maßnahmen zur Beschleunigung des Abschlusses eines Friedensvertrages mit Deutschland unternehmen wird.

4. Im Zusammenhang mit dem Appell der DDR an die vier Mächte im Namen der sowjetischen Regierung an die Regierungen der USA, Großbritanniens und Frankreichs Noten zu schicken mit dem Vorschlag, die Frage über Grundlagen eines Friedensvertrages mit Deutschland zu prüfen, und diesen ihren Entwurf der genannten Grundlagen beizulegen.

Vor der Absendung der Noten und des Entwurfes von Grundlagen eines Friedensvertrages an die drei Mächte mit dem Grundlagenentwurf die Führung der DDR und die Regierungen Polens und der Tschechoslowakei bekannt zu machen.

Eine Kopie der Noten an die drei Staaten und den Entwurf von Grundlagen eines Friedensvertrages ebenso der Regierung der DDR zu schicken.

Bitte um Prüfung.

2. Februar 1952

A. Vyšinskij

\section{Nr. 20 VK}

Für die Richtigkeit: [Unterschrift unleserlich]

Kopien ergingen an Molotov, Malenkov, Berija, Mikojan, Kaganovič, Bulganin, Chruščev. Abgedr. in $10 \mathrm{Ex}$.

2. II. 52

\section{Dokument 31}

RGASPI, f. 82, op. 2, d. 1042, S. 34, 4. 2.1952

Vyšinskij: Legt den Beschluss des Kollegiums des Außenministeriums vom 26.Januar d. J. über die Maßnahmen zur Verbesserung der Arbeit der USA-Abteilung vor. Das Kollegium verpflichtete die Abteilung dazu, die Aufmerksamkeit auf die hauptsächlichen operativen Fragen der sowjetisch-amerikanischen Beziehungen zu richten und insbesondere auf die Entlarvung der Politik der Vorbereitung eines neuen Krieges durch die amerikanischen Führungskreise, auf die Entlarvung der Aggression der USA gegen Korea und China, auf die Teilnahme an den Vorbereitungen von Vorschlägen für einen Friedensvertrag mit Deutschland und ebenso auf andere wichtige Fragen der Außenpolitik der USA, die die 
Interessen der UdSSR berühren, auf die Frage der Abrechnungen des Land-Lease, auf das Gesetz von 1951 über die subversive Tätigkeit gegen die UdSSR und auf die Grenzverletzungen der UdSSR durch amerikanische Flugzeuge im Fernen Osten.

\section{Dokument 32}

RGASPI, f. 82, op. 2, d. 1170, S. 20f, 8.2.1952

Streng geheim Ex. Nr. $1^{180}$

An Genossen Molotov V. M.

Übersende Kopien der Entwürfe des Beschlusses des ZK der VKP/b/ und der Anweisung an die Gen. Čujkov, Semenov, die Gen. Poskrebyšev zur Ausfertigung geschickt wurden.

A. Gromyko

/A. Gromyko/

„8“ Februar 1952

Eing. 179/AG

M-1603.

Streng geheim

Entwurf

Beschluss des ZK der VKP/b/

Über die Maßnahmen zur Beschleunigung des Abschlusses eines Friedensvertrages mit Deutschland ${ }^{181}$ und der Schaffung eines einheitlichen, demokratischen, friedliebenden deutschen Staates

Zum Ziele der Beschleunigung des Abschlusses eines Friedensvertrages mit Deutschland, der Schaffung eines einheitlichen, demokratischen, friedliebenden deutschen Staates und der Verstärkung des Widerstandes seitens des deutschen Volkes gegen die Pläne der Remilitarisierung Westdeutschlands ist der beiliegende Entwurf von Anweisungen an die Gen. Čujkov und Semenov zu bestätigen, der die Empfehlung an die Führung der DDR darüber beinhaltet, dass die Regierung der DDR in den nächsten Tagen den Regierungen der UdSSR, der USA, Großbritanniens und Frankreichs den Appell über die Beschleunigung des Abschlusses eines Friedensvertrages mit Deutschland abschicken möge.

${ }^{180}$ Handschriftlich hinzugefügt. Auf der linken Seite der handschriftliche Vermerk: „zu den Akten. 8. II.“ mit unleserlicher Unterschrift.

${ }^{181}$ Von Molotov handschriftlich eingefügt. 


\section{Dokument 33}

RGASPI, f. 82, op. 2, d. 1042, S. 40, 9.2.1952

Zorin: Legt einen Bericht über Unstimmigkeiten im Nordatlantikbündnis vor, in dem es heißt, dass die Realisierung militärisch-wirtschaftlicher Maßnahmen des aggressiven Blocks zu einer starken Verschlechterung der wirtschaftlichen Lage der Länder Westeuropas geführt hat. Im Zusammenhang damit trafen die amerikanischen Forderungen über eine weitere Ausweitung der Rüstungsproduktion und Vergrößerung der Streitkräfte auf enormen Widerstand der europäischen Mitglieder des Bündnisses. Bei der Tagung im September 1951 in Ottawa des Rates des Bündnisses ergaben sich ernsthafte Unstimmigkeiten in der Frage der Aufteilung der Last der militärischen Ausgaben. Im Zusammenhang damit wurde ein spezielles Komitee zur Suche nach Möglichkeiten eines „Ausgleiches der militärischen Forderungen mit den reellen politisch-wirtschaftlichen Faktoren “ gegründet. Nachdem die USA auf enormen Widerstand der westeuropäischen Länder in der Frage der Beschleunigung des Tempos der Wiederbewaffnung getroffen war, verlagerten die USA in der letzten Zeit das Zentrum ihrer Aufmerksamkeit von einer „perspektivischen“ Wiederbewaffnung auf die Annahme von Maßnahmen zur Bewaffnung bereits existierender und formierter Divisionen. Den Mitgliedern des aggressiven Blocks gelang es bisher auch noch nicht, die Unstimmigkeiten in den Fragen über die Wege des Einschlusses Westdeutschlands in den antisowjetischen Block, über den Zeitrahmen der Formierung, über die Ausrüstung und Zahl der neu zu schaffenden Truppeneinheiten und über die Verteilung der Kommandoposten in den Streitkräften zu überwinden.

Erging an Gen. Stalin und die and. Genossen des Achterkollegiums, ebenso an die Gen. Vyšinskij, Gromyko.

\section{Dokument 34}

RGASPI, f. 82, op. 2, d. 1042, S. 42, 10.2. 1952

Ignat'ev: Legt einen Bericht über Unstimmigkeiten zwischen den Mitgliedsländern des Nordatlantikbündnisses vor, in dem es heißt, dass die Verschärfung dieser Unstimmigkeiten in den Jahren 1950 und 1951 in erster Linie dadurch hervorgerufen wurde, dass die europäischen Mitgliedsländer des Nordatlantikbündnisses ihre nationalen Militärprogramme nicht erfüllt hätten, was die Gefahr des Scheiterns des „mittelfristigen Planes“ des Bündnisses hervorgerufen habe, demzufolge die Gründung von großen Truppenkontingenten und einer mächtigen „Abwehr“-Linie am Rhein bis zum Jahr 1954 vorgesehen ist. Auf den Tagungen des Rates des Nordatlantikbündnisses in Ottawa (September 1951) und in Rom (November 1951) bekundeten die europäischen Länder ihre Ablehnung der amerikanischen Forderungen nach Vergrößerung der nationalen Militärprogramme, wenn sie hierfür von den USA nicht zusätzliche finanzielle Mittel und militärisches Material erhalten. Im Zusammenhang damit wurde dem provisorischen Komitee der Auftrag erteilt, einen neuen Entwurf eines Militärprogramms des Bündnisses für 1952-54 zu erstellen. In diesem Entwurf ist eine gewisse Verkleinerung der Zahl der Divisionen der Landstreitkräfte im Vergleich zu dem, was früher geplant war, vorgesehen. Die Vereitelung der Erfüllung der militärischen Programme rief in den Regierungs- und Militärkreisen der westlichen Länder Zweifel bezüglich der Effektivität der militärischen Zusammenarbeit im Rahmen des Nordatlantikbündnisses hervor. Es gibt Mitteilungen, dass im Zusammenhang damit, dass die 
europäischen Länder ihre militärischen Verpflichtungen nicht fristgerecht erfüllen [sic!]. Die USA beabsichtigen, ihre militärisch-strategischen Pläne in Europa zu überdenken und ihre hauptsächlichen militärischen Kräfte auf den Basen in den Pyrenäen, den britischen Inseln und in Nordafrika zu konzentrieren und vom Plan der „Verteidigung“ Europas an der Rhein-Linie Abstand zu nehmen. Es ist möglich, dass diese Gerüchte über die Veränderungen der Planungen der USA absichtlich verbreitet werden, um die europäischen Länder zu erschrecken und sie dazu zu bringen, eine Entscheidung über die Vergrößerung der Beiträge für die militärischen Programme des Nordatlantikbündnisses anzunehmen.

Erging an alle Mitglieder des Achterkollegiums.

\section{Dokument 35}

RGASPI, f. 82, op. 2, d. 1185, S. 48-50, 13.2.1952

$\underline{\text { Kopie }}^{182}$

\section{An Genossen Stalin}

Die Genossen Čujkov und Semenov teilten mit, dass sich die Führung der Sozialistischen Einheitspartei Deutschlands in Moskau über die Fragen der Vorbereitung der zweiten Parteikonferenz, deren Einberufung für den Juli 1952 vorgesehen ist, beratschlagen möchte und bittet Genossen Stalin, Ende April die Gen. Pieck, Grotewohl und Ulbricht zu empfangen,

Die Außenpolitische Kommission legt einen Antwortentwurf an die Gen. Čujkov und Semenov bei.

Ich bitte um Prüfung.

Der Vorsitzende der Außenpolitischen

Kommission des ZK der VKP(b)

V. Grigor'jan

(V. Grigor'jan)

13. Februar 1952

Kopien ergingen an die Genossen Malenkov, Molotov, Berija, Bulganin, Mikojan, Kaganovič, Chruščev

Nr. $15-G-0015^{183}$

Entwurf

Beschluss des ZK der VKP(b)

\section{Frage der SED}

182 Darunter ein handschriftliches Kreuz Molotovs.

${ }^{183}$ Links unten Eingangsstempel: S[ckretaria]t V. M. Molotov: 13.II.1952. Eingangsnummer [in russischer Abkürzung]: Nr. 1836. Daneben der Vermerk: „Zu den Akten“ [Unterschrift unleserlich], rechts daneben das Kürzel: $10-l k$. 
Den Text des Telegramms an die Gen. Čujkov und Semenov zu bestätigen (liegt bei) ${ }^{184}$

Berlin

An Čujkov und Semenov

Richten Sie den Genossen Pieck, Grotewohl und Ulbricht aus, dass sie entsprechend der überbrachten Bitte zu einer von ihnen festgesetzten Zeit (Ende April) nach Moskau kommen können.

Gromyko $^{185}$

\section{Dokument 36}

RGASPI, f. 82, op. 2, d. 1042, S. 46, 14.2.1952

Ignat'ev: Trägt Mitteilungen über ernsthafte Unstimmigkeiten zwischen Westdeutschland und Frankreich vor, die im Zuge der Verhandlungen zwischen Adenauer und den Hohen Kommissaren der 3 Westmächte über die Frage sog. zusätzlicher Verträge zum Generalvertrag über die politische Regelung für Westdeutschland aufgetreten sind. Adenauer wandte sich gegen den Abschluss eines zusätzlichen Vertrages „über die Sicherheit betreffende Fragen“, (über Verbote und Begrenzungen im Bereich der westdeutschen Rüstungsproduktion) und begründete dies damit, dass im Entwurf des Vertrages über die Gründung einer „Europa-Armee“ Artikel enthalten sind, die die Rüstungsproduktion in Ländern betreffen, die am Vertrag beteiligt sind. Scharfe Unstimmigkeiten bestehen ebenso im Zusammenhang mit dem Vertrag „über den finanziellen Beitrag der Bundesrepublik an der Verteidigung des Westens“. Die Bonner Regierung fordert die Befreiung Westdeutschlands von den Besatzungskosten und besteht auf die Kürzung des „finanziellen Beitrages“ Westdeutschlands. Der Leiter der Presseabteilung des Außenministeriums Frankreichs, de Leusse, gab in einem persönlichen Gespräch Anfang Februar zu verstehen, dass die Franzosen Adenauer entgegengekommen seien. Nach den Worten von de Leusse ist es für das Außenministerium Frankreichs wichtig, dass die Deutschen die zusätzlichen Verträge wenigstens im allgemeinen Charakter unterschreiben, was die Möglichkeit geben würde, den antifranzösischen Charakter des „Generalvertrages“ zu überdecken.

Erging an Gen. Stalin und die and. Genossen des Achterkollegiums, ebenso an Gen. Vyšinskij

\section{Dokument 37}

RGASPI, f. 82, op. 2, d. 1042, S. 48, 14.2. 1952

Zorin: Informiert über die Bilanz der Debatten im Bonner Bundestag am 7. und 8. Februar d. J. bezüglich des „Generalvertrages“ und des Beitrages Westdeutschlands zur „Verteidigung Europas“. Die Initiative zur Einbringung dieser Frage in den Bundestag ging von der

184 Links unten das Kürzel: 10-lk.

${ }^{18.5}$ Links unten das Kürzel: 10-lk. 
FDP aus, die die Interessen der nationalistischen Kreise der Großbourgeoisie vertritt. Dies zeugt von einer Verschärfung der Beziehungen innerhalb der Regierungskoalition. Nachdem Adenauer mit seiner Regierungserklärung aufgetreten war, war er gezwungen zu manövrieren. Auf einer Konferenz mit Acheson, Eden und Schuman im November 1951 begrüßte Adenauer den Entwurf des „Generalvertrages“, der die Festigung der politisch ungleichen rech tlichen Lage Westdeutschlands innerhalb des antisowjetischen Blocks vorsieht. In seiner Rede im Bundestag verbarg Adenauer alle Artikel des „Generalvertrages“, die die Beibehaltung der Besatzungskontrolle der Westmächte über Westdeutschland fixieren. Die Auftritte der Sozialdemokraten Ollenhauer, Arndt und Schmidt zeigten, dass die Schumacheristen keinen ernsthaften Kampf gegen Adenauers Remilitarisierungskurs führen möchten. Die Forderung der Schumacheristen nach Durchführung neuer (vorzeitiger) Wahlen zum Bundestag beurteilt sogar die bourgeoise Presse als parlamentarisches Manöver der Sozialdemokraten. Die Bilanz der Wahlen zu den Landtagen der Bundesländer, die 1951 stattfanden, zeigte, dass die „Oppositions“-Taktik der Sozialdemokraten ihnen einen bestimmten Erfolg bringt. Wenn man dies berücksichtigt, wäre es zielführend, in der deutschen demokratischen Presse, aber auch in den sowjetischen Radiosendungen nach Deutschland die Entlarvung der verräterischen Tätigkeit der Schumacheristen zu verstärken.

Erging an Gen. Stalin und die and. Genossen des Achterkollegiums, ebenso an Gen. Vyšinskij, Gromyko.

\section{Dokument 38}

RGASPI, f. 82, op. 2, d. 1170, S.34f., 15.2.1952

$\underline{\text { Streng geheim }}^{186}$

An Genossen Stalin I. V. ${ }^{18 \imath}$

Im Zusammenhang mit dem Appell der Regierung der DDR an die Regierungen der UdSSR, der USA, Englands und Frankreichs mit der Bitte um Beschleunigung des Abschlusses eines Friedensvertrages mit Deutschland, legt das Außenministerium der UdSSR einen Antwortentwurf der sowjetischen Regierung auf diesen Appell anstelle des am 15. Februar übersandten Entwurfs vor. ${ }^{188}$

Was die Frage der Übermittlung der Note der sowjetischen Regierung an die Regierungen der drei Mächte mit dem der Note beigelegten Entwurf von Grundlagen eines Friedensvertrages mit Deutschland betrifft, so hält es das Außenministerium der UdSSR für zielführend, diese Frage einige Tage später zu prüfen, wenn die Reaktion der drei Mächte $^{189}$ und der Bonner Regierung auf den Appell der Regierung der DDR und die Antwort der sowjetischen Regierung auf diesen Appell klar sein wird.

Ein Beschlussentwurf liegt bei.

${ }^{186}$ Darunter ein handschriftliches Kreuz, Molotovs Zeichen für besondere Wichtigkeit.

${ }_{187}$ Auf der linken Seite der handschriftliche Vermerk „zu den Akten“.

188 An dieser Stelle handschriftliche Korrekturen redaktioneller Art von Molotov wieder ausradiert bzw. durchgestrichen.

189 Von Molotov vorangestellt. Ursprünglich: „der Bonner Regierung und der drei Mächte“. 
Bitte um Prüfung.

A. Gromyko

„15190" Februar 1952

Kopien ergingen an die Genossen Molotov, ${ }^{191}$ Malenkov, Berija, Mikojan, Kaganovič, Bulganin, Chruščev.

Für die Richtigkeit: $M$. Gribanov ${ }^{192}$

Streng geheim

Beschluss des ZK der VKP/b/

Über die Antwort der sowjetischen Regierung auf den Appell

der Regierung der DDR an die Regierungen der UdSSR, der USA

Englands und Frankreichs zur Frage der Beschleunigung des Abschlusses

eines Friedensvertrages mit Deutschland

1. Den Antwortentwurf der sowjetischen Regierung auf den Appell der Regierung der DDR an die Regierungen der UdSSR, der USA, Englands und Frankreichs zur Frage der Beschleunigung des Abschlusses eines Friedensvertrages mit Deutschland zu bestätigen (liegt bei).

Die Antwort in der Form einer Verbalnote am 18. Februar durch Gen. Puškin zu überbringen.

2. Die Antwort der sowjetischen Regierung auf den Appell der Regierung der DDR in der Presse veröffentlichen.

\section{Dokument 39}

RGASPI, f. 82, op. 2, d. 1042, S. 47, 16.2.1952

Ignat'ev: Legt den Text des Telegramms des französischen Hohen Kommissars in Westdeutschland, François-Poncet, an das Außenministerium Frankreichs vom 6. Februar d. J. über die Konferenz der Hohen Kommissare der drei Westmächte mit Adenauer am 5. Februar d. J. vor. Auf der Konferenz gab es scharfe Unstimmigkeiten über den Abschluss eines zusätzlichen Vertrages, der eine Begrenzung der Rüstungsproduktion in Westdeutschland, ein Verbot den Erfordernissen eines Krieges angepasster Formationen und auch eine Begrenzung der Größe der westdeutschen Polizei vorsieht. Diese Frage wurde auf Initiative der Franzosen auf die Tagesordnung gesetzt. Adenauer trat entschieden gegen die französischen Vorschläge auf und nannte sie den Grundsätzen des Vertrages über die Gründung einer „Europa-Armee“ nicht entsprechend. Nach den Worten François-Poncets endete die Konferenz in einer „schwierigen Atmosphäre“, ohne irgendwelche Entscheidungen zu „Sicherheitsfragen" getroffen zu haben. Auf der Konferenz am 5. Februar d. J. wurde auch die

\footnotetext{
190 Von Molotov handschriftlich eingefïgt.

191 Von Molotov unterstrichen.

192 Von Molotov handschriftlich eingefügt.
} 
Frage der Lage der sowjetischen Verbindungsmission in Westdeutschland nach dem Inkrafttreten der zweiseitigen Verträge erörtert. Die Hohen Kommissare bestanden darauf, dass die Bonner Regierung versicherte, dass sie auch weiterhin nach Inkrafttreten der zweiseitigen Verträge die Privilegien und Immunität der sowjetischen Verbindungsmission anerkenne, die sie gegenwärtig genießt. Diese Forderung begründeten die Hohen Kommissare damit, dass die Westmächte nicht die Zahl ihrer Verbindungsoffiziere begrenzen möchten, die sich unter sowjetischem Kommando in Potsdam befinden.

Erging an Gen. Stalin und die and. Genossen des Achterkollegiums, ebenso an Gen. Vyšinskij

\section{Dokument 40}

RGASPI, f. 82, op. 2, d. 1170, S. 36f., 18.2.1952

$\underline{\text { Streng geheim }}$

An Genossen Stalin I. V. ${ }^{193}$

Im Zusammenhang mit dem Appell der Regierung der DDR an die Regierungen der UdSSR, der USA, Englands und Frankreichs mit der Bitte um Beschleunigung des Abschlusses eines Friedensvertrages mit Deutschland, ${ }^{194}$ legt das Außenministerium der UdSSR einen Antwortentwurf der sowjetischen Regierung auf diesen Appell anstelle des am 15. Februar übersandten Entwurfs vor.

Was die Frage des Übermittelns der Note der sowjetischen Regierung an die Regierungen der drei Mächte mit dem der Note beigelegten Entwurfs von Grundlagen eines Friedensvertrages mit Deutschland betrifft, so hält es das Außenministerium der UdSSR für zielführend, diese Frage einige Tage später zu prüfen, wenn die Reaktion der drei Mächte und der Bonner Regierung auf den Appell der Regierung der DDR und die Antwort der sowjetischen Regierung auf diesen Appell klar wird.

Ein Beschlussentwurf liegt bei.

Bitte um Prüfung.

A. Gromyko

„18 195 “ Februar 1952

Kopien ergingen an die Genossen Molotov, ${ }^{196}$ Malenkov, Berija, Mikojan, Kaganovič, Bulganin, Chruščev.

193 Daneben ein handschriftliches Zeichen Molotovs, vermutlich „M“.

${ }^{194}$ Von Molotov unterstrichen.

195 Von Molotov handschriftich eingefügt.

196 Von Molotov unterstrichen. 
Streng geheim

\title{
Beschluss des ZK der VKP/b/
}

\author{
Über die Antwort der sowjetischen Regierung auf den Appell \\ der Regierung der DDR an die Regierungen der UdSSR, der USA, \\ Englands und Frankreichs zur Frage der Beschleunigung des Abschlusses \\ eines Friedensvertrages mit Deutschland
}

1. Den Antwortentwurf der sowjetischen Regierung auf den Appell der Regierung der DDR an die Regierungen der UdSSR, der USA, Englands und Frankreichs zur Frage der Beschleunigung des Abschlusses eines Friedensvertrages mit Deutschland zu bestätigen. Die Antwort in der Form einer Verbalnote am 19. Februar über Gen. Puškin zu überbringen. 2. Die Antwort der sowjetischen Regierung auf den Appell der Regierung der DDR in der Presse veröffentlichen.

\section{Dokument 41}

RGASPI, f. 82, op. 2, d. 1042, S. 49, 23.2. 1952

Ignat'ev: Berichtet, dass Adenauer am 31. Dezember 1951 eine spezielle Konferenz der Vertreter der Koalitionsparteien zur Erörterung der Frage über die Reisen Niemöllers nach Moskau und Wirths nach Berlin zusammengerufen hat. Auf dieser Konferenz brachte Adenauer seine Unzufriedenheit darüber zum Ausdruck, dass Niemöller seine Reise „gerade zu der Zeit, in der die westdeutsche Regierung bestrebt ist, den Westmächten zu zeigen, dass es in der Bundesrepublik keine derart ernsthafte Opposition gegen einen harten Westkurs gibt, " unternimmt. Adenauer teilte seinen Entschluss mit, eine aktive Propaganda gegen Niemöller und Wirth zu beginnen.

Erging an die Gen. Malenkov und Gromyko.

\section{Dokument 42}

RGASPI, f. 82, op. 2, d. 1042, S. 54, 25.2. 1952

Zorin: Teilt mit, dass die Unzufriedenheit mit der Politik der französischen Regierung in der Frage der Remilitarisierung Westdeutschlands nicht nur die demokratischen Kreise Frankreichs erfasst hat, sondern auch einige Schichten der Bourgeoisie, die befürchten, dass Frankreich als Ergebnis dieser Politik endgültig seine politischen und wirtschaftlichen Positionen in Europa verliert. In allen bourgeoisen Parteien sind mehr oder weniger bedeutsame Gruppen von Gegnern der neuen Zugeständnisse zum Nutzen Westdeutschlands entstanden und Regierungskreise erwiesen sich im Zustand der Fassungslosigkeit und Verwirrung. Diese Krise der Politik der französischen Regierungskreise in der deutschen Frage zeigte sich im Zuge der Debatten in der Nationalversammlung Frankreichs bezüglich der Gründung einer „Europa-Armee“, die vom 11. bis 19. Februar d. J. stattfanden. Gegen den Entwurf der Resolution der Regierungsmehrheit stimmten nicht nur die Kommunisten und Abgeordneten der RPF, sondern auch nicht weniger als 50-60 Abge- 
ordnete der Parteien der Regierungsmehrheit und Sozialisten, darunter viele Abgeordnete der „Bauernpartei“, 6 Abgeordnete der MRP, 6 Radikale und 20 Sozialisten. Die Ergebnisse der Abstimmung: für die Resolution - 327, dagegen - 287. Die angenommene Resolution antwortet in ihrem Grundtenor auf den amerikanischen Plan der beschleunigten Remilitarisierung Westdeutschlands. Jedoch ist in der Resolution eine Reihe von Punkten enthalten, die zu einer neuen Verschärfung der Unstimmigkeiten zwischen Frankreich und Westdeutschland führen und folglich die weiteren Verhandlungen über eine „EuropaArmee" erschweren muss. Zu diesen Punkten zählen Einwände gegen den Beitritt Deutschlands zum Nordatlantikbündnis und die Forderung, die Verluste Frankreichs im Krieg in Vietnam bei der Verteilung der Ausgaben für die Unterhaltung einer „Europa-Armee“ zu berücksichtigen.

Erging an die Gen. Molotov, Vyšinskij, Gromyko, Bogomolov und Grigor’jan.

\section{Dokument 43}

RGASPI, f. 82, op. 2, d. 1042, S.55, 25.2. 1952

Gromyko: Legt eine Verbalnote der britischen Botschaft in Moskau, die am 23. Februar d. J. im Außenministerium eintraf, vor, in der es heißt, dass der englischen Regierung bekannt geworden sei, dass die Sowjetische Kontrollkommission in Deutschland „eine Entwicklung von Ereignissen zuließ, die in gar keiner Weise den Verpflichtungen der sowjetischen Regierung zum Schutz ausländischen Eigentums, Rechten und Interessen in der sowjetischen Besatzungszone Deutschlands" entspricht. Die englische Botschaft wendet sich an die sowjetische Regierung mit der Bitte, „die Maßnahmen abzustellen, die bis zum jetzigen Zeitpunkt gegen britisches Eigentum unternommen werden“. „Im Falle einer nicht zufriedenstellenden Antwort wird es keinen anderen Ausweg geben, als der sowjetischen Regierung die Verantwortung für den dadurch entstandenen Schaden an den britischen Interessen in der sowjetischen Besatzungszone Deutschlands und im sowjetischen Sektor Berlins zu übertragen."

Erging an alle Mitglieder des Achterkollegiums.

\section{Dokument 44}

RGASPI, f. 82, op. 2, d. 1042, S. 55, 25.2. 1952

Gromyko: Trägt eine am 23. Februar im Außenministerium eingetroffene Verbalnote der französischen Botschaft in Moskau über die Frage des Schadens, der angeblich französischem Eigentum in der „sowjetischen Besatzungszone Deutschlands und im sowjetischen Sektor in Berlin“ zugefügt wurde, vor. Die französische Botschaft bittet die sowjetische Regierung, „die Maßnahmen abzustellen, die bis zur Gegenwart gegen französisches Eigentum unternommen werden“. „Im Falle einer nicht zufriedenstellenden Antwort“, heißt es in der Note, „wird die französische Regierung genötigt sein, die sowjetische Regierung für den Schaden, der den französischen Interessen in der sowjetischen Besatzungszone Deutschlands und im französischen Sektor Berlins zugefügt worden sein soll, verantwortlich zu machen."

Erging an alle Mitglieder des Achterkollegiums. 


\section{Dokument 45}

RGASPI, f. 82, op. 2, d. 1042, S. 54, 26. 2. 1952

Ignat'ev: Legt den Inhalt des Berichtes der Hohen Kommissare der drei Westmächte in Westdeutschland an die Außenminister der USA, Englands und Frankreichs vom 12. Februar d. J. über den Stand der Verhandlungen mit der Bonner Regierung bezüglich der zusätzlichen Verträge zum „Generalvertrag“ dar. Aus dem Bericht ist ersichtlich, dass es den Hohen Kommissaren und Adenauer nicht gelungen ist, die grundlegenden Unstimmigkeiten, die sich im Zuge der Verhandlungen zeigten, sowie die Fragen der Rüstungsindustrie und der den Erfordernissen eines Krieges angepassten Formationen in Westdeutschland zu lösen. Entsprechend dem Bericht blieben unter den Hohen Kommissaren selbst Unstimmigkeiten zur Frage der Liste der verbotenen Rüstungsproduktionsarten bestehen. Insbesondere die Amerikaner erhoben Einwände gegen ein Verbot oder Begrenzungen westdeutscher Produktion auf dem Gebiet der militärischen oder zivilen Luftfahrt und ebenso auf dem Gebiet der schweren militärischen Ausrüstung.

Erging an Gen. Stalin und die and. Genossen des Achterkollegiums und Gen. Gromyko.

\section{Dokument 46}

RGASPI, f. 82, op. 2, d. 1042, S. 59, 1.3. 1952

Ignat'ev: Legt einen Text von Spionagematerialien französischer Agenten über die DDR und die sowjetische Politik in der deutschen Frage vor. Nach den Behauptungen der französischen Spionage denkt man in den Führungskreisen der SED, dass sich gegenwärtig, nachdem die Versuche, mit der Bonner Regierung über die Einberufung einer gesamtdeutschen Konferenz erfolglos blieben, die Regierung der DDR unmittelbar an die Bevölkerung Westdeutschlands wenden muss. Die Politik der UdSSR in der deutschen Frage sieht laut den Behauptungen der französischen Spionage zwei Lösungsvarianten des deutschen Problems vor. Die erste Variante: Falls es der Regierung der DDR gelingt, die Bonner Regierung für die Durchführung gesamtdeutscher Verhandlungen zu gewinnen, kann die sowjetische Regierung folgende Direktiven geben: a) eine konstituierende Nationalversammlung auf der Grundlage von durch Vertreter Westdeutschlands und der DDR ausgearbeiteten Grundsätzen über gesamtdeutsche Wahlen einzuberufen; b) der Kontrolle über allgemeindeutsche Wahlen durch neutrale Länder nur unter der Bedingung der Einbeziehung so vieler Vertreter von Ländern der Volksdemokratie in die Kommission, dass sie „die westlichen Mächte ausgleichen könnten“, zuzustimmen; c) eine gesamtdeutsche Konferenz muss einen vorbereitenden, rein technischen Charakter haben; d) die Arbeit der Konferenz muss sowohl in Westdeutschland als auch in der DDR durchgeführt werden. Die zweite Variante: Falls es der Regierung der DDR nicht gelingt, die Bonner Regierung für die Durchführung gesamtdeutscher Wahlen zu gewinnen, wird die UdSSR in der Gründung eines Blocks aus der DDR, Polen und der Tschechoslowakei Zuflucht nehmen. Die französische Spionage behauptet, dass erste Schritte zur Vorbereitung eines solchen Blocks bereits unternommen wurden.

Erging an die Gen. Malenkov, Berija und Bulganin. 


\section{Dokument 47}

RGASPI, f. 82, op. 2, d. 1042, S. 58, 2.3.1952

Zorin: Teilt mit, dass sich, wie sich auf der Tagung des Rates des Nordatlantikbündnisses in Ottawa (September 1951) herausgestellt hat, die Erfüllung des Wiederaufrüstungsprogramms durch die westeuropäischen Länder, das von den Militärorganen des Bündnisses ausgearbeitet worden war, als zum Scheitern verurteilt erwiesen hat. In seinem Vortrag auf der Tagung in Ottawa erklärte Eisenhower, dass bei dem bestehenden Tempo der Wiederaufrüstung der Länder Westeuropas bis Mitte 1954 nicht mehr als 1/6 des geplanten Niveaus erreicht sein wird. Die Regierung der USA hat den Druck auf ihre Partner im Nordatlantikblock erhöht und erreichte auf der Lissabonner Tagung die Annahme der amerikanischen militär-wirtschaftlichen und militär-politischen Pläne. Nachdem der Plan der Organisation einer „Europa-Armee“ unter Beteiligung westdeutscher Divisionen bestätigt worden war, fällte der Rat des Nordatlantikbündnisses selbigen Beschluss, der die langen Verhandlungen über den Ablauf der Militarisierung Westdeutschlands abschloss. Die Billigung des amerikanischen Vorschlags über die Prinzipien der gegenseitigen Beziehungen zwischen der „Europäischen Verteidigungsgemeinschaft“ und den Organen des Nordatlantikbündnisses durch den Rat bedeutet ein neues gewaltiges Zugeständnis der Westmächte gegenüber der Bonner Regierung. Diese Entscheidung beseitigt nicht nur eines der Hindernisse auf dem Weg zur Gründung einer „Europa-Armee“, sondern sieht auch den faktischen Einschluss Westdeutschlands in den Nordatlantikblock vor. Die Amerikaner zwangen den Ländern Westeuropas ihre Forderungen im Zusammenhang mit der Verstärkung des Wettrüstcns auf. In dieser Frage waren sie aber auch gezwungen, Zugeständnisse zu machen. Die Gesamtsumme der zusätzlichen Ausgaben für ein 3-Jahresprogramm der Aufrüstung wurde im Zuge der Verhandlungen fast um das Zweifache gesenkt - von 2,36 Mrd. Dollar auf 1,19 Mrd. Die Amerikaner waren darüber hinaus gezwungen, anstelle von, wie sie anfangs vorgeschlagen hatten, $25 \%$, die Finanzierung von $40 \%$ der bewilligten Summe für die Errichtung militärischer Bodenanlagen auf sich zu nehmen. Im Zusammenhang mit den anglo-amerikanischen Unstimmigkeiten in Lissabon wurde die Frage des Kommandos der militärischen Seekräfte des Nordatlantikkommandos im Mittelmeer nicht entschieden. Die Lissabonner Beschlüsse, die auf die Intensivierung des Tempos der Vorbereitung eines neuen Krieges gerichtet sind, beseitigten nicht die tiefen Gegensätze zwischen den Mitgliedern des aggressiven Blocks.

Erging an alle Mitglieder des Achterkollegiums, ebenso an die Gen. Vyšinskij, Vasilevskij, Gromyko und Grigor'jan.

\section{Dokument 48}

RGASPI, f. 82, op. 2, d. 1170, S. 48-52, 3.3.1952

Geheim. Ex. Nr. 1

An Genossen Molotov V. M.

Ich schicke Ihnen die Entwürfe der Note an die drei Mächte, der Grundlagen eines Friedensvertrages mit Deutschland und des Schreibens an die Regierungen Polens und der Tschechoslowakei mit einem Entwurf eines entsprechenden Berichtes an das ZK.

Ich würde bitten, diese Entwürfe zu prüfen.

/A. Gromyko/ [darunter: Unterschrift] 
„3“ März 1952

Nr. 316/AG,

Abgedr. in 2 Ex.

1 - an die Adresse,

2 - zum Akt.

[links unten Stempel:] Sekretariat V. M. Molotov, 6. III. 1952, Eingangsnummer: 2726.

Streng geheim. Ex. Nr.

An Genossen Stalin I. V.

Der Appell der Regierung der Deutschen Demokratischen Republik an die UdSSR, USA, England und Frankreich mit der Bitte um Beschleunigung des Abschlusses eines Friedensvertrages mit Deutschland und ebenso die Antwort der sowjetischen Regierung auf diesen Appell haben in der DDR und Westdeutschland großes Echo hervorgerufen.

In ganz Ostdeutschland werden zahlreiche Demonstrationen und Versammlungen durchgeführt, auf welchen sowohl der Appell der Regierung der DDR als auch die positive Antwort der sowjetischen Regierung auf diesen Appell begrüßt werden.

In Westdeutschland riefen diese Dokumente ebenso großes Echo hervor, was in den zahlreichen begrüßenden Entschließungen und Briefen, die von verschiedenen Orten Westdeutschlands an die Adresse der Regierung der DDR gerichtet wurden, seinen Ausdruck findet.

Die aus Deutschland eintreffenden Mitteilungen zeigen, dass die Erklärung der sowjetischen Regierung darüber, dass sie den Abschluss eines Friedensvertrages unter der Teilnahme Deutschlands für notwendig hält, besonders großen Eindruck auf gesellschaftliche Kreise sowohl in der DDR als auch in Westdeutschland hervorrief. Dies bestätigte auch der Außenminister der DDR, Dertinger, in einem Gespräch mit Gen. Puškin.

Unter Berücksichtigung dessen, dass der Appell der Regierung der DDR und die Antwort der sowjetischen Regierung von der deutschen Bevölkerung positiv aufgenommen wurde, entschied sich die Bonner Regierung nicht direkt gegen die Vorschläge aufzutreten, die im Appell enthalten sind, und war gezwungen, zu manövrieren und ihre Position zu maskieren. Indem die Bonner Regierung die Vorschläge der Regierung der DDR über die Unterstützung ihrer Bitte an die vier Mächte um die Beschleunigung des Abschlusses eines Friedensvertrages öffentlich nicht ablehnt, stellt sie gleichzeitig Bedingungen, die nichts anderes bedeuten, als dass sie in der Sache nach wie vor die Beschleunigung des Abschlusses eines Friedensvertrages mit Deutschland behindert. Diese Bedingungen laufen auf Folgendes hinaus:

a/ der erste Schritt zu einer Friedenskonferenz müssen „allgemeine, freie, geheime, allgemeindeutsche Wahlen unter internationaler Kontrolle" sein;

b/ ein Friedensvertrag muss „mit einer frei gewählten allgemeindeutschen Regierung vereinbart werden";

c/ Deutschland muss an den Friedensverhandlungen „als gleichberechtigter Partner“ teilnehmen.

Außerdem bezieht sich die Bonner Regierung darauf, dass im Appell der Regierung der DDR und in der Antwort der sowjetischen Regierung keine konkreten Vorschläge darüber enthalten sind, wie man eine Friedenskonferenz verwirklichen kann. 
Was die Reaktion der USA, Englands und Frankreichs auf den Appell der Regierung der DDR und die Antwort der sowjetischen Regierung betrifft, so wurden keine offiziellen Erklärungen getätigt, in welchen diese drei Mächte direkt ihre Position zu diesen Fragen dargelegt hätten. Darüber wird auch im Communique über die am 25. Februar in Lissabon zu Ende gegangene Tagung des Rates des Nordatlantikblocks und in den Reden Achesons am 29. Februar und Edens am 28. Februar über die Bilanz der Arbeit dieser Tagung nichts gesagt. Aus den Erklärungen der offiziellen Vertreter der drei Mächte und den Meldungen von Presseorganen, die den Führungskreisen dieser Länder nahe stehen, ist jedoch ersichtlich, dass die USA, England und Frankreich nach wie vor fortfahren, ihre Pläne zur Schaffung einer „Europa-Armee“ unter Teilnahme westdeutscher Streitkräfte und den Einschluss Westdeutschlands in den aggressiven Atlantikblock zu verwirklichen. Das findet im Communique über die Ergebnisse der Lissabonner Tagung des Rates des Atlantikblocks Bestätigung. Darin heißt es, dass der Rat „die grundlegenden Grundsätze des Planes, der durch die fünf Mitglieder des Atlantikbündnisses und der Deutschen Bundesrepublik mit dem Ziel der Gründung einer europäischen Verteidigungsgemeinschaft ausgearbeitet wurden, gutheißt."

Gegenwärtig legen, wie die Lissabonner Tagung des Rates des Atlantikblocks zeigt, die Regierungen der USA, Englands und Frankreichs mit dem Abschluss der Verhandlungen mit Adenauer über den sogenannten Generalvertrag, der das Besatzungsstatut aufheben soll, Eile an den Tag. Auf dieser Tagung wurde der Vortrag der Regierungen der USA, Englands und Frankreichs bezüglich der Vertragsentwürfe, die von diesen Ländern mit der Bonner Regierung abgeschlossen werden sollen, zur Kenntnis genommen. Es ist nicht ausgeschlossen, dass die drei Westmächte hierzu die Bekanntgabe des „Generalvertrages“ beschleunigen werden, um zu versuchen, den Einfluss unserer Maßnahmen im Zusammenhang mit dem Friedensvertrag in Deutschland zu schwächen.

Von dem Dargelegten ausgehend hält es das Außenministerium der UdSSR für zielführend, in den nächsten Tagen eine Note der sowjetischen Regierung an die Regierungen der USA, Englands und Frankreichs mit dem Vorschlag zu schicken, die Frage über einen Friedensvertrag unverzüglich zu erörtern und der Note einen Entwurf von Grundlagen eines Friedensvertrages mit Deutschland beizulegen. Hierbei berücksichtigt das Außenministerium der UdSSR, dass die Antwort der sowjetischen Regierung auf den Appell der Regierung der DDR bereits in ausreichendem Maß in politischer Hinsicht von deutschen demokratischen Kreisen zur Entfaltung der Bewegung des deutschen Volkes für die Beschleunigung des Abschlusses eines Friedensvertrages genutzt wurde, ebenso, dass der Appell der Sowjetunion zusammen mit einem Entwurf von Grundlagen eines Friedensvertrages mit Deutschland noch mehr den Kampf des deutschen Volkes gegen die Remilitarisierung verstärkt. Außerdem hält es das Außenministerium der UdSSR für wünschenswert, der Möglichkeit der Kundmachung des Entwurfes des „Generalvertrages“ zuvorzukommen. Dieser neue Schritt der sowjetischen Regierung wird die Möglichkeit geben, unser positives Programm der Beschleunigung des Abschlusses eines Friedensvertrages mit Deutschland den aggressiven Maßnahmen der drei Mächte und der Remilitarisierung Westdeutschlands und seiner Einbeziehung in die militärischen Pläne des Atlantischen Blocks entgegenzusetzen. Ein Auftreten der sowjetischen Regierung mit einem Entwurf von Grundlagen eines Friedensvertrages mit Deutschland würde die Lage der drei Mächte und der Bonner Regierung, die die Aufhebung des Besatzungsstatuts mittels des erwähnten „Generalvertrages“ vorbereiten, noch mehr verkomplizieren. 
Bis zur Absendung der Note an die Regierungen der drei Mächte hält es das Außenministerium der UdSSR für zielführend, die Führung der DDR und ebenso die Regierungen Polens und der Tschechoslowakei mit dem Entwurf der Grundlagen eines Friedensvertrages mit Deutschland bekannt zu machen.

Ein Beschlussentwurf liegt bei.

Bitte um Prüfung.

/A. Gromyko/

” "März 1952

Nr. 197

\section{Dokument 49}

RGASPI, f. 82, op. 2, d. 1170, S. 96f., 10.3. 1952

Geheim. Ex. Nr. $\underline{3}$

„10“ März 1952

Nr. $\underline{3611 A G}$

Aus dem Diensttagebuch

A. A. Gromykos ${ }^{198}$

Empfang

des Botschafters Großbritanniens, Gascoigne, des Geschäftsträgers der USA, O’Shaughnessy, und des Geschäftsträgers Frankreichs, Brionval

10. März 1952

Heute ließ ich den Botschafter Großbritanniens, Gascoigne, sowie die Geschäftsträger der USA, O'Shaughnessy, und Frankreichs, Brionval, zu mir kommen und händigte ihnen die gleichlautenden Noten der sowjetischen Regierung zur Frage eines Friedensvertrages mit Deutschland aus. (Die Note liegt bei) ${ }^{199}$

Gascoigne, O'Shaughnessy und Brionval versprachen, den Text der Note und die der Note beiliegenden Entwürfe von Grundlagen eines Friedensvertrages mit Deutschland umgehend ihren Regierungen zu übergeben.

Beim Gespräch mit Gascoigne und O'Shaughnessy war der Charge d'affaires des stellvertretenden Leiters der Abteilung für die USA, Gen. Moljakov, beim Gespräch mit Brionval der 1. Sekretär der 1. Europäischen Abteilung, Gen. Švedkov, anwesend.

\footnotetext{
197 Datum und Nummer freigelassen.

198 Links oben der Vermerk: „zu den Akten. G[romyko].“

199 Am 6.3.1952 hatte Gromyko alle die Frage des Friedensvertrages mit Deutschland betreffenden Dokumente Molotov zweimal übersandt. Alle Entwürfe wurden entsprechend den Anweisungen Molotovs erstellt. Siehe RGASPI, f. 82, op. 2, d. 1170, S.69-83, Gromyko an Molotov, 6.3.1952; und ebd., S. 84-95, Gromyko an Molotov, 6.3.1952. Auf dem letzten Entwurf hielt Gromyko fest, dass er die Dokumentenentwürfe im Falle der Zustimmung Molotovs an Stalin weiterleiten würde.
} 
Der Stellvertreter des Außenministers der Sowjetunion

Für die Richtigkeit: [Unterschrift unleserlich]

Erging an die Genossen Stalin, Molotov, Malenkov, Berija, Mikojan, Kaganovič, Bulganin, und Chruščev 201

[Beilage]

Von Gen. Gromyko A. A. am 10. März 1952 während des Gesprächs ausgehändigt an den Geschäftsträger der USA O'Shaughnessy.

Nr.9

Die sowjetische Regierung hält es für notwendig, die Regierung der Vereinigten Staaten von Amerika darauf aufmerksam zu machen, dass, obwohl seit Beendigung des Krieges in Europa bereits etwa sieben Jahre vergangen sind, immer noch kein Friedensvertrag mit Deutschland abgeschlossen wurde.

Um diesen unnormalen Zustand zu beseitigen, wendet sich die sowjetische Regierung, die das Schreiben der Regierung der Deutschen Demokratischen Regierung mit der an die vier Mächte gerichteten Bitte um Beschleunigung des Abschlusses eines Friedensvertrages mit Deutschland unterstützt, ihrerseits an die Regierung der Vereinigten Staaten von Amerika und an die Regierungen Großbritanniens und Frankreichs mit dem Vorschlag, unverzüglich dic Frage eines Friedensvertrages mit Deutschland zu erwägen, damit in nächster Zeit ein vereinbarter Friedensvertragsentwurf vorbereitet und einer entsprechenden internationalen Konferenz unter Beteiligung aller interessierten Staaten zur Prüfung vorgelegt wird.

Es versteht sich, dass ein solcher Friedensvertrag unter unmittelbarer Beteiligung Deutschlands, vertreten durch eine gesamtdeutsche Regierung, ausgearbeitet werden muss, Hieraus folgt, dass die UdSSR, die USA, Großbritannien und Frankreich, die in Deutschland Kontrollfunktionen ausüben, auch die Frage der Bedingungen prüfen müssen, die die schleunigste Bildung einer gesamtdeutschen, den Willen des deutschen Volkes ausdrückenden Regierung fördern. ${ }^{202}$

Um die Vorbereitung des Entwurfs eines Friedensvertrages zu erleichtern, legt die sowjetische Regierung ihrerseits den Regierungen der USA, Großbritanniens und Frankreichs

\footnotetext{
${ }^{200}$ Links davon die russische Abkürzung: „p.p.“.

${ }^{201}$ Links unten Eingangsstempel: S[ekretaria]t V. M. Molotov, „11“. III 1952. Eingangsnr. M-3195.

${ }^{202}$ Im ersten Entwurf Gromykos vom 6.3.1952 fand sich ursprünglich folgender Absatz, der von Molotov eliminiert wurde: „Ein unverzüglicher Abschluss eines Friedensvertrages mit Deutschland wird diktiert durch die Interessen der Festigung des Friedens in Europa und der nötigen schnellsten Liquidierung der Kriegsfolgen, woran die Völker Europas sehr stark interessiert sind, darunter auch das deutsche Volk. Der Abschluss eines Friedensvertrages mit Deutschland erfordert, dass der bestehenden Teilung Deutschlands ein Ende bereitet wird, damit Deutschland wiedererrichtet wird, wie dies in den Potsdamer Beschlüssen vorgesehen ist, in der Form eines einheitlichen, demokratischen, friedliebenden Staates, was Deutschland den Weg zur Tcilnahme an der friedlichen Zusammenarbeit mit anderen Staaten auf der Grundlage der Gleichberechtigung eröffnet. Es versteht sich, dass dies bedeutet, dass in Deutschland eine einheitliche gesamtdeutsche Regierung gebildet werden muss, auf der Grundlage freier Wahlen, ohne Einmischung von außen, mit der auch der Friedensvertrag unterzeichnet wird.“ RGASPI, f. 82, op. 2, d. 1170, S.75f., 6.3.1952, Entwurf der Note, Gromyko an Molotov.
} 
den beigefügten Entwurf für die Grundlagen eines Friedensvertrages mit Deutschland zur Prüfung vor.

Die sowjetische Regierung schlägt vor, diesen Entwurf zu erörtern, und erklärt sich gleichzeitig bereit, auch andere eventuelle Vorschläge zu dieser Zeit zu prüfen.

Die Regierung der UdSSR rechnet damit, in kürzester Frist eine Antwort der Regierung der USA auf den oben erwähnten Vorschlag zu erhalten.

Gleichlautende Noten hat die sowjetische Regierung auch an die Regierungen Großbritanniens und Frankreichs gerichtet.

Moskau „10“ März 1952.

An die Botschaft der Vereinigten Staaten von Amerika Moskau

\section{Dokument 50}

RGASPI, f. 82, op. 2, d. 1170, S. 98-100, 10.3.1952

Entwurf der sowjetischen Regierung über einen Friedensvertrag mit Deutschland

Seit Beendigung des Krieges mit Deutschland sind fast sieben Jahre vergangen, jedoch hat Deutschland immer noch keinen Friedensvertrag, es ist gespalten und befindet sich gegenüber anderen Staaten in einer nicht gleichberechtigten Situation. Diesem unnormalen $\mathrm{Zu}-$ stand muss ein Ende gesetzt werden. Das entspricht dem Willen aller friedliebenden Völker. Ohne den schnellsten Abschluss eines Friedensvertrages mit Deutschland kann eine gerechte Behandlung der rechtmäßigen nationalen Interessen des deutschen Volkes nicht gewährleistet werden.

Der Abschluss eines Friedensvertrages mit Deutschland ist von großer Bedeutung für die Festigung des Friedens in Europa. Ein Friedensvertrag mit Deutschland wird die endgültige $^{203}$ Lösung der Fragen ermöglichen, die infolge des Zweiten Weltkrieges entstanden sind. An einer Lösung dieser Fragen sind die europäischen Staaten, die unter der Hitleraggression gelitten haben, besonders die Nachbarn Deutschlands, zutiefst interessiert. Der Abschluss eines Friedensvertrages mit Deutschland wird zu einer Besserung der internationalen Gesamtlage und damit zur Herstellung eines dauerhaften Friedens beitragen.

Die Notwendigkeit, den Abschluss eines Friedensvertrages mit Deutschland zu beschleunigen, wird dadurch diktiert, dass die Gefahr einer Wiederherstellung des deutschen Militarismus, der zwei Weltkriege entfesselt hat, ${ }^{204}$ nicht beseitigt ist, weil die entsprechenden Beschlüsse der Potsdamer Konferenz immer noch nicht durchgeführt sind. Ein Friedensvertrag mit Deutschland soll gewährleisten, dass ein Wiederaufleben des deutschen Militarismus und einer deutschen Aggression unmöglich wird.

203 Das Wort „endgültige“ wurde von Molotov im oben erwähnten ersten Entwurf Gromykos vom 6.3.1952 eingefügt. RGASPI, f. 82, op. 2, d. 1170, S. 77.

204 Anscheinend sorgte dieser Passus bei der Ausformulierung für Diskussionen. Molotov hatte ihn erstmals in den ersten Entwurf Gromykos vom 6.3.1952 handschriftlich eingefügt. Im genauen Wortlaut hieß es: „der zweimal den Frieden in Europa zerstört und sowohl den Ersten als auch den Zwciten Weltkrieg entfesselt hat". Ebd. Im zweiten Entwurf vom 6.3. strich Molotov den Passus wieder. Seine letzte Korrektur entsprach der Endfassung. Ebd., S. 87. 
Der Abschluss eines Friedensvertrages mit Deutschland wird für das deutsche Volk die Bedingungen eines dauerhaften Friedens herbeiführen, die Entwicklung eines Deutschlands als eines einheitlichen, unabhängigen, demokratischen und friedliebenden Staates in Übereinstimmung mit den Potsdamer Beschlüssen fordern und dem deutschen Volk die Möglichkeit einer friedlichen Zusammenarbeit mit anderen Völkern sichern.

Davon ausgehend, haben die Regierungen der UdSSR, der Vereinigten Staaten von Amerika, Großbritanniens und Frankreichs beschlossen, unverzüglich mit der Ausarbeitung eines Friedensvertrages mit Deutschland zu beginnen.

Die Regierungen der UdSSR, der USA, Großbritanniens und Frankreichs sind der Meinung, dass die Vorbereitung eines Friedensvertrages unter Beteiligung Deutschlands, vertreten durch eine gesamtdeutsche Regierung, erfolgen muss, und dass der Friedensvertrag mit Deutschland auf folgenden Grundlagen aufgebaut sein muss:

\section{Grundlagen des Friedensvertrages mit Deutschland}

\section{Die Teilnehmer}

Großbritannien, die Sowjetunion, die USA, Frankreich, Polen, die Tschechoslowakei, Belgien, Holland und die anderen Staaten, die sich mit ihren Streitkräften am Krieg gegen Deutschland beteiligt haben.

\section{$\underline{\text { Politische Leitsätze }}$}

1. Deutschland wird als einheitlicher Staat wiederhergestellt. Damit wird der Spaltung Deutschlands ein Ende gemacht, und das geeinte Deutschland gewinnt die Möglichkeit, sich als unabhängiger, demokratischer, friedliebender Staat zu entwickeln.

2. Sämtliche Streitkräfte der Besatzungsmächte müssen spätestens ein Jahr nach Inkrafttreten des Friedensvertrages aus Deutschland abgezogen werden. Gleichzeitig werden sämtliche ausländische Militärstützpunkte auf dem Territorium Deutschlands liquidiert.

3. Dem deutschen Volk müssen die demokratischen Rechte gewährleistet sein, damit alle unter deutscher Rechtsprechung stehenden Personen ohne Unterschied der Rasse, des Geschlechtes, der Sprache oder der Religion die Menschenrechte und die Grundfreiheiten genießen, einschließlich der Redefreiheit, der Pressefreiheit, des Rechtes der freien Religionsausübung, der Freiheit der politischen Überzeugung und der Versammlungsfreiheit.

4. In Deutschland muss den demokratischen Parteien und Organisationen freie Betätigung gewährleistet sein; sie müssen das Recht haben, über ihre inneren Angelegenheiten frei zu entscheiden, Tagungen und Versammlungen abzuhalten, Presse- und Publikationsfreiheit zu genießen.

5. Auf dem Territorium Deutschlands dürfen Organisationen, die der Demokratie und der Sache der Erhaltung des Friedens feindlich sind, nicht bestehen.

6. Allen ehemaligen Angehörigen der deutschen Armee, einschließlich der Offiziere und Generäle, allen ehemaligen Nazis, mit Ausnahme derer, die nach Gerichtsurteil eine Strafe für von ihnen begangene Verbrechen verbüßen, müssen die gleichen bürgerlichen und politischen Rechte wie allen anderen deutschen Bürgern gewährt werden zur Teilnahme am Aufbau eines friedliebenden, demokratischen Deutschland.

7. Deutschland verpflichtet sich, keinerlei Koalitionen oder Militärbündnisse einzugehen, die sich gegen irgendeinen Staat richten, der mit seinen Streitkräften am Krieg gegen Deutschland teilgenommen hat. 


\section{Das Territorium}

Das Territorium Deutschlands ist durch die Grenzen bestimmt, die durch die Beschlüsse der Potsdamer Konferenz der Großmächte festgelegt wurden.

\section{Wirtschaftliche Leitsätze}

Deutschland werden für die Entwicklung seiner Friedenswirtschaft, die der Hebung des Wohlstandes des deutschen Volkes dienen soll, keinerlei Beschränkungen auferlegt.

Deutschland werden auch keinerlei Beschränkungen in Bezug auf den Handel mit anderen Ländern, die Seeschifffahrt und den Zutritt zu den Weltmärkten auferlegt.

\section{Militärische Leitsätze}

1. Es wird Deutschland gestattet sein, eigene nationale Streitkräfte (Land-, Luft- und Seestreitkräfte) zu besitzen, die für die Verteidigung des Landes notwendig sind.

2. Deutschland wird die Erzeugung von Kriegsmaterial und -ausrüstung gestattet werden, deren Menge oder Typen nicht über die Grenzen dessen hinausgehen dürfen, was für die Streitkräfte erforderlich ist, die für Deutschland durch den Friedensvertrag festgesetzt sind.

Deutschland und die Organisation der Vereinten Nationen

Die Staaten, die den Friedensvertrag mit Deutschland abgeschlossen haben, werden das Ersuchen Deutschlands um Aufnahme in die Organisation der Vereinten Nationen unterstützen. 